\title{
A nursing intervention to handle patient aggression : the effectiveness of a training course in the management of aggression
}

Citation for published version (APA):

Needham, I. (2004). A nursing intervention to handle patient aggression : the effectiveness of a training course in the management of aggression. [Doctoral Thesis, Maastricht University]. Universiteit Maastricht. https://doi.org/10.26481/dis.20041223in

Document status and date:

Published: 01/01/2004

DOI:

10.26481/dis.20041223in

Document Version:

Publisher's PDF, also known as Version of record

\section{Please check the document version of this publication:}

- A submitted manuscript is the version of the article upon submission and before peer-review. There can be important differences between the submitted version and the official published version of record.

People interested in the research are advised to contact the author for the final version of the publication, or visit the DOI to the publisher's website.

- The final author version and the galley proof are versions of the publication after peer review.

- The final published version features the final layout of the paper including the volume, issue and page numbers.

Link to publication

\footnotetext{
General rights rights.

- You may freely distribute the URL identifying the publication in the public portal. please follow below link for the End User Agreement:

www.umlib.nl/taverne-license

Take down policy

If you believe that this document breaches copyright please contact us at:

repository@maastrichtuniversity.nl

providing details and we will investigate your claim.
}

Copyright and moral rights for the publications made accessible in the public portal are retained by the authors and/or other copyright owners and it is a condition of accessing publications that users recognise and abide by the legal requirements associated with these

- Users may download and print one copy of any publication from the public portal for the purpose of private study or research.

- You may not further distribute the material or use it for any profit-making activity or commercial gain

If the publication is distributed under the terms of Article $25 \mathrm{fa}$ of the Dutch Copyright Act, indicated by the "Taverne" license above, 


\title{
A NURSING INTERVENTION TO HANDLE PATIENT AGGRESSION: \\ THE EFFECTIVENESS OF A TRAINING \\ COURSE IN THE MANAGEMENT OF \\ AGGRESSION
}

\author{
Proefschrift \\ ter verkrijging van de graad van doctor \\ aan de Universiteit Maastricht, \\ op gezag van de Rector Magnificus, \\ Prof. mr. G.P.M.F. Mols \\ volgens het besluit van het College van Decanen, \\ in het openbaar te verdedigen op \\ donderdag 23 december 2004 om 16.00 uur \\ door
}

Ian Needham 


\section{Promotors}

Prof. dr. H. Philipsen

Prof. dr. T. Dassen, Humboldt Universität, Berlijn, Duitsland

Copromotor

Dr. R.J.G. Halfens

\section{Beoordelingscommissie}

Prof. dr. G. Widdershoven (voorzitter)

Prof. dr. R. de Bie

Prof. dr. S. Cowman, Royal College of Surgeons, Dublin, Ierland

Prof. dr. H. Nijman, Radboud Universiteit, Nijmegen

Prof. dr. F. van Wijmen 


\section{CONTENTS}

Introduction $\quad 5$

$\begin{array}{lr}\text { Coercive procedures and facilities in Swiss psychiatry } & 17\end{array}$

Non-somatic effects of patient aggression on nurses: a systematic review

The impact of patient aggression on carers scale (IMPACS): Instrument derivation and psychometric testing

The perception of aggression by nurses: Psychometric scale testing and derivation of a short instrument

The effect of a training course in aggression management on nursing students' confidence and perception of aggression

The effect of a training course in aggression management on mental health nurses' perception of aggression: A cluster randomised controlled trial

The effectiveness of two interventions in the management of patient violence in psychiatry: Report on a pilot study

The effect of a training course in aggression management on the prevalence of aggression and coercive measures in inpatient psychiatric settings: A randomised controlled trial

General discussion

Summary

Samenvatting

Zusammenfassung

Résumé

Acknowledgements

Curriculum vitae 



\section{Chapter 1}

INTRODUCTION 
Aggressive behaviour is a universal phenomenon and the channelling or the management of aggression presents a great challenge to all societies. A recent report of the World Health Organization (WHO) states that 1.6 million people worldwide lose their lives annually to violence which accounts for $14 \%$ of the deaths among people aged 14 to 44 years of age (Krug 2002). As the general societal situation is reflected in the health care industry it is not surprising that aggression is a great problem in hospitals and other care institutions. This is especially the case in psychiatric inpatient settings where the most acute mental disturbances are treated and where violence is considered a psychiatric emergency (Cavanaugh 1996). The rise in aggression rates in psychiatry (Davis 1991) corresponds to the general rise in aggression (Blair \& New 1991).

The term aggression originates from the Latin verb "aggredi" meaning to "approach, advance; attack, assail; undertake, seize (opportunity), attempt". The broad spectrum of behaviour constituting aggression is reflected in the descriptions given by the Oxford Concise Dictionary where aggression defined as "the act or practice of attacking without provocation, esp. beginning a quarrel or war", "an unprovoked attack", "self-assertiveness; forcefulness", and in a psychological sense as "a hostile or destructive tendency" (Thompson, Hanks et al. 1995). All these types of aggression can be observed in everyday life and indeed, some forms of aggression (e.g. in sport or in the business world) are actively encouraged. Often the social context of aggressive behaviour dictates its degree of social acceptability: Aggressive behaviour in the sports arena is instrumental to success. However, similar conduct in the school class or on the ward of a psychiatric hospital may constitute an act of deviation. Considerable variations exist regarding the definition of aggression or related terms such as violence and assault. Unfortunately no ubiquitous definition on aggression and related concepts exists even within the scientific community. Violence may be defined as a physical (Noble \& Rodger 1989; Rabinowitz \& Mark 1999), as a verbal (Cheung, Schweitzer et al. 1997) act, or as behaviour resulting in the damage of objects (Binder \& McNeil 1988). In a similar display of variability conceptions of assault may range from verbal and physical behaviour (Gates, Fitzwater et al. 1999), to sexual harassment (Flannery, Hanson et al. 1995). For this thesis the following definition coined by Morrison will be used throughout, unless stated otherwise: Aggression is "any verbal, non-verbal, or physical behaviour that is threatening (to self, others or property), or physical behaviour that actually does harm (to self, others, or property)" (Morrison 1990). This definition is the one adopted by Nijman et al. and utilised as an integral part of the "SOAS-R" (the Staff Observation of Aggression Scale in its revised form (Nijman, Muris et al. 1999).

Professionals have devised and implemented various approaches to deal with aggressive and violent behaviour. One major mode of treatment is the use of psychotropic substances to prevent potential or to treat manifest aggression. The development of major tranquillizers in the 1950s in Paris probably played an important part in the reduction of violence in inpatient settings (Ernst 1988) and led to a major breakthrough in the pharmacological 
management of aggression in institutional psychiatry. Other approaches are the prediction of aggressive behaviour (Almvik \& Woods 1998; Abderhalden, Needham et al. 2004), shaping the design of the wards to reduce negative influences (Palmstierna, Huitfeldt et al. 1991; Nijman \& Rector 1999; Ng, Kumar et al. 2001), or specific training courses for staff in the management of patient aggression (Vanderslott 1998; Lehmann, McCormick et al. 1999; Nolan, Dallender et al. 1999). This latter approach is the object of study in this thesis. Numerous factors that will be delineated below, promoted the decision to investigate the effectiveness of such a training course.

Aggressive behaviour in inpatient psychiatry is a multi-faceted phenomenon. Firstly, aggression may be a general expression of quite normal feelings. Indeed, aggression has been deemed an intrinsic characteristic of the conditio humana (Lorenz 1963) and may therefore be seen as a natural reaction to frustrating situations experienced within inpatient mental health settings. In Switzerland around one third of all psychiatric patients are referred to hospital against their will and it is noteworthy that patient aggression occurs predominantly within the first days of hospitalisation. Aggression is also associated with some types of psychopathology, especially schizophrenia, organic mental disorders, mental handicap, disorders of adult personality and behaviour, and substance abuse (Davis 1991; Steinert 1995). However, the relationship between aggression and mental disorder is not completely clear (Eronen, Angermeyer et al. 1998) and thus aggressive behaviour cannot be restricted to pathology alone (Angermeyer, Cooper et al. 1998). Within mental health settings the main reasons for aggressive behaviour of patients are, according to Steinert, conflict with staff $(52 \%)$, conflict with fellow patients $(31 \%)$, disciplinary measures $(20 \%)$, refusal to take medication $(16 \%)$, or the refusal of other types of treatment (18\%) (multiple reasons possible) (Steinert 1995). Most of these reasons point to the supposition that interaction plays a pivotal role in the mediation of aggressive behaviour. This is one reason for choosing an intervention (the training course) addressing such interactional matters.

This dissertation is also motivated by the paucity of robust evidence on the effects of training in aggression management. Such trainings are costly and especially in times of restricted economic resources in the health care industry consumers and tax payers alike need to be sure that they are getting good value for their money. The lack of robust evidence regarding the effects of training courses is associated with various methodological problems such as small sample sizes, the lack of use of control groups or the lack of randomisation. In a comprehensive review of relevant literature by the Royal College of Psychiatry on such interventions only 68 of the original body of over 10,000 publications were deemed methodologically sufficient. The Royal College concludes that there is no strong evidence that measures like training staff lead to a reduction in aggressive incidents (Royal College 1998). This position is echoed by Nijman (p. 118) who states that there is "a lack of well-controlled research on the effects of aggression reducing (nonpharmacological) interventions" (Nijman 1999). Gournay also concludes 
from his review that "the striking feature of all of the literature reviewed is the dearth of well designed and comprehensive studies" (Gournay 2001).

The choice of this study theme was also motivated by the lack of consensus and a prevailing incertitude on how to address the problem of patient aggression in psychiatric inpatient settings in Switzerland. The Swiss political system is characterised by federalism with the cantons having a great deal of sovereignty in health care matters (EOHCS 2000). There is to date no national concerted effort to standardise practices in dealing with patient aggression. Nursing education in Switzerland is also embedded within the tradition of federalism. The Swiss Red Cross was until recently mandated by the cantons to devise general directives for nursing education. Within the constraints of these broad directives the schools of nursing were quite free to develop their own curricula. On the background of these structures and traditions no standardised core nursing curriculum on the management of patient aggression has been suggested. Thus the scientific evaluation of a training course in aggression management constitutes a first step towards the development of potential recommendations to educational and clinical institutions to consider using a standardised intervention such as the one used in this study.

Nurses have traditionally been so involved in the management of patient aggression that some - unfortunately but perhaps not surprisingly regard patient aggression as an intrinsic part of the nursing profession (Poster 1996; Erickson \& Williams-Evans 2000; Jones \& Lyneham 2000). Nurses' spatial and temporal proximity to patients means that they have the most contact with aggressive patients (Ernst 1988) and thus are the most affected (Fottrell 1980; Geser 1999). The nursing profession thus needs guidance and support in handling aggressive situations. In Switzerland nurses have been instructed on how to deal with patient aggression as early as 1930 the Swiss psychiatrist Morgenthaler in his book on psychiatric nursing (Morgenthaler 1930). Since then various books (Ernst 1988; Dörner \& Plog 1996; RaveSchwank \& Winter von Lersner 1997) have been published but it is only until recently that nurses in the German speaking countries have begun to make contributions concerning the management of inpatient aggression (Fuchs 1998; Sauter \& Richter 1998; Wengle, Bitterlin et al. 2000). The intervention investigated in this thesis was developed by a psychiatric nurse and nursing scientist. The choice of this predominantly nursing intervention is intended to contribute to the body of knowledge of nursing and, hopefully, will promote the development of nursing in Switzerland.

Patient aggression not only causes suffering to carers but also to the patients themselves. Patients vary rarely act in an aggressive manner out of the blue (Ernst 1988) and often the causes for aggression are plausible. Patients report that they may also react in an aggressive manner on being treated disrespectfully, or on being ill-informed of ward rules (Bensley, Nelson et al. 1995) and some patients perceive the reason for their aggressive behaviour in coercive measures such as seclusion and restraint (Bensley, Nelson et al. 1995). It has also been demonstrated that a coercive interpersonal style is a stable predictive factor of patient aggression (Morrison 1992). Unfortunately, 
the use of coercion by staff constitutes a main intervention to counter patient aggression in mental healthcare settings. The effect of such measures can be devastating with patients experiencing them as humiliation or as punishment (Finzen, Haug et al. 1993; Haug \& Finzen 1997). Finally the environment is important with factors such as space (Chou, Lu et al. 2002), crowding (Lanza, Kayne et al. 1994), locked wards (Kho, Sensky et al. 1988), staff-patient ratios (Bensley, Nelson et al. 1995) playing a role in the genesis of aggression. All these findings indicate that in most cases patient aggression is not deliberate, wilful behaviour intending to purposely inflict harm on caregivers. Given the suffering of patients it is safe to assume that they themselves will welcome enhanced procedures to deal with aggressive situations. Indeed, many patients, when requested to propose improvements in aggression management mention the necessity to ameliorate staff-patient communication (Ilkiw Lavalle \& Grenyer 2003). The intervention under scrutiny aims at preventing aggression or, alternatively, where this is not possible endeavours to alleviate patients' suffering by managing conflict situations in an ethically (Billaud, Braissant et al. 2003) responsible manner.

The above mentioned reasons underscore the necessity of research in the field of aggression management. The intervention under investigation in this research project is a five day aggression management training course developed by Nico Oud in the Netherlands (Oud 1997). The general approach is a skill-oriented, action-centred and problem-centred participating learning package (Oud 1997). Numerous aspects of aggression management such as the nature and prevalence of aggression, violence and sexual harassment, the use of aggression scales, preventive measures and strategies, de-escalation techniques, ethical aspects of violence management and safety management (Oud 1997) are presented to the participants. The primary goal of the course is to prevent patient aggression in psychiatric practice. However, sometimes patients become aggressive in spite of preventive and de-escalation techniques. In order to deal with such contingencies the participants receive instruction in limiting freedom of aggressive patients, in break-away techniques, in control and restraint, and in post-incident care. One important part of the course is the coordination and concertation of nurses or other carers in cases where patients have engaged in aggressive behaviour. Another important assumption of the training course is the role of the patient enacting in aggressive behaviour. The "classical" role allocation of perpetrator and victim is rejected throughout the training course. The participants engaging in aggressive behaviour - the patients and the carers - are deemed actors in social interaction. Hence, the carers as representatives and enforcing agents of institutional psychiatry also play their part in the origin of aggressive behaviour. They are thus actively encouraged to reflect their own contribution to the genesis, the prevention, the management, and the aftermath of aggression. Basically speaking the training offers elements to ameliorate knowledge (e.g. prevalence rates of aggression, prediction), to enhance motor performance (e.g. hands on skills), and to incite reflective practice (e.g. ethics). The training has received anecdotal praise from participants but has never been subjected to scientific investigation. The training course under scrutiny corre- 
sponds by and large to a recently suggested core curriculum (Lee, Wright et al. 2001).

Before engaging on the scientific investigation of the training course it was assumed that the training would have an effect at two different levels:

1. At the level of the individual nurse changes in nurses' perceptions of their ability to manage patient aggression and subsequently of their attitudes toward aggression were expected

2. At the level of the patients changes were expected in terms of actual performance in dealing with patient aggression with reductions of aggressive incidents and coercive measures being indicative of modification.

The relationship between these postulated effects of such training courses has been explained recently by Lee: "Expected outcomes depend on performance efficacy judgements, that is, the outcome one expects will depend largely on how well the individual performs in given situations. For example, nurses who judge themselves inefficacious in control and restraint techniques will conjure up outcomes of grievous bodily harm, whereas those who are confident of their control and restraint capabilities will anticipate calm situations rather than frenetic situations, and will be more motivated to undertake control and restraint action" (Lee 2001). This explanation employs elements of Bandura's social cognitive theory of learning (Bandura 1977; Bandura 1986). Central to this theory is the concept of self-efficacy which denotes peoples' "judgments of their capabilities to organize and execute courses of action required to attain designated types of performances" (Bandura 1986, p. 391). This perception of one's own capacity is crucial in the development of new behavioural patterns (cf. Bandura 1986, p. 395) and is instrumental in ameliorating performance. The conception of self-efficacy will for the purposes of this thesis be equated with confidence.

In the light of these aspects of Bandura's theory the following study objectives are proposed. The first objective is to investigate the capacity of the training course to influence nurses' perceptions or opinions (Jansen, Dassen et al. 1997) regarding patient aggression. If, as Bandura contends, people regard "themselves as highly efficacious act, think, and feel differently from those who perceive themselves as inefficacious" (Bandura 1986, p. 395) it seems reasonable to assume that enhanced self-efficacy or confidence will induce a change in the perception of aggression. This objective is in effect a reiteration of an assumption by Jansen et al. who hypothesised that nurses trained to deal with patient aggression in a constructive manner would have a more positive opinion on patient aggression (Jansen, Dassen et al. 1997). The second objective is to test the efficacy of a training course in the management of patient aggression as observed in terms of the reduction of rates of aggression, attacks, coercive measures (seclusion, involuntary medication and mechanical restraint), and the severity of aggressive incidents. These objectives lead to the following hypotheses of this dissertation: 
1. The training course will lead

a) to a more positive perception of aggression,

b) to staff experiencing patient aggression in a less severe way, and

c) to a rise in confidence in handling situations involving aggressive patients by the individual nurses.

2. The training course will

a) reduce aggressive incidents,

b) attacks against persons, and

c) coercive measures.

The rationales for these hypotheses emanate from the following reasoning: Enhanced capacities in dealing with patient aggression are mediated by self-efficacy and promote confidence in dealing with patient aggression. Enhanced self-efficacy and confidence are expected to foster a more positive perception of aggression. Improved skills in the better recognition of precursors of aggressive behaviour may avoid escalation and reduce to severity of some aggressive incidents or may avoid some events completely. Hence, enhanced performance in dealing with aggressive patients is expected to lead to reductions in aggression and coercion rates (see Figure 1).

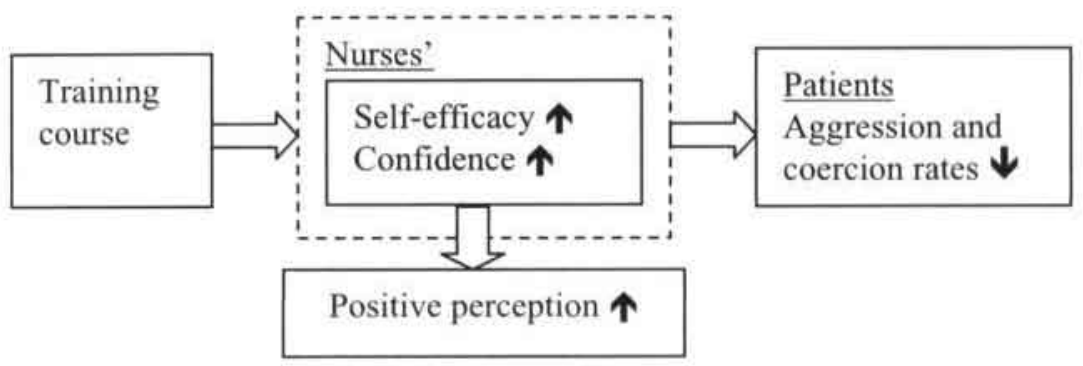

Figure 1: Expected effects of the training course

In order to achieve these objectives and test the hypotheses various studies were conducted. This dissertation consists of two parts. The first part (chapters 2 to 5 ) is comprised of preparatory studies which pave the way for the main studies. The second part (chapters 6 to 9) of the dissertation deals with the two themes, notably the impact of the training course on the nurses and on the patients. The following overview describes the various studies and the contribution they make towards the study objectives.

Chapter 2, entitled "Coercive procedures and facilities in Swiss psychiatry" is material from a representative survey in the German speaking area of Switzerland on how aggressive behaviour of patients is dealt with. The data accrues from acute admission wards of psychiatric hospitals and points to various deficits in the management of patient violence such as the haphazard ways of overwhelming dangerous patients or the reported deficiencies in the practical and theoretical training of mental health nurses. The necessity of the training course in aggression management is based on the results of this survey. 
Chapter 3 is a systematic review of adverse non-somatic (i.e. biophysiological, cognitive, emotional, and social) effects on nurses after having dealt with situations involving aggressive patients. Twenty eight main negative effects were found including anger, fear, guilt, self-blame and shame. This study demonstrates the suffering that carers can go through due to patient aggression.

Chapter $\mathbf{4}$ describes the development of a scale designed to survey nurses experiences after dealing with aggressive incidents. The "Impact of Patient Aggression on Carers Scale" (IMPACS) is based on the systematic review (chapter 3 ) and will be used to test the hypothesis that a training course in aggression management will reduce adverse effects of handling patient aggression. The results of the testing of this hypothesis are reported in chapter 7.

Chapter $\mathbf{5}$ is devoted to testing of the psychometric qualities of an instrument designed to measure the perception of aggression of nurses towards patient aggression. Given that nurses' attitudes toward patient aggression may influence their handling of such behaviour it is necessary to employ a validated instrument to be able to monitor any changes which may accrue from external interventions such as a training programme. This study also endeavoured to reduce the number of items on the scale whilst retaining good psychometric properties. This scale is used in the studies described in chapters six and seven.

Chapter 6 is the first article investigating the effect of the training course on nurses. It is a quasi-experimental study reporting on the results of a training programme administered to nursing students in basic training. Because the nursing students of today are the professionals of tomorrow and because nursing students are amongst the most vulnerable targets of patient aggression it is important to assess possible changes in attitude and perceptions of patient aggression. This study also monitors nursing students' confidence in dealing with aggressive patients. An intervention and a control group are employed in this study with a repeated measures design to monitor changes.

Chapter 7 presents the results of a multi centre randomised controlled trial of the effects of the training course on nurses working in acute admission psychiatric inpatient settings. Nurses from six randomised wards participated. The outcome measures - the perception of aggression, the rating of patient aggression in a positive and in a negative fashion and their confidence in handling aggressive patients - were measured prior to the training and three months later.

Chapter $\mathbf{8}$ is the first of two clinical studies and describes a dual centre pilot project testing the efficacy of a training course in aggression management and a systematic risk assessment on the frequencies of patient aggression and on the frequency of coercive measures. This feasibility study tests the practicability of the training and its implementation to clinical practice for use a multi centre randomised controlled trial on six wards (chapter 9). 
Chapter 9 is the second clinical study and deals with the capacity of the training course to influence patient aggression at ward level. This multi centre randomised controlled trial set out to assess changes in the frequency and the severity of patient aggression and in the frequency of coercive measures. Prevalence rates of the intervention and control wards were measured before and after the intervention to test the effectiveness of the intervention on the outcome measures.

Chapter 10 is a general discussion on the findings of this dissertation. Limitations and implications are presented, and conclusions regarding the further use of training course in aggression management as a way of dealing with aggression in inpatient settings are drawn.

The studies in this dissertation were, where necessary, approved by local and cantonal ethic committees and the data was handled to assure anonymity of the subjects involved. 


\section{References}

Abderhalden C, Needham I, Almvik R, Miserez B, Dassen T, Haug H, Fischer J (2004) Predicting inpatient violence in acute psychiatric wards using the Broset-Violence-Checklist: A multi-centre prospective cohort study. Journal of Psychiatric and Mental Health Nursing 11(4):422-427

Almvik R, Woods P (1998) The Broset Violence Checklist (BVC) and the prediction of inpatient violence: Some preliminary results. Perspectives of Psychiatric Care 5(6):208-211

Angermeyer M, Cooper B, Link B (1998) Mental disorder and violence: results of epidemiological studies in the era of deinstitutionalization. Social Psychiatry and Psychiatric Epidemiology 33(1): 1-6

Bandura A (1977) Self-efficacy: Toward a unifying theory of behavioral change. Psychological Review 84:191-215

Bandura A (1986) Social foundations of thought and action: A social cognitive theory. Englewood Cliffs, Prentice Hall

Bensley L, Nelson N, Kaufman J, Silverstein B, Shields J (1995) Patient and staff views of factors influencing assaults on psychiatric hospital employees. Issues in Mental Health Nursing 16( 5):433-446

Billaud F, Braissant C, Monteverde S, Zierath M (2003) Ethik in der Pflegepraxis. Bern, SBKASI

Binder RL, McNeil DE (1988) Effects of Diagnosis and Context on Dangerousness. American Journal of Psychiatry 145(6): 728-732

Blair T, New A (1991) Assaultive behavior: know the risks. Journal of Psychosocial Nursing 29(11):25-30

Cavanaugh SV (1996) Psychiatric emergencies. Medical Clinics of North America 70(5):11851202

Cheung P, Schweitzer I, Tuckwell V, Crowley KC (1997) A prospective study of assaults on staff by psychiatric in-patients. Medical Science and Law 37(1):46-52

Chou KR, Lu RB, Mao WC (2002) Factors relevant to patient assaultive behavior and assault in acute inpatient psychiatric units in Taiwan. Archives of Psychiatric Nursing 16(4):187-95

Davis S (1991) Violence by psychiatric inpatients: a review. Hospital, Community. Psychiatry 2(6):585-90

Dörner K, Plog U (1996) Irren ist menschlich: Lehrbuch der Psychiatrie, Psychotherapie. (4 Aufl) Bonn, Psychiatrie-Verlag

EOHCS (2000) Health Care Systems in Transition: Switzerland. Copenhagen, European Observatory on Health Care Systems

Erickson L, Williams-Evans SA (2000) Attitudes of emergency nurses regarding patient assaults. Journal of Emergency Nursing 26(3):210-5.

Ernst K (1988) Praktische Klinikpsychiatrie. (2. Aufl) Berlin, Springer

Eronen M, Angermeyer M, Schulze B (1998) The psychiatric epidemiology of violent behaviour. Social Psychiatry and Psychiatric Epidemiology 33(1):13-23

Finzen A, Haug HJ, Beck A, Lüthy D (1993) Hilfe wider Willen: Zwangsmassnahmen im psychiatrischen Alltag. Bonn, Psychiatrie-Verlag

Flannery R, Hanson M, Penk W (1995) Patients' threats. Expanded definition of assault. General Hospital Psychiatry 17(6):451-3

Fottrell E (1980) A study of violent behaviour among patients in psychiatric hospitals. British Journal of Psychiatry 136:216-221

Fuchs JM (1998) Kontrollierter Umgang mit physischer Gewalt und Aggression in der Psychiatrie? Erfahrungsbericht über ein Praxisseminar. In: Sauter D, Richter D (Hrsg). Gewalt in der psychiatrischen Pflege Bern, Huber: 59-72. 
Gates DM, Fitzwater E, Meyer U (1999) Violence against caregivers in nursing homes: Expected, tolerated, and accepted. Journal of Gerontological Nursing(4):12-22

Geser AM (1999) Aggressionen von hospitalisierten psychisch Kranken: Eine systematische Evaluation von knapp 2000 Aggressionsfällen. Unpublished Inaugural-Dissertation zur Erlangung der Doktorwürde, Universität Zürich, Zürich

Gournay K (2001) The recognition, prevention and therapeutic management of violence in mental health care: A consultation document. London, United Kingdom Central Council for Nursing, Midwifery and Health Nursing: 56

Haug H-J, Finzen A (1997) Zwangsmedikationen im psychiatrischen Alltag - Zwischen Hilfe und Gewalt. In: Mauthe J-H (Hrsg). Grenzen - gewünscht, gebraucht, erlitten? Königslutter, Vereinsverlag: $39-50$.

Ilkiw Lavalle O, Grenyer BFS (2003) Differences between patient and staff perceptions of aggression in mental health units. Psychiatric Services 54(3):389-393

Jansen G, Dassen T, Moorer P (1997) The perception of aggression. Scandinavian Journal of Caring Sciences 11(1):51-55

Jones J, Lyneham J (2000) Violence: part of the job for Australian nurses? Australian Journal of Advanced Nursing 18(2):27-32

Kho K, Sensky T, Mortimer A, Corcos C (1988) Prospective study into factors associated with aggressive incidents in psychiatric acute admission wards. British Journal of Psychiatry $172: 38-43$

Krug E (Eds) (2002) World report on violence and health. Geneva, World Health Organization

Lanza M, Kayne H, Hicks C, Milner J (1994) Environmental characteristics related to patient assault. Issues in Mental Health Nursing 15( 3):319-35

Lee F (2001) Violence in A\&E: the role of training and self-efficacy. Nursing Standard 15(46):33-38

Lee S, Wright S, Sayer J, Parr A-M, Gray R, Gournay K (2001) Physical restraint training for nurses in English and Welsh psychiatric intensive care and regional secure units. Journal of Mental Health 10(2):151-162

Lehmann LS, McCormick RA, Kizer KW (1999) A survey of assaultive behavior in Veterans Health Administration facilities. Psychiatric Services 50(3):384-9

Lorenz K (1963) Das sogenannte Böse: Zur Naturgeschichte der Aggression. Wien, BorothaSchoeler

Morgenthaler W (1930) Die Pflege der Gemüts- und Geisteskranken. Bern, Huber

Morrison E (1990) Violent psychiatric inpatients in a public hospital. Scholarly Inquiry for Nursing Practice 4(1):65-82

Morrison EF (1992) A coercive interactional style as an antecedent to aggression in psychiatric patients. Research in Nursing Health 15(6):421-431

$\mathrm{Ng} \mathrm{B}$, Kumar S, Ranclaud M, Robinson E (2001) Ward crowding and incidents of violence on an acute psychiatric inpatient unit. Psychiatric Services 52(4):521-525

Nijman H (1999) Aggressive behavior of psychiatric patients: Measurement, prevalence, and determinants. Unpublished Doctoral thesis, Rijksuniversiteit Limburg, Maastricht

Nijman H, Rector G (1999) Crowding and aggression on inpatient psychiatric wards. Psychiatric Services 50(6):831-831

Nijman HLI, Muris P, Merckelbach HLGJ, Palmstierna T, Wistedt B, Vos AM, van Rixtel A, Allertz WWF (1999) The Staff Observation Aggression Scale - Revised (SOAS-R). Aggressive Behavior 25:197-209

Noble P, Rodger S (1989) Violence by psychiatric in-patients. British Journal of Psychiatry 155:384-390

Nolan P, Dallender J, Soares J, Thomsen S, Arnetz B (1999) Violence in mental health care: the experiences of mental health nurses and psychiatrists. Journal of Advanced Nursing 30(4):934-41 
Oud NE (1997) Aggression and psychiatric nursing. Amsterdam, Broens and Oud: Partnership for consulting and training

Palmstierna T, Huitfeldt B, Wistedt B (1991) The relationship of crowding and aggressive behavior on a psychiatric intensive care unit. Hospital Community Psychiatry 42(12):12371240

Poster EC (1996) A multinational study of psychiatric nursing staffs' beliefs and concerns about work safety and patient assault. Archives of Psychiatric Nursing 10(6):365-73

Rabinowitz J, Mark M (1999) Risk factors for violence among long-stay psychiatric patients: national study. Acta Psychiatrica Scandinavia 99:341-347

Rave-Schwank M, Winter von Lersner C (1997) Psychiatrische Pflege. (7. Aufl) Stuttgart, Fischer

Royal College of Psychiatrists (1998) Management of imminent violence: clinical practice guidelines to support mental health services. Occasional Paper OP 41. London, Royal College of Psychiatrists College Research Unit

Sauter D, Richter D (1998) Gewalt in der psychiatrischen Pflege. Bern, Huber

Steinert T (1995) Aggression bei psychisch Kranken. Stuttgart, Enke

Thompson D, Hanks P, Marshall J, Chantrell G, Hodgson A, Whear A, Marjara P, Pepler K (Eds) (1995) The Concise Oxford Dictionary. (9th edition), Oxford University Press

Vanderslott J (1998) A study of incidents of violence towards staff by patients in an NHS Trust hospital. Journal of Psychiatric and Mental Health Nursing 5(4):291-298

Wengle H, Bitterlin R, Haug H-J, Schaefer J (2000) Qualitätsstandard für die Stationäre Psychiatrie. Aarau, Schweizerische Vereinigung psychiatrischer Chefärzte SVPC: 54 


\section{CHAPTER 2}

\section{COERCIVE PROCEDURES AND FACILITIES IN SWISS PSYCHIATRY}

Needham I, Abderhalden C, Dassen T, Haug H. Fischer J (2002) Coercive procedures and facilities in Swiss psychiatry. Swiss Medical Weekly 132. 253-258 


\begin{abstract}
Background: Coercive measures in psychiatry, although in many cases effective in violence management and injury reduction, have been criticised from a consumerist point of view.

Method: A questionnaire regarding coercive facilities and procedures was dispatched to the charge nurses of 86 acute psychiatric admission wards in German speaking Switzerland covering a catchment area of $75 \%$ of the Swiss population.

Results: $95 \%$ of all wards responded rendering the survey representative. The majority of wards have seclusion rooms and $55 \%$ of charge nurses perceive seclusion facilities as adequate. Two to twenty staff members are involved in overwhelming dangerous patients and some discontent is expressed at the haphazard fashion in which such events occur. Almost $70 \%$ of the wards use a form for reporting, $42 \%$ of wards keep statistics on violent incidents and $17 \%$ of wards have access to these data. Of all wards $84 \%$ register injections against patients' will, $83 \%$ seclusion, and $78 \%$ mechanical restraint and a minority of wards register the coercive administration of oral medication, forced nutrition, threats of coercive measures in case of pharmacological non-compliance.

Discussion: Isolation, the coercive administration of medicine and restraint techniques are sensitive forms of treatment. Deficits reported by the charge nurses point to the need for enhanced facilities and improved forms of coercion management such as training in the use of mechanical restraints and the overwhelming of dangerous patients.
\end{abstract}

Conclusion: The data show considerable differences in the facilities, the use, and the recording of coercive measures in the area under scrutiny. 


\section{Introduction}

Coercion is a long standing problem which has been controversially debated since the beginning of modern psychiatry and many attempts have been made to solve this problem. Some early reports regarding the humanisation of the treatment of psychiatric patients can be traced back to the 18th century when Philippe Pinel (1745 - 1876) not only freed the patients from their chains but also restricted the use of strait-jackets (Haenel 1982). In France these reforms were continued by Jean-Etienne-Dominique Esquirol $(1772-1840)$, Pinel's most prominent follower and on the other side of the Channel the British psychiatrists John Conolly $(1794-1866)$ and Robert Gardner Hill (1811 - 1878) initiated the no-restraint movement (Haenel 1982). For the management of the patients Conolly only allowed transitory isolation in a padded room (Haenel 1982). The no-restraint movement was also adopted in some Swiss hospitals e.g. by Heinrich Cramer (1831 - 1866) of Solothurn and by Ludwig Wille (1834 - 1924) of the Psychiatric Hospital in Rheinau (Haenel 1982).

In spite of such movements, coercive practices such as seclusion and restraint remain major interventions for controlling patient aggression (Visalli, McNasser et al. 1997; JCAHO 1998). Patient attacks on healthcare personnel can have devastating effects such as workplace stress (Ryan \& Poster 1989), post traumatic stress disorder (Rippon 2000; Richter \& Berger 2001) or, to a lesser extent, physical injury (Carmel \& Hunter 1993). In psychiatric settings such attacks happen to all types of care professionals. A recent study demonstrated that more than half of the physicians, psychologists and social workers in four German psychiatric hospitals have been subjected to serious injury induced by patient violence during their career (Steinert, Beck et al. 1995). But the group most affected is the nursing profession (Geser 1999) with almost $100 \%$ of nurses experiencing patient violence in the course of their career (Carmel \& Hunter 1989) compared with a rate of $61 \%$ for other therapists (physicians, psychologists, and social workers) (Wynn \& Bratlid 1998). Given the problematical nature of patient violence and the sequelae thereof, coercive measures can be seen as a possible solution and it has been demonstrated that restraint and seclusion are basically efficacious in preventing injury (Fisher 1994).

Coercive practices on the other hand are classical treatment forms which influence the image of psychiatry in the public eye (Gebhardt \& Steinert 1998). Psychiatric institutions have been criticised for their inhumane use of such methods and coercive treatments have been depicted in the media as having been carried out arbitrarily (Steinert \& Gebhardt 2000) which indeed may have been the case in the past. Few empirical investigations have been done from the patients' vantage point of the actual experience of coercive measures. Such studies reveal that coercive practices can be experienced as being punitive rather than therapeutical (Ray, Myers et al. 1996) or as having been conducted in a "brutal" fashion (Finzen, Haug et al. 1993). With the recent shift toward patient centred care and consumerism (Morrison 1990) 
trust in traditional health-care practices has dwindled (JCAHO 1998) and most patients and family members have come to view seclusion and restraint as a violation of the right to respectful care (JCAHO 1998). Thus, any attempt to reduce the number of coercive treatments will be welcomed not only by patients, their family members, and patient organisations but also by the professionals in the field of psychiatry itself.

The decentralised health-care system of the Swiss Confederation adheres to the principle of sovereignty of its 26 Cantons. Each Canton has its own constitution and determines independently how health-care functions and makes its own laws. Consequentially the Confederation has only limited powers appertaining to the health-care system at the level of the cantons. Given the federalist structure of the Swiss health-care system a great amount of variance within contemporary procedures dealing with the restraint and seclusion practices of violent patients in psychiatric hospitals must be expected. Independent of the Swiss situation other authors have noted that much variance in coercive techniques accrues from a lack of unifying rules (Gebhardt \& Steinert 1998) or that other - non-clinical - factors like cultural biases, staff role perceptions, and the attitude of the hospital administration influence coercive practices (Fisher 1994). The frequency of restraint also seems to depend on factors such as staff-patient ratios, the training level of staff (Morrison 1990), shift times, gender of staff (Klimitz, Uhlemann et al. 1998).

The aim of this cross sectional survey is to answer the following questions: Which coercive procedures are employed and which facilities exist on acute admission wards in psychiatric hospitals in German speaking Switzerland? How do the charge nurses of the wards evaluate these procedures and facilities?

\section{Method}

In this cross-sectional survey a questionnaire containing questions on ward characteristics and items on coercive practices and facilities was despatched to the 86 acute psychiatric admission wards in the German speaking part of Switzerland in September 2001.

The participating wards were recruited from psychiatric hospitals lying within the German and Romansch speaking part of Switzerland. The psychiatric hospitals in the area under scrutiny cater for the inpatient treatment of approximately $75 \%\left(5^{\prime} 376^{\prime} 800\right.$ persons $)$ of the Swiss population (BFS 2001). Not included in this survey are psychiatric hospitals in the French and Italian speaking Cantons and a small proportion of inhabitants living in the French speaking areas of predominantly German speaking Cantons (for example psychiatric hospitals in the French speaking part of Canton Berne).

Inclusion criteria: for the purpose of this survey we defined an acute psychiatric ward as following: The majority of patients have an acute psychiatric disorder, they are admitted directly onto the ward, they stay less than 
three months on the ward, they are older than 18 and younger than 65 years, and the ward is not specialised in the treatment of special disorders (e.g. depression, addiction). The proportion of involuntarily admitted patients was not taken into consideration.

The questionnaire comprised of questions on ward characteristics; number of beds, locked or open status, number (full-time equivalent) and educational status of nursing staff; seclusion facilities, facilities for mechanical restraint, management of violent incidents, reporting systems for violent incidents, and the registration of coercive measures.

The unit of observation was the single acute psychiatric admission ward. One questionnaire was collected per ward. The questionnaires were completed by the charge nurses (the nurses leading the wards and bearing the overall responsibility for nursing). We specifically instructed the charge nurses to report an unbiased picture. The charge nurses were also asked to judge whether the facilities and procedures for handling violence on their wards are sufficient or insufficient. In the case of discontent of the nurses were requested to comment on insufficiencies.

No data were gathered on actual frequencies of coercive measures applied or on patients involved. The data analysis was descriptive without any hypothesis testing.

\section{Results}

Eighty-two (94\%) of the 87 wards invited to the survey responded representing $30(94 \%)$ of the 32 institutions in the study area. The number of wards in the institutions varies from one to eight. Ten $(12 \%)$ of the wards are open, $29(53 \%)$ are partially open, and $43(53 \%)$ are locked. The number of beds varies between 6 and 25 (median 17, mean 16.6 \pm 3.7 ). The proportion of patients to nursing personnel ( $100 \%$ posts / beds) lies between 0.3 and 1.8 (median 0.7 ; mean $0.7 \pm 0.2$ )

Seclusion practices: On just over one half of the wards ( $n=43$ ) there is a lockable area (e.g. an intensive care area). The majority of the wards ( 64 or $78 \%$ ) have at least one seclusion room, 13\% have no such room and seven wards failed to respond to the item. Approximately half of the wards have one seclusion room, 22 wards $(27 \%)$ have two, with the highest reported number of seclusion rooms being six. Patients are secluded in normal single bedrooms on $33 \%$ of the wards $(n=27) .55 \%(n=45)$ of the ward nurses rate the seclusion facilities as adequate and $45 \%(\mathrm{n}=37)$ as inadequate. Table 1 demonstrates that almost $90 \%$ of all wards have at least on facility for secluding aggressive patients. Eight wards have no facilities at all for secluding aggressive patients. Four of these wards are located within hospitals having provision for seclusion on other wards. It is reasonable to assume that aggression can be managed by referring violent patients to neighbouring wards. About half of the ward nurses expressed discontent on the inadequate number of seclusion rooms or on structural drawbacks of the building. Other points of 
discontent were the necessity to displace some patients onto other wards, and the use of mechanical restraints in group bedrooms.

Mechanical restraint: On three fifths of the wards (49 or 60\%) straps to restrain aggressive patients are available but many respondents remarked that these facilities are employed only very rarely. On one ward bed bars are used in conjunction with straps made of textile. $59(72 \%)$ assess the restraint facilities as sufficient, the other $18(22 \%)$ as insufficient. Seven ward leaders expressed discontent with unsuitable beds (e.g. beds on which straps can not be fastened), six mentioned the poor quality of straps (e.g. lack of stability, unsuitable for patients of various body size), and five respondents reported a lack of experience and/or difficulties in handling mechanical restraints.

Table 1: Facilities for seclusion with percentages of total number of wards $(n=82)$

\begin{tabular}{lcccc} 
& Open wards & Partially open wards & Closed wards & Total \\
\hline & $\mathrm{n}(\%)$ & $\mathrm{n}(\%)$ & $\mathrm{n}(\%)$ & $\mathrm{n}(\%)$ \\
\hline $\begin{array}{l}\text { No seclusion facility } \\
\text { One or more seclusion }\end{array}$ & $5(6.1)$ & $1(1.2)$ & $2(2.4)$ & $8(9.8)$ \\
facilities & $4(4.9)$ & $26(31.7)$ & $37(45.1)$ & $37(81.7)$ \\
Missing & $1(1.2)$ & $1(2.4)$ & $1(4.9)$ & $7(8.5)$ \\
\hline Total & $10(12.2)$ & $29(35.4)$ & $43(52.4)$ & $82(100)$ \\
\hline
\end{tabular}

The management of violent incidents: When a violent or dangerous patient has to be overwhelmed a minimum of 2 to 20 persons are involved during the daytime (mean $=7.8 \pm 3.1$; median $=8$ ), and a maximum of $3-20$ ( mean $=9.8 \pm 3.9$; median $=10)$. The respective numbers for such incidents occurring during the night are: Minimum 2 - 11 (mean $5.3 \pm 2.7$; median 5), and maximal $2-12$ (mean $=6.1 \pm 2.4$; median $=6)$. On 29 wards $(35 \%)$ nonnursing personnel are also involved in overwhelming violent or dangerous patients.

58 of the charge nurses $(70.7 \%)$ rate the techniques for overwhelming patients as satisfactory and the other $22(26 \%)$ as unsatisfactory. Reasons for dissatisfaction with the techniques are an insufficient number of available personnel especially at non-peak working hours and during the night $(\mathrm{n}=10)$, the haphazard fashion of overwhelming which is dependent on the participating personnel, the lack of experience $(n=10)$, unfavourable environmental characteristics (e.g. restraint of a patient in a dormitory) $(n=2)$, the lack of resources to protect personnel (e.g. shields, facial masks), protracted length of time until arrival of the police, or an insufficient dosage of medicine administered.

Reporting systems for violent incidents: Almost $70 \%$ of the wards $(\mathrm{n}=57)$ use a form for reporting violent incidents. $7.5 \%(\mathrm{n}=5)$ employ the internationally used SOAS (Staff Observation Aggression Scale), 31.3\% $(\mathrm{n}=$ 21) use a form devised by the Psychiatric University Hospital Zurich (Gerber 1995), Switzerland and 49.3\% $(n=33)$ use other types of forms. These other types of forms consist of documents for registering extraordinary incidents ( $\mathrm{n}$ $=10$ ), for risk management or critical incident reporting $(\mathrm{n}=7)$, injury forms 
$(n=5)$, integral parts of the nursing documentation system, or special reports to the nursing or medical directors. $11.9 \%(\mathrm{n}=8)$ of the wards document violent incidents without the use of a specific form.

35 wards $(42.2 \%)$ keep statistics on violent incidents and on 14 wards $(17.3 \%)$ the statistics can be accessed by ward personnel. On 15 wards $(18.8 \%)$ violence induced absences of personnel are systematically recorded and in just over half of these wards the statistics can be accessed on the ward.

Forty-six charge nurses $(56.1 \%)$ are content with the reporting systems on their wards. The most numerous remarks of discontent are related to deficiencies in the systematic nature of reporting and statistical documentation $(\mathrm{n}=16)$ and to the fact that there is no feedback to the wards regarding reported incidents. Other remarks are on unsuitable or too numerous reporting forms.

The registration of coercive measures: The majority of wards record the use of coercive measures. $84.2 \%$ register injections against patients' will, $82.9 \%$ seclusion, and $77.8 \%$ mechanical restraint. In addition to these measures some wards record the coercive administration of oral medication $(n=9)$, forced nutrition $(n=7)$, threats of coercive measures in case of pharmacological non-compliance (4), the use of bed-bars, and video surveillance. 66 wards $(82.5 \%)$ use forms for recording coercive treatment measures and 35 wards $(42.7 \%)$ keep a statistical record of coercive treatments administered. Just 8 of these wards $(22.9 \%)$ have ready access to this statistical information on the ward. Exactly half of the respondents rate the reporting of coercive measures as satisfactory. The main reasons for discontent with reporting are the lack of feedback to the wards $(n=16)$, unsuitable forms (2), lack of reporting on various matters (duration of coercive measures, analysis of the measures, attacks towards personnel), lack of reporting accuracy, or double reporting.

Table 2: Wards registering coercive measures $(n=82)$

\begin{tabular}{lcccc} 
& Any measure & $\begin{array}{c}\text { Coercive } \\
\text { injections }\end{array}$ & Seclusion & $\begin{array}{c}\text { Mechanical } \\
\text { restraint }\end{array}$ \\
\hline Yes & $\mathrm{n}(\%)$ & $\mathrm{n}(\%)$ & $\mathrm{n}(\%)$ & $\mathrm{n}(\%)$ \\
No & $59(72.0)$ & $69(84.1)$ & $68(82.9)$ & $63(76.8)$ \\
Missing & $19(23.2)$ & $12(14.6)$ & $14(17.1)$ & $18(22.0)$ \\
Total & $4(4.9)$ & $1(1.2)$ & - & $1(1.2)$ \\
\hline
\end{tabular}




\section{Discussion}

Isolation, the coercive administration of medicine and restraint techniques are sensitive forms of treatment (Klimitz, Uhlemann et al. 1998) requiring special consideration within contemporary psychiatric practices. This descriptive study attempts to capture a reliable picture of such practices in the German speaking part of Switzerland and is deemed with a response rate of $94 \%$ representative. The questionnaires were completed by charge nurses who are very familiar with contemporary practices. It can thus be assumed that the factual data in this survey are valid. The data expressing the opinions of the charge nurses is of course subjective and it is thus uncertain if these views correspond with those of other nurses or professions.

It has been argued that psychiatric institutions can not be free of structural violence and that the reactions of staff to patient violence cannot be suppressed rendering violence an element of the psychiatric profession. (Cahn 1995). It has also been noted that "it is nearly impossible to operate a programme for severely symptomatic individuals without some form of seclusion or physical or mechanical restraint" (Fisher 1994). Ryan and Poster, two prominent researchers on patient violent, report of a greater assault risks to nursing personnel due to patients increased acuity (Ryan \& Poster 1989) and other authors have remarked that societal aggression is of "increasing national concern" and that "health care settings reflect this trend" (Blair \& New 1991) with assaults by patients on staff increasing over the past years (Haller \& Deluthy 1988; Noble \& Rodger 1989; Hansen 1996). Probably part of this general increase in violence against humans can be attributed to regular viewing of violent content on television. A recent longitudinal study comprising of 17 years of follow up demonstrated a five-fold increase $(45 \%$ vs. $8.9 \%)$ in violent acts against other persons by young adults who regularly viewed television for $>3$ hours daily compared with young adults viewing television for $<1$ hour per day (Johnson, Cohen et al. 2002).

With this possible long-term increase in the rate of violent incidents, it is noteworthy that most charge nurses regard the facilities for secluding patients to be basically sufficient. One of the main problems nevertheless is the deficient structural quality of seclusion rooms suggesting a need for devising recommendations on how to fit out such a facility. Within the study area four wards have neither seclusion possibilities nor neighbouring wards with such facilities. Two of these units are situated within general hospitals and the other two are located in a private clinic. It seems that these wards have either no prominent violence problem, or employ alternative practices for aggression management. Although $60 \%$ of the wards report using straps as restraint measures many note that such usage is vary rare. This and the reported lack of personnel's experience with restraint measures may indicate that such practices are on the decline. The experience deficit with mechanical restraint points to the need for training in such practices as has been suggested elsewhere (Fisher 1994; Forster, Cavness et al. 1999). 
The data on the management of violent or dangerous patients show that up to 20 persons can be involved in overwhelming an individual patient. Such numbers can be justified by the therapeutic rationale that such a display of power can in fact induce patient participation and thus avoid brachial brawls. On the other hand patients themselves have commented on being confronted by an overpowering number of staff as being "brutal" (Finzen, Haug et al. 1993). For the charge nurses a shortage of personnel and the haphazard way of dealing with the situation are the main problems in the management of incidents of patient violence. Other authors have demonstrated that such actions can lead to harm or stress not only in patients but also in personnel (Fisher 1994; Klimitz, Uhlemann et al. 1998; Marangos-Frost \& Wells 2000). These findings suggest the need for methodical and effective ways of management which render the incident less traumatic for patients and personnel alike.

Although $70 \%$ of all wards have systems for reporting violent incidents only a minority keeps a statistic and even less $(17.3 \%)$ actually have access to the statistics on the ward. This means that the probably most important step in quality management - the feedback - is lacking and begs the question of the usefulness of reporting. Given this deficit and the overabundance of reporting forms in some institutions it is to be assumed that under reporting of violent incidents will occur as reported elsewhere (Lion, Snyder et al. 1981; Lanza 1992; Owen, Tarantello et al. 1998).

Several limitations pertain to the present survey. First, the questionnaires were completed by charge nurses who are very familiar with contemporary procedures and facilities. It can thus be assumed that the factual data in this survey are valid. In contrast, the data expressing the judgements of the charge nurses is of course subjective and it is thus uncertain if these views correspond with those of other nurses or professions. Second, we did not request the gender of the respondents. Thus we have no means to estimate the possible extent of gender bias. Third, we only collected one questionnaire per ward which was completed by one person. Reporting bias cannot be ruled out. However, given the current "negative" public opinion on coercive measures, possible reporting bias is more likely to ensue in underreporting.

Bearing these limitations in mind, the present survey points to considerable differences in the facilities, in the use, and in the recording of coercive measures in the study area. Against this background it seems that the challenge of our day is twofold: To strike a good balance between the optimal management of patient violence, which ensures safety for patients and staff alike, and concurrently reducing the frequency of coercive practices in order to maintain protect the patients rights and dignity (JCAHO 1998). Thus the main conclusion in the light of these findings is that discussions are necessary at an inter-regional or national level in order to standardise some aspects of coercive practices. It is expected that such discussions aimed at establishing professional guidelines will reduce the variability and lead to a higher reflection of such treatments. Because restraint and seclusion have deleterious physical and psychological effects on patients and staff (Fisher 1994) it is 
important to keep such practices to a minimum and to monitor the development of coercive measures by repeating this survey at a future point in time. 


\section{References}

BFS (2001) Bevölkerungsstruktur. Bundesamt für Statistik. www.statistik.admin.ch/stat_ch/ber01/dufr01.htm (29.12.2001)

Blair T, New A (1991) Assaultive behavior: know the risks. Journal of Psychosocial Nursing 29(11):25-30

Cahn T (1995) Gewalt - Element des psychiatrischen Berufes. Schweizer Archiv für Neurologie, Neurochirurgie und Psychiatrie 146(3):109-114

Carmel H, Hunter M (1989) Staff injuries from inpatient violence. Hospital Community Psychiatry $40(1): 41-46$

Carmel H, Hunter M (1993) Staff injuries from patient attack: five years' data. The journal of the American Academy of Psychiatry and the Law 21(4):485-493

Finzen A, Haug HJ, Beck A, Lüthy D (1993) Hilfe wider Willen: Zwangsmassnahmen im psychiatrischen Alltag. Bonn, Psychiatrie-Verlag

Fisher WA (1994) Restraint and seclusion: A review of the literature. American Journal of Psychiatry 151:1584-1591

Forster PL, Cavness C. Phelps MA (1999) Staff training decreases use of seclusion and restraint in an acute psychiatric hospital. Archives of Psychiatric Nursing 13(5):269-271

Gebhardt RP, Steinert T (1998) Innere Struktur der stationären psychiatrischen Krankenhausversorgung 22 Jahre nach der Psychiatrie-Enquete. Nervenarzt 69(9):791-8,

Gerber A (1995) Aggressionen psychiatrischer Patienten in der Klinik: Eine 2-Jahres-Studie an der Psychiatrischen Universitätsklinik Zürich. Unpublished Dissertation, Universität Zürich, Zürich

Geser AM (1999) Aggressionen von hospitalisierten psychisch Kranken: Eine systematische Evaluation von knapp 2000 Aggressionsfällen. Unpublished Inaugural-Dissertation zur Erlangung der Doktorwürde, Universität Zürich, Zürich

Haenel T (1982) Zur Geschichte der Psychiatrie: Gedanken zur allgemeinen und Basler Psychiatriegeschichte. Basel, Birkhäuser

Haller R, Deluthy R (1988) Assaults on staff by psychiatric in-patients: A critical review. British Journal of Psychiatry 152:174-179

Hansen B (1996) Workplace violence in the hospital psychiatric setting. An occupational health perspective. American Association of Occupational Health Nurses Journal 4(12):575-580

JCAHO (1998) Reducing restraint use in the acute care environment. Oakbrook Terrace, Joint Commission on Accreditation of Healthcare Organizations

Johnson J, Cohen P, Smailes E, Kasen S, Brook J (2002) Television viewing and aggressive behavior during adolescence and adulthood. www.science.org (5.4.2002)

Klimitz H, Uhlemann H, Fahndrich E (1998) Fixieren wir zu häufig? Indikation, Häufigkeit und Randbedingungen von Fixierungen in einer allgemeinen psychiatrischen Abteilung: Eine prospektive Studie, 25(5):235-9.

Lanza ML (1992) Nurses as patient assault victims: An update, synthesis, and recommendations. Archives of Psychiatric Nursing 6(3):163-171

Lion JR, Snyder W. Merrill GL (1981) Underreporting of assaults on staff in a state hospital. 32(7):497-8

Marangos-Frost S, Wells D (2000) Psychiatric nurses' thoughts and feelings about restraint use: a decision dilemma. Journal of Advanced Nursing 31(2):362-9.

Morrison P (1990) A multidimensional scalogram analysis of the use of seclusion in acute psychiatric settings. Journal of Advanced Nursing 15(1):59-66.

Noble P, Rodger S (1989) Violence by psychiatric in-patients. British Journal of Psychiatry 155:384-390 
Owen C, Tarantello C, Jones M, Tennant C (1998) Violence and aggression in psychiatric units. Psychiatric Services 49(11):1452-1457

Ray NK, Myers KJ, Rappaport ME (1996) Patient perspectives on restraint and seclusion experiences: A survey of New York State psychiatric facilities. Psychiatric Rehabilitation Journal 20(1):11-8.

Richter D, Berger K (2001) Patientenübergriffe auf Mitarbeiter - Eine prospektive Untersuchung der Hăufigkeit, Situation und Folgen. Nervenarzt 72(9):693-9

Rippon TJ (2000) Aggression and violence in health care professions. Journal of Advanced Nursing 31(2): $452-60$

Ryan JA, Poster EC (1989) The assaulted nurse: short-term and long-term responses. Archives of Psychiatric Nursing 3(6):323-31

Steinert T, Beck M, Vogel W, Wohlfahrt A (1995) Gewalttätige Patienten: Ein Problem für Therapeuten an psychiatrischen Kliniken? Nervenarzt 66:207-211

Steinert T, Gebhardt RP (2000) Erfolgen Zwangsmassnahmen willkürlich? Psychiatrische Praxis 27(6):282-5.

Visalli H, McNasser G, Johnstone L, Lazzaro C (1997) Reducing high-risk interventions for managing aggression in psychiatric settings. Journal of Nursing Care Quality 11(3):54-61

Wynn R, Bratlid T (1998) Staff's experiences with patient's assaults in a Norwegian psychiatric hospital: A pilot study. Scandinavian Journal of Caring Sciences 12:89-93 


\section{ChaPTER 3}

\section{NON-SOMATIC EFFECTS OF PATIENT AGGRESSION ON NURSES: A SYSTEMATIC REVIEW}

Needham I, Abderhalden C. Halfens RJG. Fischer JE. Dassen T. Accepted for publication in the Journal of Advanced Nursing 


\section{Abstract}

Background: Patient aggression towards nurses is a longstanding problem in most nursing domains. Although reports on the consequences of physical aggression are more numerous, the non-physical effects create much suffering.

Aim: This paper describes a systematic review of the predominant non-somatic effects of patient assault on nurses.

Method: A systematic review of literature from 1983 to May 2003 was conducted using the Medline, CINAHL, PsychINFO and PSYINDEX databases. Articles from international journals in English or German and reporting at least three non-somatic responses to patient aggression were included.

Findings: The electronic search produced 6616 articles. After application of the inclusion and exclusion criteria, 25 texts from 8 countries and 4 domains of nursing remained. Twenty-eight main effects were found, and these were categorised using a system suggested by Lanza and including biophysiological, emotional, cognitive, and social dimensions. The predominant responses were anger, fear or anxiety, post-traumatic stress disorder symptoms, guilt, self-blame, and shame. These main effects occurred across most countries and nursing domains.

Conclusion: Despite differing countries, cultures, research designs and settings, nurses' responses to patient aggression are similar. Standardised questionnaires could help improve estimations of the real prevalence of nonsomatic effects. Given the suffering caused by non-somatic effects, research should be aimed at preventing patient aggression and at developing better ways to prepare nurses to cope with this problem.

Key words: Aggression, violence, assault, nursing, victim, systematic review, post-traumatic stress disorder 


\section{Introduction}

Patient violence is long-standing problem in nursing (Hansen 1996) especially in psychiatric nursing, in accident and emergency nursing and in the care of the elderly. Research on physical injuries inflicted on health care staff by patients is common (Noble \& Rodger 1989; Hanson \& Balk 1992; Bensley, Nelson et al. 1997; Lee, Gerberich et al. 1999). Rates for physical injury range from $2 \%$ (Noble \& Rodger 1989) to $16 \%$ (Carmel \& Hunter 1993). A recent study conducted in Germany revealed that $10 \%$ of healthcare workers (predominantly nurses) needed medical treatment after assault, and one nurse contracted life-threatening injuries (Richter \& Berger 2000).

However, serious injuries occur much more rarely than minor ones with little or no physical injury (Fottrell 1980; Whittington \& Wykes 1992). In a study of psychiatric patients' violence to staff, only $2 \%$ of the assaults led to major physical injuries as compared to $59 \%$ which induced no detectable injury (Noble \& Rodger 1989). Non-somatic effects of aggression have been deemed by nurses themselves and by the literature as petty and not worthy of serious research (Haller \& Deluthy 1988; Whittington \& Wykes 1992). The primacy of physical injury is illustrated by Rippon (2000), who reports that after a sexual assault one nurse received no support; however, after being punched by a patient she was assisted.

The terminology on aggressive behaviour varies considerably. Some researchers apply the term assault solely to the physical dimension (Owen, Tarantello et al. 1998), but for others verbal acts constitute assault (Chambers 1998; Vanderslott 1998; Gates, Fitzwater et al. 1999). Sometimes sexual harassment (Vanderslott 1998) or unwanted sexual acts (Flannery, Hanson et al. 1995) are used in conjunction with aggressive patient behaviour. Other authors leave the definition of patient aggression to the victims (Hauck 1993). Differing operational definitions render data collection and the comparison of aggression rates difficult.

Research has demonstrated that psychological and emotional wounds may linger on and interfere with normal working and leisure lifestyles for months or years after the incident (Rippon 2000), with $49 \%$ of nurses in a study on assaults by psychiatric patients expressing the belief that it takes several months to recover emotionally from an assault (Baxter, Hafner et al. 1992). One study (Richter \& Berger 2000) reports that $14 \%$ of assaulted staff suffer from some severe symptoms of post-traumatic stress disorder (PTSD), and another study on short- and long-term effects of patient assault reports that some nurses suffer from moderate to severe PTSD at one year following the attack (Ryan \& Poster 1989). On an organisational level, Richter notes that the effects of psychological sequelae for the organisation cannot be estimated (Richter 1998).

\section{Aim}

The aim of this literature review was to identify and categorise the predominant non-somatic effects of patient assault on nurses. 


\section{Search methods}

We conducted an electronic search, used citations found in relevant articles, and consulted experts in the field for suggestions about texts. Texts fully or partially devoted to emotional, psychological, bio-physiological or social sequelae of patient aggression on nurses and written or published between 1983 and May 2003 in English or German were sought, as shown in Table 1.

\section{Table 1: Inclusion criteria}

Articles in English or German

Articles containing at least three empirically acquired non-somatic effects

Articles published between 1983 and May of 2003

The electronic search aimed at inclusiveness and sensitivity (Greenhalgh 2001) in order to cover a broad range of nursing populations and settings. This strategy was adopted because no indexing or MESH (Medical Subject Headings) terms exist for non-somatic consequences of patient aggression towards carers. The search included the databases MEDLINE (PUBMED online), Cumulative Index of Nursing and Allied Health Literature (CINAHL), PsychINFO, and PSYINDEX, with the search strategy tailored to the data bank in question. The search strategy for PUBMED, for example, was: ((Aggression [MESH:NOEXP] OR Violence [MESH:NOEXP] OR Dangerous behaviour [MESH]) AND (Psychiatry [MESH] OR Health facilities [MESH] OR Health personnel [MESH] OR Nursing [MESH] OR Nursing, practical [MESH])).

Non-somatic effects were defined according to the categorisation of Lanza (1992) which entails bio-physiological, emotional, cognitive, and social reactions As Lanza did not elaborate on the four categories, the following conceptualisations are employed in this review:

- Bio-physiological effects refer to non-visible somatic responses in a physiologically involuntary fashion.

- Emotions are sentiments not associated with any kind of psychological or psychiatric pathology but rather are common or "normal" feelings.

- Cognition is defined as a non-emotive mode of perceiving, including perception of self or referring to a person's system of beliefs or convictions.

- Social interaction refers to interpersonal exchange.

\section{Results}

The electronic search revealed 6616 articles. After excluding articles in languages other than German and English and abstracts or those without authors, 3009 remained. After inspection of the titles, keywords and abstracts, hard copies were acquired for the 114 articles deemed suitable for the review. All these were assessed according to the inclusion and exclusion criteria by at 
least two members of the research group. The reasons for the 91 exclusions are shown in Table 2.

Table 2: Articles excluded from the review

\begin{tabular}{lr}
\hline Reason for exclusion & $\mathbf{n}$ \\
\hline Articles containing no non-somatic effects & 61 \\
Articles containing < 3 non-somatic effects & 10 \\
Articles containing no empirical data or containing insufficient description of methods & 12 \\
Articles reiterating other findings published elsewhere & 8 \\
\hline Total & $\mathbf{9 1}$ \\
\hline
\end{tabular}

Two unpublished studies (Hauck 1993; Vincent, Perlt et al. 2000) were drawn to our attention by experts. The 25 articles included in this review are characterised and arranged in alphabetical order in the appendix. The main non-somatic effects, according to the categories suggested by Lanza, are presented according to the nursing domains (psychiatric, emergency, residential and gerontological, general and mixed nursing settings) in Table 3.

Bio-physiological effects: Anxiety or fear is the most frequently reported bio-physiological effect. Anxiety may occur in a generalised form (Lanza 1983; Ryan \& Poster 1989; Whittington \& Wykes 1992) and fear may relate, for example, to the workplace (Bin Abdullah, Khim et al. 2000; Arnetz \& Arnetz 2001), or patients (Fernandes, Raboud et al. 2002). Fear can be differentiated as fear of the perpetrator or of other patients (Lanza 1983; Whittington \& Wykes 1992; Hauck 1993), fear for oneself or one's family (Fry, O'Riordan et al. 2002), fear of permanent side effects of the assault or of becoming physically dependent on others (Lanza 1983), fear of retaliation towards the aggressor (Lanza 1983; Ryan \& Poster 1989), or fear of coworkers or of the future (Hauck 1993). The reported rates of fear range from $12.4 \%$ (Richter \& Berger 2000) to $49 \%$ (Arnetz \& Arnetz 2001) ( $\mathrm{n}=85$ and 8531 respectively). Guilt or self-blame or shame is also a prominent reaction to aggression reported in a majority of the studies. Some nurses feel guilty for not handling the situation in a more appropriate way (Hauck 1993).

Patient aggression may lead in a minority of cases to a fullyestablished Post-Traumatic Stress Disorder (PTSD) or isolated symptoms of this. PTSD is a long-lasting anxiety response following a traumatic or catastrophic event, and consists of various symptoms in the following groups: persistent re-experience of the traumatic event (e.g. including images, thoughts, or perceptions, recurrent distressing dreams), persistent avoidance of trauma-associated stimuli (e.g. thoughts, feelings, or conversations, efforts to avoid activities, places, or people that arouse recollections of the trauma, inability to recall an important aspect of the trauma), and persistent symptoms of increased arousal such as difficulty falling or staying asleep (American Psychiatric Association 1994). Isolated PTSD symptoms have been reported implicitly or explicitly by numerous authors (Table 3 ). Caldwell reports that 137 of $224(56.1 \%)$ traumatised clinical staff in psychiatry contracted some PTSD symptoms but only $22(9.8)$ suffered the full clinical PTSD (Caldwell 1992). In a study of aggression victims in a German psychiatric setting not a 
single person suffered from fully-established PTSD (Richter \& Berger 2000), which demonstrates the need to differentiate between isolated symptoms and all three dimensions of PTSD.

Cognitive effects: Various threats to personal integrity or pride are reported, with some victims perceiving themselves as disrespected, unappreciated, violated, robbed of their rights (Gates, Fitzwater et al. 1999), humiliated (Lanza, Kayne et al. 1991; Hauck 1993), compromised (Chambers 1998), or intimidated, harassed and threatened (Fry, O'Riordan et al. 2002). Others perceive themselves as being at the mercy of the perpetrator (Hauck 1993), whilst yet others experience disbelief that the assault occurred (Ryan \& Poster 1989; Adams \& Whittington 1995; Chambers 1998; May \& Grubbs 2002; Hislop \& Melby 2003). Denial or rationalisation of the assault (Lanza 1983) or disbelief at being involved in the incident (Chambers 1998) may also occur. Some incidents can lead to a radical transformation of the conception of the world, with some victims stating that nothing will ever be the same again (Hauck 1993), that the event has a disruptive meaning (Flannery, Hanson et al. 1995), or that the world has become less predictable (Hauck 1993; Gates, Fitzwater et al. 1999) or threatening (Hauck 1993).

Emotional effects: Emotional reactions constitute the greatest variety of symptoms, with anger being the most frequently reported. Anger may be directed towards the nurses themselves, superiors (Hauck 1993) or the institution (Hauck 1993; Chambers 1998). The range of percentages of nurses experiencing anger is greatest in the emergency services, with rates from $14 \%$ $(\mathrm{n}=763)$ (Fernandes, Raboud et al. 2002) to $68.6 \%(\mathrm{n}=35)$ (Bin Abdullah, Khim et al. 2000). Two groups of authors report higher anger rates following verbal aggression than physical aggression (O'Connell, Young et al. 2000; Fernandes, Raboud et al. 2002). Feelings of guilt and self-blame are sometimes reinforced by superiors placing the blame for assaults on the victims (Hauck 1993). Guilt sometimes occurs in conjunction with shame ( $\AA$ ström, Bucht et al. 2002) and may lead to impairments in self-confidence (Hauck 1993). The other emotional effects are shown in Table 3.

Social effects: Assaults can affect (Gates, Fitzwater et al. 1999; Suserud, Blomquist et al. 2002) or undermine (Flannery, Hanson et al. 1995) the nurse-patient relationship and lead to behaviours such as less eagerness to spend time with residents, less willingness to answer residents' call lights (Gates, Fitzwater et al. 1999), avoiding patients (Flannery, Hanson et al. 1995; Levin, Hewitt et al. 1998), or adopting a passive role (Chambers 1998). Some nurses report becoming callous towards patients (Levin, Hewitt et al. 1998).

Nurses' perceptions of their job competency and security at or satisfaction with the workplace may be affected. Some of the assaulted nurses question the normalcy of a job in which workers are assaulted (Hauck 1993), or even consider changing job (Lanza 1983; Bin Abdullah, Khim et al. 2000). Some actually change ward or employer (O'Connell, Young et al. 2000). Many assault victims feel insecure at work (Hauck 1993; Bin Abdullah, Khim et al. 2000; Vincent, Perlt et al. 2000; May \& Grubbs 2002), more vulnerable 

al. 1991).

Patient aggression and assault can lead to real or perceived impairments in professional performance, leading nurses to doubt the quality of their work (Bin Abdullah, Khim et al. 2000), their competency (Whittington \& Wykes 1992), or perceive themselves as having failed.

Other effects: The following effects of aggression on nurses were reported fewer than three times in the 25 articles used in this review: biophysiological (decreased energy, hyper vigilance and hyper alertness), cognitive (impaired concentration, increased cautiousness), emotion (burn-out, feeling confused, crying, feeling sorry for the perpetrator, dependency, depression, distress, embarrassment, laughter, numbness, resignation, thoughts of suicide, and vulnerability), and social (impaired expression of feelings, changed or impaired relationships to co-workers or family members, stigmatisation of victims).

\section{Discussion}

The aim of this review was to identify and categorise the non-somatic effects of patient violence on nurses. The review produced 28 predominant non-somatic effects, which were categorised according to the system suggested by Lanza (1992). The effects were derived from studies conducted in 8 counties and 4 settings. If we had employed the 114 texts considered prior to the application of the exclusion criteria, the number of effects would have been greater. The variability of nurses' reactions, vocabulary in which nurses express their reactions and lack of standardisation of terms expressing reaction are three possible reasons for the great number of responses. Because of the semantic proximity of some effects (e.g. guilt, self-blame, and shame), we summarised some effects into categories in the synoptic table (Table 3). This procedure is a trade-off between semantic precision and a manageable number of effects.

The most frequently reported effects are anger, anxiety (fear), and guilt (self-blame, shame). The data in Table 3 suggest that these three primary reactions occur in all domains and in most countries. Anger and anxiety are considered relatively normal reactions and should not be confused with pathology. Guilt, self-blame, and shame may be linked to nurses' double role maintaining one's own rights whilst offering the best quality of care- in dealing with aggressive patients. Chambers (1998) remarks on some nurses' tendency to blame themselves, to assume responsibility and often to set themselves unrealistically high standards when attempting to deal with violent patients. Murray and Snyder report on healthcare workers' high expectations of themselves (Murray \& Snyder 1991). Such high moral standards, whilst being laudable, may lead to the ethical dilemma of endeavouring to fulfil professional moral standards whilst concurrently wishing to safeguard and maintain the nurse's own rights. 
Powerlessness is reported in the articles from all nursing domains except psychiatry. This finding may be associated with the socialisation and education of psychiatric nurses. Given the high rates of aggression in psychiatric nursing, this may indicate habituation to or better personal and structural resources for managing patient aggression.

Because of the focus of the review on adverse effects on assaulted nurses, no references to those on whom patient aggression and assault have little or no effect are included in this paper. Certain nurses are apparently not affected (Lanza 1983; Vincent, Perlt et al. 2000) and it is conceivable that patient aggression may have a positive effect (e.g. strengthening of certain personality traits) on some. As Flannery notes, $65 \%$ of nurses saw some meaning in the assault (Flannery, Fulton et al. 1991) and. regarding intention to leave the job, one group of authors notes that $54 \%$ of nurses had never considered doing this because of violence.

\section{Limitations}

Several methodological limitations apply to this systematic review. There is always the danger of missing relevant literature. This is possibly the case with some articles we discovered in languages (Finnish, Swedish) beyond our scope. It is also difficult to detect unpublished literature on the subject under scrutiny. Thus, in spite of the fact that two unpublished studies are included, and notwithstanding good feedback from international experts on the comprehensiveness of our search (Greenhalgh 2001), some selection bias may have occurred.

The 28 predominant effects found here are the result of a simple enumeration process and do not reflect any association with severity of suffering of the victims. The number and quality of non-somatic effects also seems to be affected by the research question and study design. An illustration of this difficulty is the non-somatic reactions of anxiety and fear: possible explanations for the differing rates of anxiety or fear ranging from $2.7 \%$ (trainee nursing aides) to $40.0 \%$ experienced caring staff are sampling (assaulted vs. non-assaulted, convenience vs. randomised sample), status (trainee vs. experienced), age of participants, setting (high level aggressions care settings such as psychiatry or accident and emergency), or definition of threat, aggression, violence and attack. A similar caveat applies to anger as the most frequently reported effect: whilst anger is reported in accident and emergency and general and mixed nursing settings, it only occurs in some psychiatric settings. This finding can be explained by the fact that most authors not reporting anger in psychiatric nursing (Caldwell 1992; Whittington \& Wykes 1992; Adams \& Whittington 1995; Flannery, Hanson et al. 1995; Richter \& Berger 2000) conducted studies placing the emphasis on PTSD or related concepts. It must also be stressed that the apparent concentration of PTSD symptoms in the domain of psychiatric nursing (Table 3 ) may possibly be a product of researchers' interest in this syndrome rather than an expression of real rates in this nursing domain. 
The studies employing qualitative research methods used in this review (Hauck 1993; Chambers 1998; Hislop \& Melby 2003) produced on average 10.3 non-somatic effects as compared 5.8 in quantitative studies, indicating that an open response format may influence the reporting of experienced effects.

Although we sought to counteract these problems by stringent application of the inclusion and exclusion criteria (Greenhalgh 2001), the results must be interpreted with caution.

\section{Conclusions}

However, in spite of these shortcomings, this review demonstrates various points. Nurses' reactions to patient aggression are complex and encompass a broad spectrum of non-somatic reactions. This finding is reflected in a comment by Chambers (1998 p. 433) that nurses involved in the management of aggressive patients are involved in a "complex mesh of feelings and interrelated experiences, some of which appear to contradict others". In spite of individual variability in nurses' reactions to patient aggression, some reactions seem to be consistent between countries and nursing settings.

Although evidence on the real frequencies and prevalence rates of non-somatic effects of patient aggression on nurses is inconclusive, the most predominantly reported consequences are anger, fear or anxiety, PTSD symptoms, guilt, self-blame, and shame. These effects exist despite differing countries, cultures and nursing settings. The use of standardised instruments and representative samples would be helpful to derive material suitable for comparison and meta-analysis. Given the effects of patient aggression on nurses and the subsequent suffering further research should concentrate on interventions to prevent patient aggression and to prepare nurses to cope with such effects. 


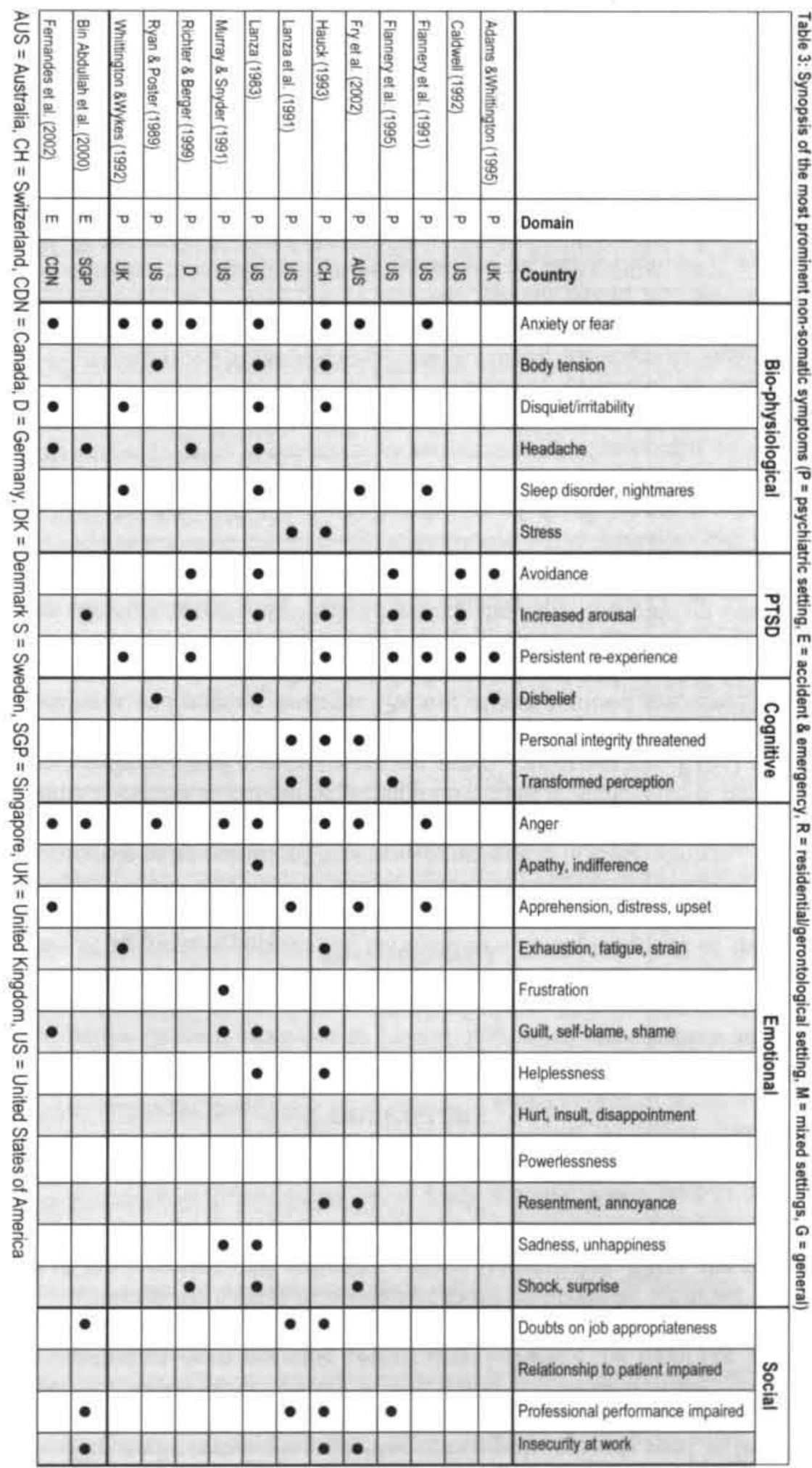




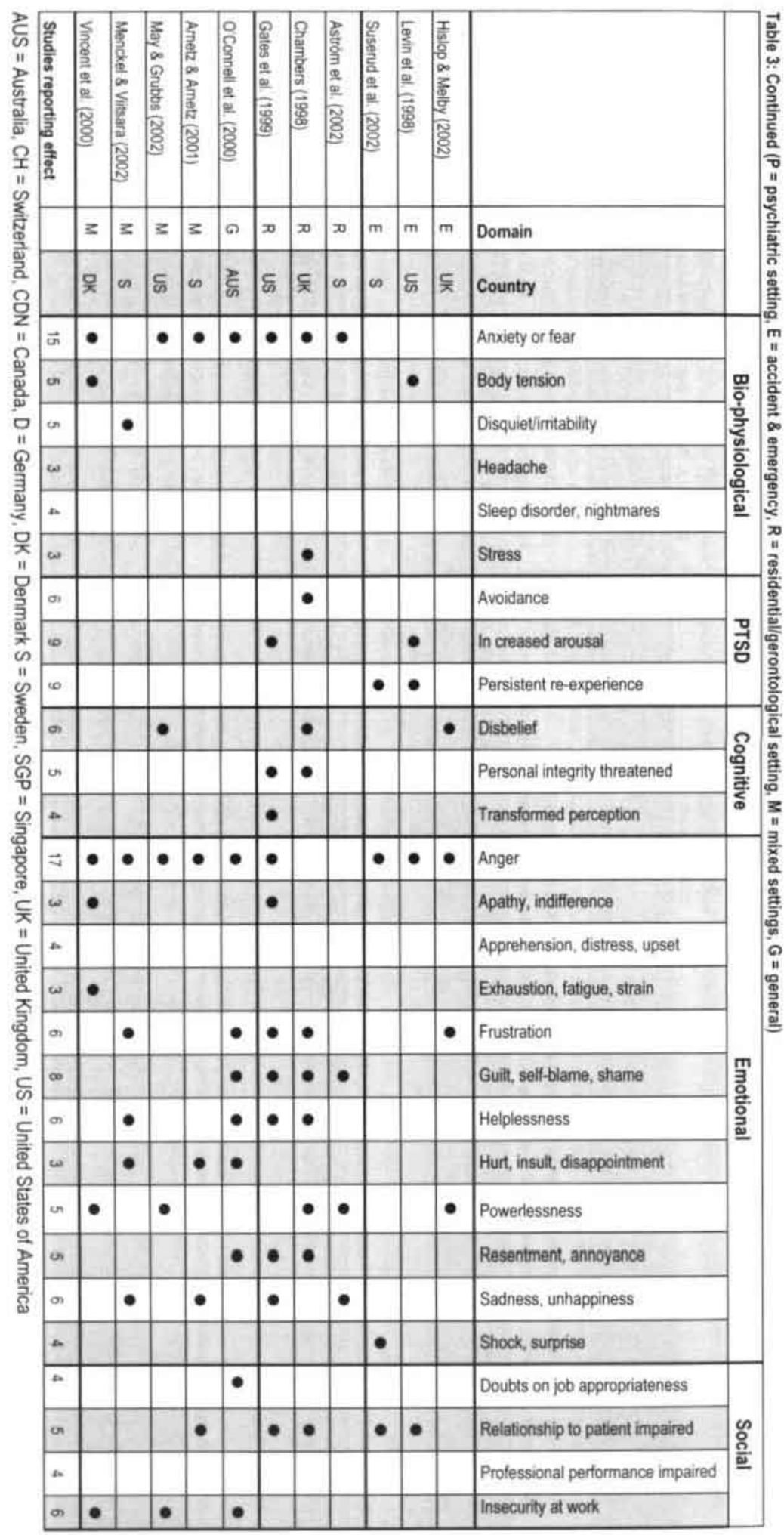


Appendix: Articles used In the systematic review

\begin{tabular}{|c|c|c|c|c|}
\hline Author(s) & Setting, subjects, sample & Study type, aim, definition & Instrument, analys/s & Hain results related to non-somatic eHects \\
\hline $\begin{array}{l}\text { Adams \& } \\
\text { Whittington } \\
\text { 1995: }\end{array}$ & $\begin{array}{l}68 \text { psychiatric nursing staff, } \\
\text { UK, c }\end{array}$ & $\begin{array}{l}\text { Prospective survey on verbal } \\
\text { abuse and threats: TV }\end{array}$ & $\begin{array}{l}\text { IRF, RIES, descriptive } \\
\text { statistics, testing }\end{array}$ & $\begin{array}{l}50 \text { episodes of verbal aggression reported by } 20 \text { nurses evoked intrusion and avoidance symptoms resulting in } \\
\text { a score of } 30.9 \text { on the RiES, whilst an eartier study produced a RIES score of } 10.3 \text { following physical aggres- } \\
\text { sion. }\end{array}$ \\
\hline $\begin{array}{l}\text { Amelz } 8 \text { Amelz } \\
200:\end{array}$ & $\begin{array}{l}8531 \text { (in } 61-76 \% \text { ) general } \\
\text { hospital statt, S, C }\end{array}$ & $\begin{array}{l}\text { Action research on association } \\
\text { between patient violence and } \\
\text { care qualky: } T \text {, no definition of } \\
\text { violence }\end{array}$ & $\begin{array}{l}\text { Quality of care instru- } \\
\text { Iment. descriptive stalis- } \\
\text { tics and testing }\end{array}$ & $\begin{array}{l}284 \text { hospital staft (12\%) had experienced violerwe In the precoding year with the most common ivactions being } \\
\text { anger. sadness, disappointment and tear. Othel reactions were post-violence cautiousness, fear, less enjoy- } \\
\text { ment working with patients. Workplace violence was significantly related to non somatic symploms. }\end{array}$ \\
\hline $\begin{array}{l}\text { Aström et al. } \\
2002 \text { : }\end{array}$ & $\begin{array}{l}506(\pi 78 \%) \text { nursing staff in } \\
\text { residential settings, S, } c\end{array}$ & $\begin{array}{l}\text { Cross sectional survey on } \\
\text { incidence of violence and staff's } \\
\text { emotional reactions: no defini- } \\
\text { tion }\end{array}$ & $\begin{array}{l}\text { Questionnaire, descriplive } \\
\text { statistics }\end{array}$ & $\begin{array}{l}\text { A considerable proportion of nurses report aggression consequences such as powerlessness ( } 56 \%) \text {, unhappl- } \\
\text { ness. }(51 \%) \text { and anger }(49 \%) \text {. Shame ( } 11 \%) \text { and guilt ( } 15 \%) \text { were also reported. }\end{array}$ \\
\hline $\begin{array}{l}\text { Bin Abdullah el } \\
\text { al. } 2000\end{array}$ & $\begin{array}{l}35 \text { (ח 869) emergancy } \\
\text { staft, SNG, C }\end{array}$ & $\begin{array}{l}\text { Survey on prevalence and } \\
\text { effects of patienl violence, PV }\end{array}$ & $\begin{array}{l}\text { Questionnaire, descriptive } \\
\text { statistics }\end{array}$ & $\begin{array}{l}\text { 94\% reporled p.5ychological effects following patient violence including anger and iritability (69\%), feelings of } \\
\text { insecunity (69\%), depression (3\%) and anxiery ( } 9 \% \text {. }\end{array}$ \\
\hline Caldwell 1992. & $\begin{array}{l}224 \text { (rr } 45 \% \text { ) mental health } \\
\text { staff, USA, c }\end{array}$ & $\begin{array}{l}\text { Survey on violence, conse- } \\
\text { quences and debriefing: no } \\
\text { definition }\end{array}$ & $\begin{array}{l}\text { Questionnaire, descriplive } \\
\text { slatistics }\end{array}$ & $\begin{array}{l}62 \% \text { (n=138) of staff gave accounts of critical violence incidents with } 61 \% \text { reporting PTSD symptoms, } 10 \% \text { (23) } \\
\text { met the criteria for PTSD. }\end{array}$ \\
\hline Chambers 1998 & $\begin{array}{l}5 \text { assaulted gerontologicai } \\
\text { nurses, UK, c }\end{array}$ & $\begin{array}{l}\text { Phenomenological study on } \\
\text { experiences with violence: no } \\
\text { definilion }\end{array}$ & $\begin{array}{l}\text { In-depth interviews, } \\
\text { Colaizzi analysis }\end{array}$ & $\begin{array}{l}\text { An exhaustive description of the experience of managing violent patients is given which includes experiences } \\
\text { of powerlessness, resentment, resignation, and anger by the nursesi. }\end{array}$ \\
\hline $\begin{array}{l}\text { Fernandes et al. } \\
199 g_{1}\end{array}$ & $\begin{array}{l}\text { los }(\pi r 65 \%) \text { emergency } \\
\text { department staff in CND, C }\end{array}$ & $\begin{array}{l}\text { Survey on perceived incidencis } \\
\text { and consequences of violence: } \\
\text { no definition }\end{array}$ & $\begin{array}{l}\text { Questionnaire, descriptive } \\
\text { statistics }\end{array}$ & $\begin{array}{l}\text { Nurses reported consideration of job change (38\%), short, medium and long term impaired job performance } \\
(25 \%, 24 \% \text {, and } 19 \% \text { respectively), fear of patients }(73 \%) \text {, and impaired job satisfaction }(74 \%) \text {. }\end{array}$ \\
\hline $\begin{array}{l}\text { Femandes el al. } \\
2002\end{array}$ & $\begin{array}{l}667 \text { (rr 84\%) emergency } \\
\text { departmenl stafi, CND, c }\end{array}$ & $\begin{array}{l}\text { Prospective survey on the } \\
\text { effects of volence management: } \\
\text { PV }\end{array}$ & $\begin{array}{l}\text { Questionnaire, descriplive } \\
\text { statistics }\end{array}$ & $\begin{array}{l}\text { Surveys were conducled at baseline and at } 3 \text { and } 6 \text { months post-training with nurses constituting } 56 \%, 55 \% \text {, } \\
\text { and } 66 \% \text { of the samples respectively. The impacts of verbal and physical violence are feeling upset, blame, } \\
\text { fear of being alone with patient, increased intability, anger, and headache. }\end{array}$ \\
\hline
\end{tabular}

Note: $\|=$ response rate $\mathrm{c}=$ convenience sample, $\mathrm{P}=$ physical, $\mathrm{V}=$ verbat, $\mathrm{T}=$ threat

Countries: $A$ US $=$ Australia, $C H=$ Switzerland, $C D N=$ Canada, $D=$ Germany, $O K=$ Denmark, $S=$ Sweden, $S G P=$ Singapore, UK = United Kingdom, US = United Stales of America 


\begin{tabular}{|c|c|c|c|c|}
\hline Author(s) & Setting, subjects, sample & Study type, aim, definition & Instrument, analysis & Main results related to non-somatic effocts \\
\hline $\begin{array}{l}\text { Flannery et al. } \\
1991\end{array}$ & $\begin{array}{l}62 \text { assaults on healthcare } \\
\text { workers in a mental } \\
\text { hospital, USA, C }\end{array}$ & $\begin{array}{l}\text { Prospective survey on effects of } \\
\text { an intervention for the as. } \\
\text { saulted, VP }\end{array}$ & $\begin{array}{l}\text { Interviews, description of } \\
\text { effects }\end{array}$ & $\begin{array}{l}\text { During interviews conducted as part of the "Assaulted Staff Action Program" (ASAP) the victims reported on } \\
\text { experiencing fright, anger, apprehension, sleep disturbances, intrusive memories, recall of traumatic incidents } \\
\text { and hyper vigilance. }\end{array}$ \\
\hline $\begin{array}{l}\text { Flannery et al. } \\
1995\end{array}$ & $\begin{array}{l}19 \text { assaults on psychiatric } \\
\text { slaff, USA, c }\end{array}$ & $\begin{array}{l}\text { Prospective survey on fre. } \\
\text { guency and impact of threats on } \\
\text { carers, } T\end{array}$ & $\begin{array}{l}\text { PTSD monitoring. } \\
\text { descriptive statistics }\end{array}$ & $\begin{array}{l}\text { Some of the nurses involved in } 19 \text { cases of severe threat experienoed PYSD-tike symptoms ( } n=9) \text { and disnup- } \\
\text { tion in mastery and meaning ( } n=11 \text { ). }\end{array}$ \\
\hline Fry et al. 2002 & $\begin{array}{l}\text { Community mental health } \\
\text { staff }(n=92, n 77 \%) \text {, AUS. } \\
\text { c }\end{array}$ & $\begin{array}{l}\text { Survey on characteristics of } \\
\text { aggressive incidents and statf } \\
\text { experiences with aggression, } \\
\text { PV }\end{array}$ & $\begin{array}{l}\text { Questionnaire based on } \\
\text { the OAS. descriptive } \\
\text { statistics }\end{array}$ & $\begin{array}{l}\text { Respondents of the cross sectional survey reported anxiety ( } 44 \%) \text {, emotional distress }(35 \%) \text {, feelings of } \\
\text { vulnerability, violation of psychological integrity }(9 \%) \text { including intimidation, harassment, and threat) and fear. } \\
\text { Other experiences were e.g. nightmares, thoughts about further attacks, or preoccupation with risk and safety } \\
\text { "Less common" reactions were e.g. surprise annoyance, shock, laughter, or burnout. }\end{array}$ \\
\hline $\begin{array}{l}\text { Gales el al. } \\
1999\end{array}$ & $\begin{array}{l}\text { 60 nursing home rurses, } \\
\text { USA, } c\end{array}$ & $\begin{array}{l}\text { Focus group on perceptions of } \\
\text { violence: PTV }\end{array}$ & $\begin{array}{l}\text { Structured questions, } \\
\text { content analysis, descrip- } \\
\text { tive depiction of effects; }\end{array}$ & $\begin{array}{l}\text { In focus groups the victims of palient aggression report on the following feelings: Hurt, anger, frustration, } \\
\text { resentment, sadness, feelings of hurt and unipredictablity, lack of respect, shock, madness fear, feeling ban, } \\
\text { and ambivalence. }\end{array}$ \\
\hline Hauck 1993 & $\begin{array}{l}7 \text { assaulted psychiatric } \\
\text { nurses. } \mathrm{CH}, \mathrm{C}\end{array}$ & $\begin{array}{l}\text { Content analysis on the experi- } \\
\text { ence of assaulted nurses: no } \\
\text { definition }\end{array}$ & $\begin{array}{l}\text { Open interview, coding. } \\
\text { categorising procedures }\end{array}$ & $\begin{array}{l}\text { Assaulted nurses reported anger, resentment, guilt/self-blame, numbness, exhaustionifatigue, threats to } \\
\text { nersonal integrity, transformed perception, impaired capacity to express feelings, stigmatisation, doubts on job } \\
\text { appropriateness, and feelings of workplace insecurity impairment in professional performance. }\end{array}$ \\
\hline $\begin{array}{l}\text { Hisiop \& Melby } \\
2002\end{array}$ & $\begin{array}{l}\text { Accidenl and emergency } \\
\text { nurses }(n=26, \pi=95 \%) \text {, } \\
\text { UK. } c\end{array}$ & $\begin{array}{l}\text { Phenomenological inquiry into } \\
\text { the lived expenence of violence: } \\
\text { PTV }\end{array}$ & Giorgi method of analysis & $\begin{array}{l}\text { The oore category why me? of the lived experience of AaE nurses includes frustration, powerlessneas, } \\
\text { incapacity to understand being the target of aggression, embarrassment, and anger. In the care calegory } \\
\text { "sense of isolation" responden's report feeling being left lotally alone (by management), and fear (of personal } \\
\text { injury). }\end{array}$ \\
\hline $\begin{array}{l}\text { Lanza et al. } \\
1991\end{array}$ & $\begin{array}{l}21 \text { (rt unclear) psychiatric } \\
\text { nurses, USA, sampling } \\
\text { unclear }\end{array}$ & $\begin{array}{l}\text { Prospective survey on charac- } \\
\text { teristics of assaulted nurses: no } \\
\text { definition }\end{array}$ & $\begin{array}{l}\text { VIS. NSCF, descriptive } \\
\text { statistics }\end{array}$ & $\begin{array}{l}\text { Of the } 7 \text { assaulled nurses } 30 \% \text { felt more apprehensive. } 10 \% \text { more vulnerable. } 10 \% \text { less in control, } 10 \% \\
\text { intended job change, and } 10 \% \text { experienced strained farnily relationships. }\end{array}$ \\
\hline Lanza (1983) & $\begin{array}{l}40 \text { assaulted nurses in } \\
\text { psychiatry, US, c }\end{array}$ & $\begin{array}{l}\text { Explorative survey summarising } \\
\text { reactions to assaull: }\end{array}$ & $\begin{array}{l}\text { Questionnaire, descriptive } \\
\text { statistics }\end{array}$ & $\begin{array}{l}\text { After administration of a questionnaire with } 108 \text { possible response reactions numerous short and long term } \\
\text { emotional, social, bic-physiological, and cognilive reactions were found (e.g. anger, helplessness, anxiety, of } \\
\text { changes in relationships to others). Some nurses were not prone lo reaction affer assault. }\end{array}$ \\
\hline $\begin{array}{l}\text { Levin et al. } \\
1998\end{array}$ & $\begin{array}{l}22 \text { emergency departmen! } \\
\text { nurses. USA, O }\end{array}$ & $\begin{array}{l}\text { Focus groups on nurses views } \\
\text { on assaults: } P\end{array}$ & $\begin{array}{l}\text { Coding procedures, } \\
\text { descriptive depiction of } \\
\text { effects }\end{array}$ & $\begin{array}{l}\text { Victims reported long-term chronic pain, muscle tension, loss of sleep. nightmares, flashback, anger, with- } \\
\text { drawal from patients, callousness, bumout, impaiment of personal relationships. }\end{array}$ \\
\hline
\end{tabular}

Note: $\pi=$ response rate $c=$ convenience sample, $P=$ physical, $V=$ verbal, $T=$ threat

Countries: $A \cup S=$ Australia, $C H=$ Switzerland, $C D N=$ Canada, $D=$ Germany, $D K=$ Denmark, $S=S$ Sweden, $S G P=$ Singapore, UK $=$ United Kingdom, US $=$ United Siztes of America 


\begin{tabular}{|c|c|c|c|c|}
\hline Author(s) & Selting, subjects, sample & Study type, aim, definition & Instrument, anaiysis & Main results related to non-somatic effects \\
\hline $\begin{array}{l}\text { May \& Grubbs } \\
2002\end{array}$ & $\begin{array}{l}86 \text { (n 69\%) geners. } \\
\text { emergency, ICU nurses, } \\
\text { USA, C. }\end{array}$ & $\begin{array}{l}\text { Survey on patient assaults on } \\
\text { nurses: PTV }\end{array}$ & $\begin{array}{l}\text { HASN, descriptire } \\
\text { statistics, ANOVA }\end{array}$ & $\begin{array}{l}\text { Victims of patient violence experienced: Decreased job satisfaction (65\%), anger ( }(66 \%) \text {, anxiety }(53 \%) \text {, fear } \\
(36 \%) \text {, emotional distress }(36 \%) \text {, disbelief }(34 \%) \text {, powerlessness }(23 \%) \text {, and impaired job confidence }(20 \%) \text {. }\end{array}$ \\
\hline $\begin{array}{l}\text { Menckel \& } \\
\text { Viltasara } 2002\end{array}$ & $\begin{array}{l}2380 \text { ( }(\pi) 85 \%) \text { care work- } \\
\text { ers. S, stratified sampling }\end{array}$ & $\begin{array}{l}\text { Survey on prevalence and } \\
\text { consequences al threats and } \\
\text { violence: no definition of } \\
\text { vickence. }\end{array}$ & $\begin{array}{l}\text { Questionnaire, descriptive } \\
\text { depiction ol ellects }\end{array}$ & 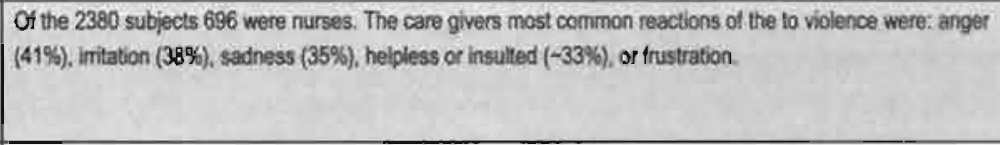 \\
\hline $\begin{array}{l}\text { Murray } 8 \\
\text { Snyder } 1991\end{array}$ & $\begin{array}{l}19(\pi 54 \%) \text { assauthed } \\
\text { psychiatic staft, USA c }\end{array}$ & $\begin{array}{l}\text { Survey to assess stress at B } \\
\text { weeks post-assault } P\end{array}$ & $\begin{array}{l}\text { Questionnaire, descriptive } \\
\text { depiction of eflects }\end{array}$ & $83 \%$ of assaulted nurses reported reactions of frustration, anger, self-criticism, disbeliet, and sadness. \\
\hline $\begin{array}{l}\text { OConnell et al } \\
2000\end{array}$ & $\begin{array}{l}200 \text { (n 52\%) general } \\
\text { nurses, AUS, i }\end{array}$ & $\begin{array}{l}\text { Survey on the perception and } \\
\text { experience of violence. no } \\
\text { definition }\end{array}$ & $\begin{array}{l}\text { Questionnaire, descriptiva } \\
\text { 5tatistics }\end{array}$ & 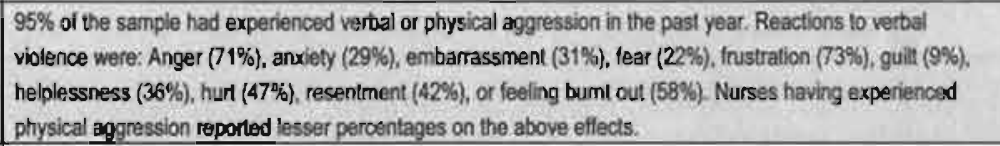 \\
\hline $\begin{array}{l}\text { Richter \& } \\
\text { Berger } 2000\end{array}$ & $\begin{array}{l}85(\pi t 50 \%) \text { assaulled } \\
\text { psychiatric workers in D, c }\end{array}$ & $\begin{array}{l}\text { Prospective survey on patient } \\
\text { assault and consequencess: } P\end{array}$ & $\begin{array}{l}\text { Interview. PTSD ques- } \\
\text { tonnaite, descriptive } \\
\text { statistics }\end{array}$ & 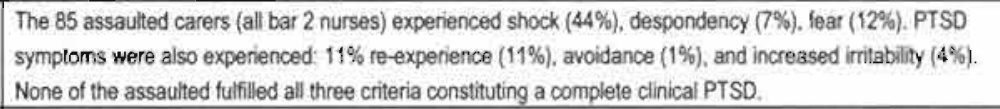 \\
\hline $\begin{array}{l}\text { Ryan \& Poster } \\
1989\end{array}$ & $\begin{array}{l}61 \text { assaulted nursing staff, } \\
\text { USA, } \mathrm{C}\end{array}$ & $\begin{array}{l}\text { Prospective longitudinal survay } \\
\text { on assault effects: PT }\end{array}$ & $\begin{array}{l}\text { ARQ, ATPAQ, Interview, } \\
\text { inferential statistics }\end{array}$ & $\begin{array}{l}\text { The following reactions to violence were found Anger }(40-50 \%) \text {, anxiousness, feeling sorry for the perpetra- } \\
\text { lor, leelings of inadequacy in preventing the aggressive incidert (30-40\%), increased body lension and } \\
\text { awareness }(40-50 \%) \text {, with social and cognilive responses having been experienced at "a lower rate". }\end{array}$ \\
\hline $\begin{array}{l}\text { Suservd et at. } \\
2002\end{array}$ & $\begin{array}{l}66 \text { (r 92\%) ambulanco } \\
\text { service nurses, S, c }\end{array}$ & $\begin{array}{l}\text { Survey on experiences with } \\
\text { threats and vicience: } T \text {, no clear } \\
\text { definition of violence }\end{array}$ & $\begin{array}{l}\text { Questionnaire, descriptive } \\
\text { depiction of effects }\end{array}$ & $\begin{array}{l}\text { Ambulance nurses having experienced violence perceived impairment of performance, anger, feeling con- } \\
\text { lounded, shock, impairment of nurse-patient relationship, and difficulty to concentrate. }\end{array}$ \\
\hline $\begin{array}{l}\text { Vincent el al. } \\
2000\end{array}$ & $\begin{array}{l}660 \text { ( } 69 \% \text { ) health care } \\
\text { trainees; DK, } c\end{array}$ & $\begin{array}{l}\text { Survey on assoult conso- } \\
\text { quences: PTSV }\end{array}$ & $\begin{array}{l}\text { Questionnaire, descriplive } \\
\text { statistics }\end{array}$ & $\begin{array}{l}\text { Trainees in social work (428), nursing (228) and nursing aides (184) participated. Of the } 860 \text { students } 428 \text { had } \\
\text { experienced violence of threats of violence. The main expenences were: Body lension, anxiety/fear ( } 48 \% \text { ), } \\
\text { anger 17.1\%), powerlessness, indifference, exhaustiontlatigue, feelings of workplace insecuntly. }\end{array}$ \\
\hline $\begin{array}{l}\text { Whittington \& } \\
\text { Wykes } 1992\end{array}$ & $\begin{array}{l}23 \text { assaulted nurses, one } \\
\text { assaulted docror. UK, C }\end{array}$ & $\begin{array}{l}\text { Prospective longitudinal survey } \\
\text { on post assautt strain and } \\
\text { support: } P\end{array}$ & $\begin{array}{l}\text { SSEV, SQ, VSQ, inleren- } \\
\text { tial statistics }\end{array}$ & $\begin{array}{l}\text { Vittims of patient violence were interviewed three times }(<72 \mathrm{~h}, 7 \text {, and } 14 \text { days). The following non somatic } \\
\text { responses varied individually in intensity across time: Sleep disorder, nightmares. andietyflear, exhaustion, } \\
\text { with fatigue and irrtability being the most prominent reactions. }\end{array}$ \\
\hline
\end{tabular}

Note: $\pi=$ response rale $c=$ convenience sample, $P=$ physical, $V=$ verbal, $T=$ threat

Countries: AUS = Australia, $\mathrm{CH}=$ Switzeriand, $\mathrm{CDN}=\mathrm{Canada}, \mathrm{D}=\mathrm{Germany}, \mathrm{DK}=$ Denmark, $S=$ Sweden, $S G P=$ Singapore, UK $=$ United Kingdom, US $=$ United States of America 
Legend of abbreviated instruments employed in the studies

$\mathrm{ARQ}=$ Assault Response Questionnaire

ATPAQ $=$ Attitudes Toward Patient Physical Assault Questionnaire

HASN $=$ Hospital Assault Survey for Nurses

IRF $=$ Incident Report Form

NSCF $=$ Nursing Staff Characteristics Form

$\mathrm{OAS}=$ Overt Aggression Scale

PTSD-Interview $=$ Post-Traumatic Stress Disorder Interview, German version RIES = Revised Impact of Events Scale

$\mathrm{SQ}=$ Strain Questionnaire

SSEV $=$ Spielberger's Self Evaluation Questionnaire

VIS $=$ Victim Interview Schedule

VSQ $=$ Victim Support Questionnaire 


\section{References}

Adams J, Whittington R (1995) Verbal aggression to psychiatric staff: Traumatic stressor or part of the job? Perspectives in Psychiatric Care 2(2):171-74

American Psychiatric Association (1994) Diagnostic and Statistical Manual of Mental Disorders. (4 Aufl) Washington D.C., American Psychiatric Association

Ametz JE, Ametz BB (2001) Violence towards health care staff and possible effects on the quality of patient care. Social Science and Medicine 52(3):417-27.

Aström S, Bucht G, Eisemann M, Norberg A, Saveman BI (2002) Incidence of violence towards staff caring for the elderly. Scandanavian Journal of Caring Sciences 16(1):66-72

Baxter E, Hafner RJ, Holme G (1992) Assaults by patients: the experience and attitudes of psychiatric hospital nurses. Australian and New Zealand Journal of Psychiatry 26(4):56773

Bensley L, Nelson N, Kaufman J, Silverstein B, Kalat J, Shields J (1997) Injuries due to assaults on psychiatric hospital employees in Washington State. American Journal of Industrial Medicine 1(1):92-9

Bin Abdullah AM, Khim LYL, Wah LC, Bee OG, Pushpam S (2000) A study of violence towards nursing staff in the emergency department. Singapore Nursing Journal 27(3):30-37

Caldwell MF (1992) Incidence of PTSD among staff victims of patient violence. Hospital and Community Psychiatry 43(8):838-9

Carmel H, Hunter M (1993) Staff injuries from patient attack: five years' data. The journal of the American Academy of Psychiatry and the Law 21(4):485-493

Chambers N (1998) 'We have to put up with it-don't we?' The experience of being the registered nurse on duty, managing a violent incident involving an elderly patient: a phenomenological study. Journal of Advanced Nursing 27(2):429-36

Fernandes CM, Raboud JM, Christenson JM, Bouthillette F, Bullock L, Ouellet L, Moore CF (2002) The effect of an education program on violence in the emergency department. Annals of Emergency Medicine 39(1):47-55

Flannery R, Fulton P, Tausch J (1991) A program to help staff cope with psychological sequelae of assaults by patients. Hospital and Community Psychiatry 41(9):935-938

Flannery R, Hanson M, Penk W (1995) Patients' threats. Expanded definition of assault. General Hospital Psychiatry 17(6):451-3

Fottrell E (1980) A study of violent behaviour among patients in psychiatric hospitals. British Journal of Psychiatry 136:216-221

Fry AJ, O'Riordan D, Turner M, Mills KL (2002) Survey of aggressive incidents experienced by community mental health staff. International Journal of Mental Health Nursing 11(2):11220

Gates DM, Fitzwater E, Meyer U (1999) Violence against caregivers in nursing homes: Expected, tolerated, and accepted. Journal of Gerontological Nursing (4):12-22

Greenhalgh T (2001) How to read a paper: The basics of evidence based medicine. (2nd edition) London, BMJ Books

Haller R, Deluthy R (1988) Assaults on staff by psychiatric in-patients: A critical review. British Journal of Psychiatry 152:174-179

Hansen B (1996) Workplace violence in the hospital psychiatric setting. An occupational health perspective. American Association of Occupational Health Nurses Journal 4(12):575-580

Hanson R, Balk J (1992) A replication study of staff injuries in a state hospital. Hospital and Community Psychiatry 43(9):836-837

Hauck M (1993) Die Wut bleibt - Gewalt von Patienten gegenüber Pflegenden (The anger remains - patient violence towards nurses). Unpublished Unpublished Thesis, Kaderschule für die Krankenpflege. Aarau 
Hislop E, Melby V (2003) The lived experience of violence in accident and emergency. Accident and Emergency Nursing 11(1):5-11

Lanza M, Kayne H, Hicks C, Milner J (1991) Nursing staff characteristics related to patient assault. Issues in Mental Health Nursing 12(3):253-265

Lanza ML (1983) The reactions of nursing staff to physical assault by a patient. Hospital Community Psychiatry 34(1):44-7.

Lee SS, Gerberich SG, Waller LA, Anderson A, McGovern P (1999) Work-related assault injuries among nurses. Epidemiology 10(6):685-691

Levin PF, Hewitt JB, Misner ST (1998) Insights of nurses about assault in hospital-based emergency departments. Image Joumal of Nursing Scholarship 30(3):249-54

May DD, Grubbs LM (2002) The extent, nature, and precipitating factors of nurse assault among three groups of registered nurses in a regional medical center. Journal of Emergency Nursing 28(1):11-7

Murray G, Snyder JC (1991) When staff are assaulted. A nursing consultation support service. Journal of Psychosocial Nursing and Mental Health Services 29(7):24-29

Noble P. Rodger S (1989) Violence by psychiatric in-patients. British Journal of Psychiatry 155:384-390

O'Connell B, Young J, Brooks J, Hutchings J, Lofthouse J (2000) Nurses' perceptions of the nature and frequency of aggression in general ward settings and high dependency areas. Journal of Clinical Nursing 9(4):602-10.

Owen C. Tarantello C, Jones M, Tennant C (1998) Violence and aggression in psychiatric units. Psychiatric Services 49(11):1452-1457

Richter D (1998) Gewalt und Gewaltprävention in der psychiatrischen Pflege- eine Übersicht über die Literatur. In: Sauter D, Richter D (Hrsg). Gewalt in der psychiatrischen Pflege Bern, Huber.

Richter D, Berger K (2000) Physische und psychische Folgen bei Mitarbeitem nach einem Patientenübergriff: Eine prospektive Untersuchung in sechs psychiatrischen Kliniken. Arbeitsmedizin, Sozialmedizin, Umweltmedizin 35(8):357-362

Rippon TJ (2000) Aggression and violence in health care professions. Journal of Advanced Nursing 31(2):452-60

Ryan JA, Poster EC (1989) The assaulted nurse: short-term and long-term responses. Archives of Psychiatric Nursing 3(6):323-31

Suserud BO, Blomquist M, Johansson 1 (2002) Experiences of threats and violence in the Swedish ambulance service. Accident and Emergency Nursing 10(3):127-35

Vanderslott J (1998) A study of incidents of violence towards staff by patients in an NHS Trust hospital. Journal of Psychiatric and Mental Health Nursing 5(4):291-298

Vincent C, Perlt D, Sørensen S, Winther L (2000) Violence against trainees - a questionnaire study. Copenhagen, Socialt Udviklingscenter SUS: 38

Whittington R, Wykes T (1992) Staff strain and social support in a psychiatric hospital following assault by a patient. Journal of Advanced Nursing 17(4):480-486 


\section{CHAPTER 4}

THE IMPACT OF PATIENT AGGRESSION ON CARERS SCALE (IMPACS): INSTRUMENT DERIVATION AND PSYCHOMETRIC TESTING

Needham I, Abderhalden C, Halfens RJG, Dassen T, Haug HJ, Fischer JE,.

Submitted for publication. 


\begin{abstract}
Patient aggression towards carers constitutes a problem for patients and carers alike. Patients' aggressive behaviour often leads to adverse consequences for carers, especially nurses. Various extensive instruments have been developed to measure such adverse effects on carers. The "Impact of Patient Aggression on Carers Scale" (IMPACS) is a short instrument intended for use in monitoring the monitor negative consequences of such incidents. The items of the IMPACS were derived basically from a review of the literature on negative effects of patient aggression on nurses. The IMPACS was administered to a convenience sample of nurses working on 14 psychiatric acute admission wards in the German speaking part of Switzerland.

Factor analysis led to the exclusion of three of the original items and to an interpretable three factor solution with all factors demonstrating Eigen values higher than 1. The factors demonstrate moderate to good internal consistency. Canonical correlation analysis using the dimensions of the Maslach Burnout Inventory (MBI) produced a correlation coefficient of 0.457 , thus demonstrating external reliability. In spite of some caveats such as possible response bias and the necessity of the investigation of the test retest stability of the scale this study suggests that the IMPACS is a good measure of adverse effects and thus merits further development.
\end{abstract}

Keywords: aggression management, adverse feelings, staff, violence, emotional reactions

Acknowledgement

This study was supported by grant number $3251 \mathrm{~B} 0-100710$ of the Swiss National Science Foundation. 


\section{Introduction}

Aggressive and violent patients pose a major problem in health care institutions. In the course of their careers $82 \%$ of nurses in accident and emergency nursing (Erickson \& Williams-Evans 2000), and about $70 \%$ of nurses in psychiatric settings (Abderhalden, Needham et al. 2002) are assaulted at least once. Some situations involving patient aggression towards nurses create ethical dilemmas: One the one hand the nurses have to fend for their own rights and on the other hand concurrently endeavour to act in the best interests of the patients. This "catch 22" situation often leads to emotional scrupulosity and cognitive dissonances. These problems are often reinforced by the fact nursing education ill-equips them to deal with patient aggression in a professional and ethically satisfactory fashion. Thus, the management of patient aggression often provokes adverse feelings and experiences of nurses which will be referred to here as the "Impact of Patient Aggression on Carers".

Various authors have noted that nurses can experience guilt or self blame on being involved in aggressive incidents with patients (Ryan \& Poster 1989; Murray \& Snyder 1991; Hauck 1993; Gates, Fitzwater et al. 1999; O'Connell, Young et al. 2000) and sometimes experience feeling sorry for the patient (Murray \& Snyder 1991; Arnetz \& Arnetz 2001). Adverse consequences such as avoiding the perpetrator (Adams \& Whittington 1995; Chambers 1998; Richter 1999), or the perception of an impaired relationship with the patient involved (Chambers 1998; Levin, Hewitt et al. 1998; Gates, Fitzwater et al. 1999; Arnetz \& Arnetz 2001) may also occur after being involved in aggressive incidents and sometimes lead to some nurses feeling insecure in dealing with the patients (Hauck 1993; Poster 1996; Bin Abdullah, Khim et al. 2000; O'Connell, Young et al. 2000; Fry, O'Riordan et al. 2002). Aggressive incidents may also lead to nurses doubting their professional abilities (Lanza, Kayne et al. 1991; Hauck 1993; Flannery, Hanson et al. 1995; Bin Abdullah, Khim et al. 2000) or even provoke feelings of being a failure (Hauck 1993). Sometimes nurses may become angry towards the hospital they are working in (Lanza, Kayne et al, 1991; Hauck 1993; Chambers 1998) and even ask themselves if they are working in the right profession (Lanza, Kayne et al. 1991; Hauck 1993; Bin Abdullah, Khim et al. 2000; O'Connell, Young et al. 2000).

Various methods and instruments have been devised to assist data collection on such adverse experiences. Whilst some researchers have used the phenomenological or hermeneutical approach with the methodology of an open questioning format (Collins 1994; Cutcliffe 1999) others have recorded nurses' adverse feelings following dealing with aggressive patients by employing special questionnaires. The "Assault Response Questionnaire" (Lanza 1983 ) uses 57 items relating to the social, emotional, cognitive, and biophysiological dimensions of nurses' responses after being attacked by patients. Another scale - the "Attitudes toward Patient Physical Assault Questionnaire" (Poster 1996) - consists of 31 items concerning safety, staff per- 
formance and legal issues. The authors do not report anything on its psychometric properties. The 26 item "Strain Questionnaire" (Whittington \& Wykes 1992) - partially adapted from "The Assault Response Questionnaire" - covers the dimensions of unsatisfactory emotional processing, physical and psychological symptoms and has a "good" test-retest reliability. Other authors have used validated psychological scales like the "Spielberger's State anxiety Questionnaire" (Whittington \& Wykes 1992) or "Post Traumatic Stress Disorder" instruments (Richter \& Berger 2000).

Given the number of effects measured by and given the differing quality of the psychometric properties of the scales we decided to embark on this study. The objective was to develop a practical, parsimonious instrument designed to measure nurses' adverse feelings after dealing with aggressive patients - the Impact of Patient Aggression on Carers Scale (IMPACS) and to test its psychometric properties. The IMPACS is intended to be used to monitor possible changes of carers' adverse sentiments in conjunction with interventions such as courses in the management of aggression, control and restraint, or ethical reflection on dealing with aggressive patients.

\section{Materials, sample and methods}

Questionnaire: In this study employing a cross sectional design a questionnaire was administered to a sample of nurses working in acute psychiatric admission wards. The questionnaire contained items regarding sociobiographic data, nursing experience, experience of aggression, the "Maslach Burnout Inventory" (MBI), the "Confidence in Dealing with Aggression" scale (Thackrey 1987), and the 13 items of the IMPACS scale. The questionnaires were administered in a way to ensure anonymity. Nurses gave their informed consent at the outset of the study which had been previously approved by the local ethical committees of the cantons of the clinics involved.

Sample: Two hundred and fifty four nurses from 14 acute admission wards of eight hospitals in the German speaking part of Switzerland were invited to participate in this study on a voluntary basis. One hundred and sixty five questionnaires were completed representing a return rate of $64 \%$. The sample consisted of 65 males $(39.4 \%)$ and 100 females $108(60.6 \%)$, with a mean age of 38 years (SD 10) and with a minimum and maximum of 21 and 62 years. Their nursing experience in psychiatry ranged from 1 to 35 years with a mean of 9 years $(\mathrm{SD}=8)$.

Methods: The methodological steps employed in this study were firstly to establish the IMPACS and secondly to test its psychometric properties. Based on a review of relevant material on negative consequences of patient aggression on nurses (Needham, Abderhalden et al.) and based on our experience in psychiatric nursing we chose 13 items to constitute the first draft of the IMPACS. The scale employs a Likert-type format with five choices representing the frequency of feelings ("never", "rarely", "sometimes", often" and "always") after dealing with aggressive patients. Psychometric testing was conducted employing the following steps: Initially factor 
analysis was conducted on the 165 responses to detect the underlying dimensions and Cronbach's alpha was employed to test the internal consistency of the IMPACS. During psychometric testing competing factor models were considered in an iterative process comprising of factor analysis and reliability testing. Finally canonical correlation was conducted between the factors of the IMPACS and the dimensions of the Maslach Burnout Inventory. Because this scale measures carers' emotions ("personal accomplishment", "emotional exhaustion" and "depersonalisation") correlations with the dimensions of the IMPACS were expected. If established such correlations would serve to test external validity.

\section{Results}

Factor analysis was conducted with Eigen values set at $>1$ and using varimax rotation. After factor analysis reliability analysis was conducted to test internal reliability of the factors. The initial analysis using the 13 original items revealed an ambiguous 4 factor solution. After deletion of three items failing to contribute to the factor solution - "I question whether I am working in the right profession", "I have doubts on my professional abilities", and "I have inhibitions to talk about these aspects of my work" - a three factor solution was chosen (Table 1).

Table 1: Factor solution of the IMPACS

\begin{tabular}{lccc}
\hline After dealing with patient aggression... & F1 & F2 & F3 \\
\hline I avoid contact with this patient & 0.859 & -0.062 & 0.044 \\
I feel insecure in working with the patient & 0.792 & 0.316 & -0.023 \\
I feel insecure at work & 0.730 & 0.217 & 0.278 \\
I experience a disturbance in the relationship to the patient & 0.556 & 0.362 & 0.081 \\
I have a "guilty consciences" towards the patient & 0.152 & 0.800 & 0.049 \\
I feel sorry for the patient & 0.117 & 0.728 & -0.158 \\
\hline I feel ashamed of my work & 0.175 & 0.610 & 0.335 \\
I have feelings of being a failure & 0.451 & 0.510 & 0.302 \\
I have feelings of anger towards the clinic I am working in & 0.109 & 0.009 & 0.826 \\
I feel that I am having to deal with societies' problems & 0.072 & 0.068 & 0.800 \\
\hline
\end{tabular}

The three factors yielded Eigen values of 3.68, 1.39 and 1.16 and account cumulatively for $62 \%$ of the total variance with a Kaiser-MeyerOlkin measure of sampling adequacy $=0.792(\mathrm{df}=45, \mathrm{p}=0.001)$. The properties of the remaining items are demonstrated in Table 2. 


\begin{tabular}{|c|c|c|c|c|c|c|c|}
\hline Item & $\mathbf{N}$ & $\frac{\frac{2}{2}}{\frac{2}{z}}$ & 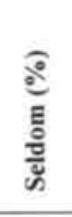 & $\begin{array}{l}\text { 巳 } \\
\text { है } \\
\text { E } \\
\text { हू } \\
\text { हू }\end{array}$ & $\frac{\widehat{d}}{\stackrel{0}{0}}$ & $\frac{2}{2}$ & $\frac{\mathrm{E}}{\mathrm{E}}$ \\
\hline $\begin{array}{l}\text { I have a "guilty conscience" towards the } \\
\text { patient }\end{array}$ & 165 & 21.2 & 50.3 & 24.2 & 4.2 & 0.0 & 2.12 \\
\hline $\begin{array}{l}\text { I experience a disturbance in the relation- } \\
\text { ship to the patient }\end{array}$ & 165 & 10.9 & 49.1 & 31.5 & 8.5 & 0.0 & 2.38 \\
\hline I avoid contact with this patient & 165 & 47.9 & 41.8 & 9.1 & 0.6 & 0.0 & 1.64 \\
\hline I feel sorry for the patient & 165 & 9.7 & 31.5 & 40.6 & 17.0 & 1.2 & 2.68 \\
\hline I feel insecure in working with the patient & 165 & 22.4 & 48.5 & 24.2 & 4.2 & 0.6 & 2.12 \\
\hline $\begin{array}{l}\text { I feel that I am having to deal with socie- } \\
\text { ties' problems }\end{array}$ & 165 & 21.2 & 24.2 & 38.2 & 16.4 & 0.0 & 2.50 \\
\hline $\begin{array}{l}\text { I have feelings of anger towards the clinic } \\
\text { I am working in }\end{array}$ & 165 & 40.6 & 40.6 & 18.2 & 0.6 & 0.0 & 1.79 \\
\hline I feel insecure at work & 165 & 41.8 & 49.7 & 7.9 & 0.6 & 0.0 & 1.67 \\
\hline I have feelings of being a failure & 165 & 45.5 & 43.6 & 10.3 & 0.6 & 0.0 & 1.67 \\
\hline I feel ashamed of my work & 165 & 70.3 & 26.1 & 3.6 & 0.0 & 0.0 & 1.33 \\
\hline
\end{tabular}

Factor one is interpreted as "impairment of relationship between patient and carer", factor two as "adverse moral emotions" and factor three as "adverse feelings to external sources". Cronbach's alphas of the factors proved satisfactory at $0.78,0.68$ and 0.60 for factors one to three respectively. Descriptive statistics of the three factors together with the $95 \%$ confidence intervals are presented in Table 3 .

Table 3: Descriptive statistics on the factor solution of the IMPACS

\begin{tabular}{lccccc}
\hline & $\mathbf{N}$ & Range & Mean & SD & $\mathbf{9 5 \%}$ Cl \\
\hline $\begin{array}{l}\text { Impairment of relationship between } \\
\text { patient and carer }\end{array}$ & 165 & $4-16$ & 7.50 & 2.197 & 7.16 to 7.84 \\
Adverse moral emotions & 165 & $4-14$ & 7.63 & 2.201 & 7.31 to 7.95 \\
Adverse feelings to external sources & 165 & $2-8$ & 4.29 & 1.501 & 4.06 to 4.52 \\
\hline
\end{tabular}

Canonical correlation analysis between the dimensions of the Maslach Burnout Inventory ("emotional exhaustion" $=-0.13$, "depersonalisation" $=-0.74$, "personal accomplishment" $=0.54$ ) and the factors of the IMPACS ("impairment of relationship" $=-0.93$, "adverse moral emotions" $=$ 0.08 , "adverse feelings to external sources" $=-0.30$ ) produced a canonical correlation coefficient of 0.457 (Table 4). The items "impairment of relationship between patient and carer" and "adverse moral emotions" correlated modestly with the "Confidence in Dealing with Aggression" scale (Thackrey $1987)$ with nonparametric coefficients of $-0.23(\mathrm{p}=0.001)$ and $-0.21(\mathrm{p}=$ 
0.012 ) respectively. The third factor ("adverse feelings to external sources") demonstrated no significant correlation with this measure of confidence.

Table 4: Canonical correlations between the Maslach Burnout Inventory and IMPACS

Standardised

canonical coefficients

Maslach Burnout Inventory

\begin{tabular}{lc}
\hline Emotional exhaustion & -0.13 \\
Depersonalisation & -0.74 \\
Personal accomplishment & 0.54 \\
IMPACS & \\
\hline Impairment of relationship between patient and carer & -0.93 \\
Adverse moral emotions & 0.08 \\
Adverse feelings to external sources & -0.30 \\
\hline Variance & $\mathbf{2 1} \%$ \\
Canonical correlation & $\mathbf{0 . 4 6}$ \\
\hline
\end{tabular}

\section{Discussion}

The aim of this study was to derive a short practical instrument with the capacity to measure carers' adverse feelings after dealing with situations involving aggressive patients. Such an instrument is necessary to monitor changes in carers' sentiments after being subjected to interventions aimed at enhancing the management of situations involving aggressive patients. Ten of the 13 original items derived mainly from published literature on such feelings were retained. Possibly the deleted items are too general or too sweeping. The content of the eliminated items - having doubts regarding the work domain and personal competency - may overemphasise adverse sentiments accruing form the management of violence.

Factor analysis rendered an interpretable solution with three dimensions of experience. The Eigen values of the factors and the amount of variance accounted for render the factor solution stable. The internal consistency of the factors "impairment of relationship between patient and carer" and "adverse moral emotions" are respectable and minimally acceptable (Dukes 1998) respectively. The low Cronbach's alpha of the third factor - "adverse feelings to external sources" - can be accounted for by the small number of items included.

External validity was determined by comparing the factors of the IMPACS with a concurrently administered scale in the questionnaire. The two dimensions of the MBI - "emotional exhaustion" and "depersonalisation" measure adverse experiences relating to working with clients with difficulties. A low score of the third dimension - "personal accomplishment" - is interpreted as expression of burnout. The set of canonical correlations be- 
tween the MBI and the IMPACS renders a moderate indication of external validity. Furthermore, the nonparametric inverse correlations between the confidence scale and the factors "impairment of relationship between patient and carer" and "adverse moral emotions" corroborate validity.

Various limitations apply to this study. Given the low scores on the items of the IMPACS ranging from $1.34-2.68$ one must consider the possibility of response bias with nurses experiencing higher levels of adverse effects being underrepresented. However, because the IMPACS is still under development there is no reference data for comparison. The low scores corroborate similar findings pointing to lower psychological stress levels of psychiatric nurses than nurses in other domains. Kilfedder et al. reported that emotional exhaustion and depersonalisation rates in psychiatric nursing are significantly lower than normative data (Kilfedder, Power et al. 2001). The burnout study and the results found here may point to the mental robustness of the psychiatric carers involved. The return rate of $64 \%$ is not entirely satisfactory. Nevertheless, the hospitals and wards involved in the study represent a good cross-section of nurses working in acute psychiatry.

Despite the plausible factor solution the item "I experience a disturbance in the relationship to the patient" proved somewhat ambiguous with loadings of 0.527 and 0.391 on factors one and two respectively. Although satisfactory, a clearer allocation to one factor would have been welcomed. However, the factor structure is statistically stable and theoretically plausible.

The homogeneity of the sample consisting solely of nurses working on psychiatric acute admission wards prevents the generalisation of the results to nurses and other carers in other setting. Because the IMPACS could be a useful instrument in other caring domains further testing of the instrument is necessary and desirable.

It is obvious that further investigation on the IMPACS is required. One of the next projects is to ascertain its test and retest stability. Furthermore, the administration of the instrument on known groups - i.e. groups with and without an intervention to influence adverse feelings - is necessary to ascertain the capacity of the instrument to monitor change. Another important research question to be addressed in the future is the response by carers in other domains (e.g. general, accident and emergency nursing, or in residential settings). However, in spite of these caveats the results of this primary investigation merit the use and the further development of the IMPACS. 


\section{References}

Abderhalden C, Needham I, Friedli TK, Poelmans J, Dassen T (2002) Perception of aggression among psychiatric nurses in Switzerland. Acta Psychiatrica Scandinavica 106 Supplementum (412):110-117

Adams J, Whittington R (1995) Verbal aggression to psychiatric staff: Traumatic stressor or part of the job? Perspectives in Psychiatric Care 2(2):171-74

Arnetz JE, Arnetz BB (2001) Violence towards health care staff and possible effects on the quality of patient care. Social Science and Medicine 52(3):417-27.

Bin Abdullah AM, Khim LYL, Wah LC, Bee OG, Pushpam S (2000) A study of violence towards nursing staff in the emergency department. Singapore Nursing Journal 27(3):30-37

Chambers N (1998) 'We have to put up with it--don't we?' The experience of being the registered nurse on duty, managing a violent incident involving an elderly patient: a phenomenological study. Journal of Advanced Nursing 27(2):429-36

Collins J (1994) Nurses' attitudes towards aggressive behaviour, following attendance at "The prevention and management of aggressive behaviour programme". Journal of Advanced Nursing 20:117-131

Cutcliffe JR (1999) Qualified nurses' lived experience of violence perpetrated by individuals suffering from enduring mental health problems: a hermeneutic study. International Journal of Nursing Studies 36(2):105-116

Dukes K (1998) Encyclopedia of biostatistics. In: Armitage P, Colton T (Eds). Chichester, John Wiley and Sons.

Erickson L, Williams-Evans SA (2000) Attitudes of emergency nurses regarding patient assaults. Journal of Emergency Nursing 26(3):210-5.

Flannery R, Hanson M, Penk W (1995) Patients' threats. Expanded definition of assault. General Hospital Psychiatry 17(6):451-3

Fry AJ, O'Riordan D, Turner M, Mills KL (2002) Survey of aggressive incidents experienced by community mental health staff. International Journal of Mental Health Nursing 11(2):11220

Gates DM, Fitzwater E, Meyer U (1999) Violence against caregivers in nursing homes: Expected, tolerated, and accepted. Journal of Gerontological Nursing(4):12-22

Hauck M (1993) Die Wut bleibt - Gewalt von Patienten gegenüber Pflegenden (The anger remains - patient violence towards nurses). Unpublished Thesis, Kaderschule für die Krankenpflege, Aarau

Kilfedder CJ, Power KG, Wells TJ (2001) Burnout in psychiatric nursing. Journal of Advanced Nursing 34(3):383-96.

Lanza M, Kayne H, Hicks C, Milner J (1991) Nursing staff characteristics related to patient assault. Issues in Mental Health Nursing 12(3):253-265

Lanza ML (1983) The reactions of nursing staff to physical assault by a patient. Hospital Community Psychiatry 34(1):44-7.

Levin PF, Hewitt JB, Misner ST (1998) Insights of nurses about assault in hospital-based emergency departments. Image Journal of Nursing Scholarship 30(3):249-54

Murray G, Snyder JC (1991) When staff are assaulted. A nursing consultation support service. Journal of Psychosocial Nursing and Mental Health Services 29(7):24-29

Needham I, Abderhalden C, Halfens R, Fischer J, Dassen T (In press) Non somatic effects of patient aggression on nurses: A systematic literature review.

O'Connell B, Young J, Brooks J, Hutchings J, Lofthouse J (2000) Nurses' perceptions of the nature and frequency of aggression in general ward settings and high dependency areas. Journal of Clinical Nursing 9(4):602-10. 
Poster EC (1996) A multinational study of psychiatric nursing staffs' beliefs and concerns about work safety and patient assault. Archives of Psychiatric Nursing 10(6):365-73

Richter D (1999) Patientenübergriffe auf Mitarbeiter psychiatrischer Kliniken: Häufigkeit, Folgen, Prãventionsmöglichkeiten. Freiburg im Breisgau, Lambertus

Richter D, Berger K (2000) Physische und psychische Folgen bei Mitarbeitern nach einem Patientenübergriff: Eine prospektive Untersuchung in sechs psychiatrischen Kliniken. Arbeitsmedizin, Sozialmedizin, Umweltmedizin 35(8):357-362

Ryan JA, Poster EC (1989) The assaulted nurse: short-term and long-term responses. Archives of Psychiatric Nursing 3(6):323-31

Thackrey M (1987) Clinicial confidence in coping with patient aggression: Assessment and enhancement. Professional Psychology: Research and Practice 18(1):57-60

Whittington R, Wykes T (1992) Staff strain and social support in a psychiatric hospital following assault by a patient. Journal of Advanced Nursing 17(4):480-486 


\section{CHAPTER 5}

\section{THE PERCEPTION OF AGGRESSION BY NURSES: PSYCHOMETRIC SCALE TESTING AND DERIVATION OF A SHORT INSTRUMENT}

Needham 1., Abderhalden C., Halfens R., Dassen T., Haug H. \& Fischer J. (2004) The perception of aggression by nurses: Psychometric scale testing and derivation of a short instrument. Journal of Psychiatric and Mental Health Nursing 11, 36-42. 


\begin{abstract}
Patient aggression is a serious problem in psychiatric nursing. Nurses' attitudes towards aggression have been identified as mediating the choice of nursing interventions. To date investigations are lacking which elucidate the stability of one of the few scales for measuring the attitude of aggression. This study aimed to investigate the test-retest stability of the Perception of Aggression Scale (POAS) and to derive a shortened version. In order to test the reliability of the POAS items, three groups of psychiatric nurses were requested to fill in the POAS twice ( 30 student nurses after 4 days, 32 qualified nurses after 14 days and 36 qualified nurses after 70 days). We derived the shortened version from an independent dataset obtained from 729 psychiatry nurses using principal component analysis, aiming to maximise parsimony and Cronbach's alpha. Amongst competing short versions we selected those with the highest reliability at 70 or 14 day retest. A scale using 12 of the original 32 items was derived yielding alphas of $r=0.69$ and $r=$ 0.67 for the two POAS factors with retest reliabilities of $r=0.76$ and $r=0.77$. The shortened scale offers a practical and viable alternative to the longer version.
\end{abstract}

\title{
Acknowledgements
}

This study was supported by grant BK $361 / 01$ of the Swiss Academy of Medical Science and by a financial contribution of the Swiss Association of Nursing Experts. 


\section{Introduction}

Aggression in care institutions has been a prominent problem for many years and is according to some authors (Hansen 1996) on the increase. Nurses in acute psychiatry are amongst the most exposed to aggression and it has been reported that patient aggression is associated with the intention to leave the nursing profession (Arnetz, Arnetz et al. 1998; Ito, Eisen et al. 2001). Thus dealing with aggressive or violent patients and coping with the sequelae thereof is a major challenge for nurses.

Nurses' behaviour towards and their style of interaction with aggressive and/or violent patients may be determined by various personal and contextual factors such as age, gender, education, experience, or characteristics of psychiatric services. Another possible factor influencing nurses' behaviour towards aggressive patients may be their perception of aggression or violence. Morrison found great disagreement between nurses in their perception of the seriousness of various forms of aggression manifested in clinical practice and stressed the need for research on the influence of perception of violence on clinical predictions of dangerousness (Morrison 1993).

Nurses' perception of aggression or violence may also influence clinical behaviour such as the reporting of aggressive incidents (Poster \& Ryan 1989; Jansen, Dassen et al. 1997) or the choice of interventions (Whittington \& Higgins 2002). Given that coercive practices are a frequent response to patient violence, the function of the care worker's attitude may be an influencing factor on clinical decision making. This point has been raised by Fisher who stated that "local non-clinical factors, such as cultural biases, staff role perceptions, and the attitude of the hospital administration" have a greater influence on rates of restraint and seclusion than pure clinical considerations (Fisher 1994). Given such influences of the role of nurses' attitude on clinical practice, the necessity for research work in this area becomes clear. A prerequisite for such research is a valid and reliable instrument to measure perceptions and attitudes towards aggression.

In 1989 Poster and Ryan presented their "attitudes toward patient physical assault questionnaire", an instrument consisting of 31 items measuring attitudes on aggression relating to patients' responsibility, staff competence and performance, ethical, legal and safety issues (Poster \& Ryan 1989). Face validity and test-retest reliability were established using a nonrandomised sample of 44 nurses yielding a retest reliability of $r=0.69$ at six weeks (Poster \& Ryan 1989). Collins (1994) also derived an attitudinal instrument - the "attitudes toward aggressive behaviour questionnaire" - which incorporates three items of Poster and Ryan. The 12 statements refer to the predictability of aggression, the causes of or reasons for aggression, patients' accountably for aggression, and nurses' reactive patterns to patient aggression (Collins 1994). As well as face validity a high test-retest stability $(r=0.972)$ has been established (Collins 1994). However, a limitation of these instruments is their lacking distinction between the perception, the prediction and the practical management of aggression. 
A conceptually different instrument used to assess psychiatric nurses' perception of aggression is the "perception of aggression scale" (POAS) (Jansen, Dassen et al. 1997). The POAS focuses solely on the views of care workers on patient aggression whereas the above mentioned instruments include concepts like patient responsibility or accountability for violence or the reactions of the nurses. The POAS consists of 32 Likert-scaled statements on aggression which are posed in statements expressing various views on the issue. From a survey involving 274 Dutch nurses, three dimensions of aggression emerged: Aggression as a normal reaction or acceptable reaction to feelings of anger, aggression as a violent reaction being experienced as threatening and aggression as a functional reaction (Jansen, Dassen et al. 1997). The POAS was employed by Muro et al. to measure the attitude of 90 nursing students in Spain. The study demonstrated high agreement with the Dutch results regarding aggression as a violent and as a normal reaction, but low agreement regarding aggression as a functional reaction (Muro, Tomas et al. 2002). The authors found no significant relationships between the student nurses' attitudes to aggression and their respective scores on the "General Health Questionnaire" and the "International Personality Disorder Examination" but a significantly higher proportion of males perceiving aggression as a violent reaction (Muro, Tomas et al. 2002). These findings suggest that the POAS is insensitive to general health matters and personality disorders in the observed sample.

The POAS has recently been employed on representative sample of 729 nurses in psychiatric departments in the German speaking part of Switzerland. Principal component analysis revealed two factors of the perception of aggression (aggression as a functional / comprehensible and as a dysfunctional / undesirable phenomenon) (Abderhalden, Needham et al. 2002). In this study no significant differences of the mean factor scores pertaining to the perception of aggression were found regarding the socio-demographic characteristics of the nurses (work experience, nursing educational grade, employment status) nor regarding their self reported frequency of experienced patient aggression (Abderhalden, Needham et al. 2002). Having established that the perceptions of aggression as measured by the POAS are barely sensitive to the socio-biographic and the experiential characteristics of respondents, the question remains: Which POAS items are reliable and thus lend themselves to the measurement of stable perceptions? Until now no investigation on the test-retest reliability has been undertaken to answer this question. Given the considerable number of items needed to measure the two POAS dimensions the development of a short version of the POAS would also be of great practical value. These two circumstances form the rationale for the formulation of the following research questions:

- Which items of the POAS demonstrate good test-retest stability?

- Which items should be included in a shorter form of the POAS?

- Will a shortened form of the POAS render a similar factor solution as the original instrument? 


\section{Methods}

Subjects and sampling: We undertook a cross-sectional study and an independent longitudinal study to devise a shortened version of the POAS and to elucidate the test-retest reliability of the instrument. The database of the cross-sectional study consisted of 729 nurses employed in psychiatric wards in the German speaking part of Switzerland. This study was part of an endeavour of the European Violence in Psychiatry Research Group (EViPRG) to elucidate the perception of aggression across European psychiatric services. Members of the Swiss Network for Nursing Research distributed 1009 questionnaires to psychiatric nurses working on acute, rehabilitation, geronto-psychiatric, forensic, and psychotherapy wards. The response rate was $72 \%$. This dataset served to develop more parsimonious candidate short versions of the POAS comprising fewer items. This large dataset provided only one measurement point. Due to anonymous responses, we were unable to access these nurses for providing re-test evaluations. Therefore, we conducted re-test analysis in three independent samples of psychiatric nurses, with a 4-day, 14-day and 70-day interval, respectively. In order to avoid the participation of previous respondents in the EViPRG study we choose a sample of psychiatric student nurses for the 4-day retest, and sampled qualified nurses for the two other retest samples from psychiatry wards that had not been included in the EViPRG study. Our previous study (Abderhalden et al. 2002) had revealed that student nurses perceive aggression in a similar fashion to experienced psychiatry nurses.

The three samples needed to elucidate the retest reliability were recruited as convenience samples from two hospitals and a nursing school in the German speaking part of Switzerland. The sample of psychiatric student nurses was recruited in order to test the stability of the instrument in an educational environment. Due to the fact that it remains unknown, whether educational measures can affect the perception of aggression on a short-term basis we decided on a retest interval of four days. The groups re-completing after a 14- and 70-day interval were qualified nurses working on acute, rehabilitation, geronto-psychiatric, forensic, and psychotherapy wards within psychiatric hospitals. The rationale for the employment of these intervals was to derive an instrument stable enough to measure attitudes at differing intervals. Forty POAS questionnaires were distributed to each group and eventually a total of 98 questionnaires were completed anonymously (overall response rate $82 \%$ ). All nurses in both samples gave informed consent. The characteristics of the study samples are presented in Table 1.

The questionnaire consisted of items on socio-biographic data of the nurses and the German version of the POAS, which had been previously translated form the original Dutch. The translation was performed by an international team of researchers comprising of several bilingual members. Afterwards the German translation was compared with the original Dutch version by a researcher from the Netherlands. In a final step every definition was checked by some researchers from the team by comparing the English, Dutch and German versions with corrections being made where necessary. 
Table 1: Characteristics of the groups constituting the sample

\begin{tabular}{llllllllllll} 
& & \multicolumn{4}{c}{ Sex } & \multicolumn{3}{c}{ Age in years } & \multicolumn{3}{c}{ Nursing experience (yrs) } \\
\hline Sample & $n$ & Domain & F & M & Mean & Range & SD & Mean & Range & SD \\
\hline $\begin{array}{l}\text { Cross } \\
\text { section }\end{array}$ & 729 & $\begin{array}{l}\text { Psychiatric } \\
\text { nursing }\end{array}$ & 442 & 281 & 37.0 & $20-64$ & 10.5 & 9.7 & $1-42^{*}$ & 9.2 \\
4 days & 30 & $\begin{array}{l}\text { Student } \\
\text { nurses }\end{array}$ & 24 & 6 & 28.2 & 21.49 & 8.9 & 1.0 & $1-1$ & 0 \\
14 days & 32 & $\begin{array}{l}\text { Psychiatric } \\
\text { nursing }\end{array}$ & 18 & 14 & 39.3 & 21.59 & 8.8 & 10.5 & $1-36^{*}$ & 8.9 \\
70 days & 36 & $\begin{array}{l}\text { Psychiatric } \\
\text { nursing }\end{array}$ & 22 & 14 & 37.7 & 21.59 & 8.7 & 11.0 & $1-36^{*}$ & 8.8 \\
\hline
\end{tabular}

- Excluding years of experience during nursing training

Data analysis: Data analysis comprised of the following steps: a) assessing the test retest reliability across all 32 POAS items, and the aggregated factors over the 4,14 and 70 day interval; b) elucidating the correlation of the two factors derived from principal components analysis and c) constructing a shortened POAS scale employing test-retest reliability, confirmatory factor analysis, and reliability analysis.

The retest reliability was assessed by determining the Spearman-rank correlation coefficients in the three groups of the longitudinal study. The pooled mean of the Spearman-rank correlations over the three groups was obtained by taking the mean of the Fisher's Z-transformed coefficients and reconverting the results back into a correlation value (Law 1995). To derive the short version of the POAS, we followed the following iterative procedure: First, we excluded items with poor retest reliability from the list of items. Next we performed factor analysis on the reduced set of items on the dataset containing 729 questionnaires. After ascertaining that the two original factors were retained, we further reduced the number of items contributing to each factor by aiming to maintain the highest possible internal consistency (Cronbach's alpha). This procedure was repeated three times until we had a 16item, and two 12-item solutions. These three solutions yielded similar Cronbach's alpha. They were then assessed as to the factors' aggregated retest reliability and as to the amount of variance in the full item model captured by the reduced item set. From this last step, the solution offered in the results section provided the best balance or reliability, internal consistency and proportion of explained variance of the original scale. All analyses were carried out using SPSS software (Version 10.1, SPSS Inc. Chicago, Illinois, USA) and SAS (Version 8.2, SAS Institute, Cary, North Carolina, USA). 


\section{Results}

The POAS data from the 729 psychiatric nurses constituting the cross-sectional sample (mean age 31.3 years, mean professional experience 9.2 years) were used to derive a factor solution using principal component analysis. The POAS data from the independent sample of 98 nurses partaking in the longitudinal study (mean age 35.3 years, mean professional experience 7.8 years) served to assess the retest reliability of the instrument and the suggested short form. The response rates in the two samples were $72 \%$ and $82 \%$ respectively.

The individual POAS items differed substantially as to their retest reliability ranging from $\mathrm{r}=0.15$ to $\mathrm{r}=0.78$ for individual retest comparisons, and from 0.26 to 0.70 when pooled over all three samples. The dispersion of the individual POAS items aggregated across all three samples also demonstrated considerable variability ranging from a minimum to a maximum standard deviation of 0.03 and 0.24 respectively. The items with the poorest reliability did not show any clear conceptual pattern. Examples of the items with correlations of 0.36 or lower are: Aggression as an undesirable way to fulfil own interests, aggression as an impulse leading to dominate others, aggression as a mean to pacify oneself or aggression as self protection. Particularly stable items were those relating to the perception of aggression as a potentially positive phenomenon. Details on all the POAS items are provided in Table 4 in the appendix.

Various models using differing combinations of the original POAS items were considered. The solution was determined by an iterative procedure taking three parameters into consideration: These parameters were the testretest reliability of the data deriving from the longitudinal study, the confirmatory factor analysis conducted on the large cross-sectional sample, and the amount of variance in the full dataset explained by the items from the short version. From various competing models we offer the following 12 -item solution. Table 2 shows the properties of the chosen items in the individual samples and across the three retest points. 
Table 2: Items constituting the shortened version of the POAS demonstrating Spearman's coefficients and $95 \%$ CI of mean

\begin{tabular}{|c|c|c|c|c|c|c|c|}
\hline POAS item & 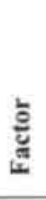 & 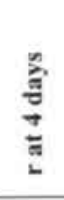 & 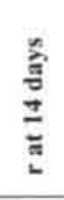 & 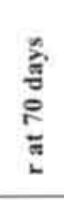 & 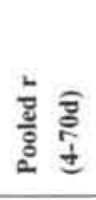 & 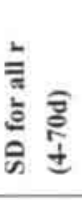 & $\frac{\frac{5}{g}}{\frac{d}{g}}$ \\
\hline 02 Violence towards self or others & 1 & 0.59 & 0.58 & 0.46 & 0.55 & 0.07 & $0.395-0.675$ \\
\hline 05 Conscious battery & 1 & 0.52 & 0.76 & 0.56 & 0.63 & 0.13 & $0.493-0.736$ \\
\hline 14 Mental or physical harm to others & 1 & 0.47 & 0.27 & 0.58 & 0.45 & 0.16 & $0.276-0.595$ \\
\hline 15 Physical violence & 1 & 0.50 & 0.50 & 0.33 & 0.45 & 0.09 & $0.276-0.595$ \\
\hline 24 Mean to dominate others & 1 & 0.53 & 0.50 & 0.41 & 0.48 & 0.06 & $0.311-0.619$ \\
\hline $\begin{array}{l}28 \text { Expression rendering others } \\
\text { insecure or threatened }\end{array}$ & 1 & 0.32 & 0.48 & 0.56 & 0.46 & 0.13 & $0.288-0.603$ \\
\hline 04 Valve function & 2 & 0.61 & 0.36 & 0.33 & 0.44 & 0.16 & $0.265-0.587$ \\
\hline $\begin{array}{l}07 \text { Opens new pathways in nursing } \\
\text { care }\end{array}$ & 2 & 0.59 & 0.62 & 0.56 & 0.59 & 0.03 & $0.443-0.706$ \\
\hline 17 Help for new nursing perspective & 2 & 0.59 & 0.65 & 0.65 & 0.63 & 0.04 & $0.493-0.736$ \\
\hline 19 Emotion like laughing and crying & 2 & 0.61 & 0.75 & 0.54 & 0.64 & 0.11 & $0.506-0.744$ \\
\hline $\begin{array}{l}26 \text { Expression of protection of } \\
\text { private sphere }\end{array}$ & 2 & 0.52 & 0.56 & 0.62 & 0.57 & 0.05 & $0.419-0.690$ \\
\hline $\begin{array}{l}27 \text { Start of positive patient-nurse } \\
\text { relationship }\end{array}$ & 2 & 0.72 & 0.71 & 0.53 & 0.66 & 0.11 & $0.531-0.759$ \\
\hline
\end{tabular}

The shortened form of the POAS rendered a similar factor solution as the original instrument: Using the data from the large cross-sectional study on 729 nurses and employing principal component analysis with varimax rotation, we obtained the confirmatory factor analysis presented in Table 3 . The Kaiser-Meyer-Olkin measure of adequacy was 0.753 with a highly significant Bartlett's test of sphericity $\left(\mathrm{p}<0.0001, \chi^{2}=1240.1, \mathrm{df}=66\right)$. Cumulatively the two factors account for $39.4 \%$ of the total variance compared with $35.0 \%$ of explained variance of the original factor solution using the full POAS (Abderhalden et al. 2002). The factors of the shortened POAS explain $77 \%$ and $81 \%$ of the variance and Spearman's correlation coefficients between the factors is $r=-0.19$, compared to $r=-0.26$ of the original demonstrating improved orthogonality of the short scale. Figure 1 presents the component plot for the shortened version.

Reliability analysis rendered satisfactory internal consistency with Cronbach's $\alpha$ of 0.69 for factor 1 and 0.67 for factor 2. The average retest reliability across 4,14 and 70 days of the shortened POAS scale was $r=0.76$ for factor 1 and $\mathrm{r}=0.77$ for factor 2 . 
Table 3: Confirmatory factor analysis demonstrating factors and factor loadings of the items constituting the shortened POAS

\begin{tabular}{llrr}
\hline Factor & Item & Component 1 & Component 2 \\
\hline 1 & 14 Mental or physical harm to others & 0.738 & -0.108 \\
1 & 15 Physical violence & 0.665 & -0.166 \\
1 & 02 Violence towards self or others & 0.623 & -0.120 \\
1 & 28 Expression rendering others insecure or & 0.572 & 0.031 \\
1 & threatened & 0.564 & -0.106 \\
1 & 05 Conscious battery & 0.542 & 0.044 \\
\hline 2 & 24 Mean to dominate others & 0.025 & 0.692 \\
2 & 17 Heip for new nursing perspective & -0.078 & 0.682 \\
2 & 07 Opens new pathways in nursing care & -0.133 & 0.643 \\
2 & 27 Start of positive patient-nurse relationship & -0.086 & 0.585 \\
2 & 26 Expression of protection of private sphere & -0.188 & 0.559 \\
2 & 19 Emotion like laughing and crying & 0.047 & 0.514 \\
\hline
\end{tabular}

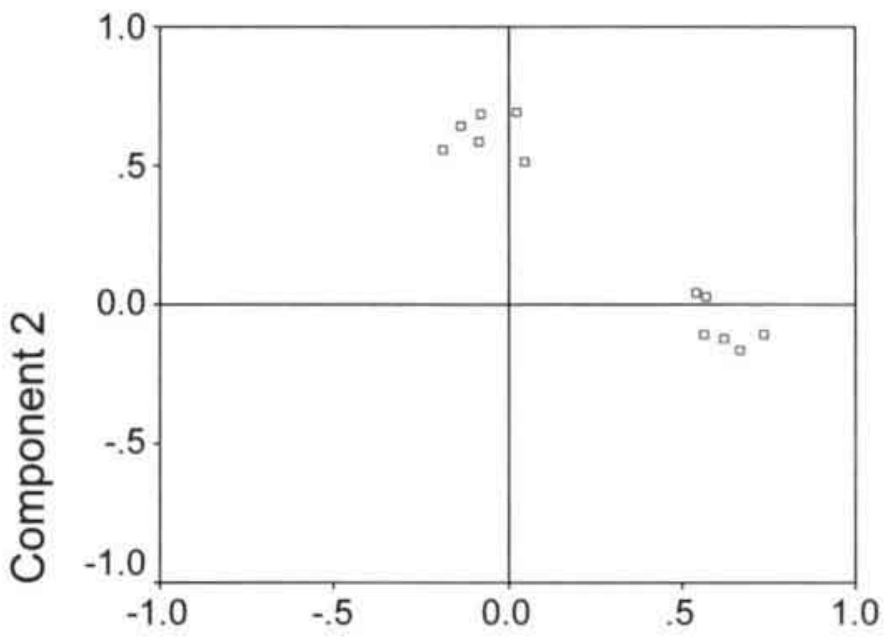

Component 1

Figure 1: Loading plot in rotated space of the shortened POAS 


\section{Discussion}

We undertook a cross-sectional study and a longitudinal study of Swiss psychiatric nurses to assess the retest reliability of the POAS and to obtain a shortened version.

With regard to the test-retest reliability as measured by the Spearman correlation coefficients considerable variability across items of the original scale was discovered. One half of the correlations was under 0.5 and the six weakest under 0.4 . The volatile nature of some POAS items showing erratic patterns over varying time intervals is difficult to interpret: Item 1 for example shows correlation coefficients of $0.46,0.60$, and 0.17 at the time intervals of 4,14 , and 70 days respectively. Other findings appear more plausible. Item 18 for example shows moderate correlation coefficients at the two shorter periods with a sharp decline at 70 days suggesting an association between time and test-retest reliability.

It remains unknown, whether these poor psychometric properties of numerous POAS items are idiosyncratic to our sample of Swiss German psychiatric nurses or whether they reflect a general feature of the scale. Possibly, the participants had changed their attitudes in the interval between test and retest. Alternatively the POAS may comprise of items referring to concepts of differing stability such as traits and states. This question needs to be addressed in longitudinal intervention studies aiming to alter the perception of aggression. Such a study is currently under way in Switzerland, but final results are not expected until 2004.

After establishing the test-retest values it was interesting to note that in conjunction with the procedures of factor analysis and reliability analysis the items with the best correlations were not necessarily the best for inclusion in the 12-item shortened version. The items of the shortened version lead to the same two factor solution as in the original (Abderhalden et al. 2002) and render at least equivalent results regarding the amount of variance explained ( $39 \%$ in the shortened scale versus $35 \%$ in the original study). The orthogonality of the factors as displayed by the plot in rotated space demonstrates good discriminatory properties of the 12 -item solution. A further improvement compared to the original POAS is the slightly lower correlation between the two factors.

However several limitations pertain to our study. One major drawback of this study appertains to the need to recruit independent samples from the original large dataset for elucidating the retest reliability. Ideally, subsets of the large sample should have been recruited to ascertain the 4-day 14-day and 70-day retest reliability. Moreover, we suggest that our results should be generalised with caution beyond the perceptions of Swiss psychiatric nurses. Before measuring the perception of aggression of nurses from other countries and cultures a replication of this study should be undertaken. Such suspected trans-cultural differences may accrue because of the complex wording employed in some of the POAS items. The suspected problem of a lack of discrimination between state and trait items of the POAS items is a threat to 
validity of our findings. This matter is of great importance because the measurement of test and retest reliability assumes a certain amount of stability in attitudes.

In spite of these caveats we conclude that the shortened version of the POAS (POAS-S) renders almost the same amount of information on the perception of aggression using less than half of the original items and considerably less effort to complete the questionnaire. This improves the practicability of its use. Further studies should replicate our findings in other cultural settings. 


\begin{tabular}{|c|c|c|c|c|c|c|}
\hline POAS item & 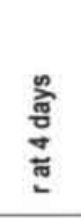 & 突 & 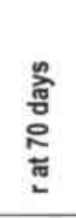 & 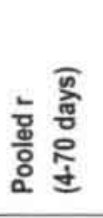 & 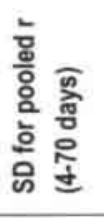 & $\begin{array}{l}\frac{2}{\mathrm{D}} \\
\frac{\mathrm{E}}{\mathrm{O}} \\
\frac{0}{0}\end{array}$ \\
\hline 01 Injures self or others & 0.46 & 0.60 & 0.17 & 0.42 & 0.22 & $0.242-0.571$ \\
\hline 02 Violence towards self or others & 0.59 & 0.58 & 0.46 & 0.55 & 0.07 & $0.395-0.675$ \\
\hline 03 Destructive and undesirable & 0.30 & 0.63 & 0.27 & 0.41 & 0.20 & $0.230-0.563$ \\
\hline 04 Valve function & 0.61 & 0.36 & 0.33 & 0.44 & 0.16 & $0.265-0.587$ \\
\hline 05 Conscious battery & 0.52 & 0.76 & 0.56 & 0.63 & 0.13 & $0.493-0.736$ \\
\hline 06 Threat against persons or things & 0.42 & 0.35 & 0.39 & 0.39 & 0.03 & $0.208-0.546$ \\
\hline 07 Opens new pathways in nursing care & 0.59 & 0.62 & 0.56 & 0.59 & 0.03 & $0.443-0.706$ \\
\hline 08 Human energy to achieve goals & 0.27 & 0.59 & 0.60 & 0.50 & 0.19 & $0.335-0.635$ \\
\hline 09 Extension of personal limits/boundaries & 0.40 & 0.30 & 0.28 & 0.33 & 0.06 & $0.141 \cdot 0.496$ \\
\hline 10 Undesirable way to fulfil own interests & 0.30 & 0.27 & 0.21 & 0.26 & 0.05 & $0.065-0.436$ \\
\hline 11 Conscious behaviour except for psychotics & 0.68 & 0.60 & 0.23 & 0.53 & 0.24 & $0.371-0.659$ \\
\hline 12 Impulse leading to domination of others & 0.31 & 0.54 & 0.20 & 0.36 & 0.18 & $0.174-0.521$ \\
\hline 13 Unnecessary and not acceptable & 0.47 & 0.61 & 0.50 & 0.53 & 0.07 & $0.371 \cdot 0.659$ \\
\hline 14 Mental or physical harm to others & 0.47 & 0.27 & 0.58 & 0.45 & 0.16 & $0.276-0.595$ \\
\hline 15 Physical violence & 0.50 & 0.50 & 0.33 & 0.45 & 0.09 & $0.276-0.595$ \\
\hline 16 Detestable behaviour & 0.74 & 0.61 & 0.60 & 0.65 & 0.08 & $0.518-0.751$ \\
\hline 17 Help for new nursing perspective & 0.59 & 0.65 & 0.65 & 0.63 & 0.04 & $0.493-0.736$ \\
\hline 18 Conscious injury to others & 0.62 & 0.56 & 0.28 & 0.50 & 0.18 & $0.335-0.635$ \\
\hline 19 Emotion like laughing and crying & 0.61 & 0.75 & 0.54 & 0.64 & 0.11 & $0.506-0.744$ \\
\hline 20 Uncooperative attitude & 0.31 & 0.46 & 0.14 & 0.31 & 0.16 & $0.119 \cdot 0.479$ \\
\hline 21 Poisons atmosphere and treatment & 0.54 & 0.64 & 0.61 & 0.60 & 0.06 & $0.456-0.713$ \\
\hline 22 Self protection & 0.43 & 0.54 & 0.39 & 0.45 & 0.08 & $0.276 \cdot 0.595$ \\
\hline 23 Negative and not acceptable & 0.54 & 0.65 & 0.58 & 0.59 & 0.06 & $0.443-0.706$ \\
\hline 24 Mean to dominate others & 0.53 & 0.50 & 0.41 & 0.48 & 0.06 & $0.311-0.619$ \\
\hline 25 Non destructive communication & 0.56 & 0.71 & 0.78 & 0.70 & 0.11 & $0.582-0.789$ \\
\hline 26 Expression of protection of private sphere & 0.52 & 0.56 & 0.62 & 0.57 & 0.05 & $0.419 \cdot 0.690$ \\
\hline 27 Start of positive patient-nurse relationship & 0.72 & 0.71 & 0.53 & 0.66 & 0.11 & $0.531-0.759$ \\
\hline $\begin{array}{l}28 \text { Expression rendering others insecure or } \\
\text { threatened }\end{array}$ & 0.32 & 0.48 & 0.56 & 0.46 & 0.13 & $0.288-0.603$ \\
\hline 29 Result of poweriessness & 0.54 & 0.63 & 0.54 & 0.57 & 0.05 & $0.419-0.690$ \\
\hline 30 Mean to pacify ones self & 0.34 & 0.24 & 0.43 & 0.34 & 0.09 & $0.152-0.504$ \\
\hline 31 Healthy reaction to feelings of anger & 0.78 & 0.68 & 0.41 & 0.65 & 0.19 & $0.518-0.751$ \\
\hline 32 Not to be tolerated & 0.65 & 0.71 & 0.63 & 0.66 & 0.04 & $0.531-0.759$ \\
\hline
\end{tabular}




\section{References}

Abderhalden C, Needham I, Friedli TK, Poelmans J, Dassen T (2002) Perception of aggression among psychiatric nurses in Switzerland. Acta Psychiatrica Scandinavica 106 Supplementum (412):110-117

Ametz J, Arnetz B, Soderman E (1998) Violence toward health care workers. Prevalence and incidence at a large, regional hospital in Sweden. American Association of Occupational Health Nurses Journal 46(3):107-114.

Collins J (1994) Nurses' attitudes towards aggressive behaviour, following attendance at "The prevention and management of aggressive behaviour programme". Journal of Advanced Nursing 20:117-131

Fisher WA (1994) Restraint and seclusion: A review of the literature. American Joumal of Psychiatry 151:1584-1591

Hansen B (1996) Workplace violence in the hospital psychiatric setting. An occupational health perspective. American Association of Occupational Health Nurses Journal 4(12):575-580

Ito H, Eisen SV, Sederer LI, Yamada O, Tachimori H (2001) Factors affecting psychiatric nurses' intention to leave their current job. Psychiatric Services 52(2):232-234

Jansen G, Dassen T, Moorer P (1997) The perception of aggression. Scandinavian Journal of Caring Sciences 11(1):51-55

Law KS (1995) The use of Fisher's Z in Schmid t-Hunter-type meta-analyses. Journal of Educational and Behavioral Statistics 20:287-306

Morrison EF (1993) A comparison of perceptions of aggression and violence by psychiatric nurses. Int J Nurs Stud 30(3):261-268

Muro C, Tomas C, Moreno L, Rubio V (2002) Perception of aggression, personality disorders and psychiatric morbidity in nursing students. Acta Psychiatrica Scandinavica 106 Supplementum (412): 118-120

Poster EC, Ryan JA (1989) Nurses' attitudes toward physical assaults by patients. Archives of Psychiatric Nursing 3(6):315-322

Whittington R, Higgins L (2002) More than zero tolerance? Burnout and tolerance for patient aggression amongst mental health nurses in China and the UK. Acta Psychiatrica Scandinavia 106 Supplementum (412):37-40 


\section{CHAPTER 6}

THE EFFECT OF A TRAINING COURSE IN AGGRESSION MANAGEMENT ON NURSING STUDENTS' CONFIDENCE AND PERCEPTION OF AGGRESSION

Needham I, Abderhalden C. Zeller A, Dassen T. Haug HJ, Fischer JE. MD, Halfens RJG. Accepted for publication in the Jounal of Nursing Education 


\begin{abstract}
Patient aggression is a problem in many nursing domains with nursing students being amongst the most vulnerable. Training courses have been suggested to equip nurses to deal with patient aggression in a better fashion. Such courses can lead to greater confidence and to changes in attitude towards aggression. This quasi-experimental study investigates the effect of a training course on nursing students' confidence, attitude, and perception of aggression. The intervention group demonstrated a higher confidence level but no change in attitude after the course in the management of aggression whilst the controls remained stable on all measures. The short time frame, the training itself, and the instruments used for monitoring attitude and the perception of aggression are seen as possible reasons for these results. We tentatively conclude that in this sample it is possible to enhance nursing students' perceived confidence in dealing with aggressive patients without having to change their fundamental attitudes.
\end{abstract}

Keywords: aggression, attitude, perception of aggression, nursing students, training in aggression management 


\section{Introduction}

Aggressive behaviour of patients towards nursing personnel is a major problem in healthcare. This problem is according to some on the advance and may be a reflection of increasing readiness for aggression in society (Whittington, Shuttleworth et al. 1996; Rippon 2000). Patient aggression can cause injuries such as lacerations, bruising (Rix \& Seymour 1988) or head injuries (Lanza, Kayne et al. 1991; Carmel \& Hunter 1993) or can provoke various psycho-social sequelae such as mental distress, tension, anxiousness, burnout, posttraumatic stress disorder (Hubschmid 1996) or emotional stress (Lanza, Kayne et al. 1991). Aggression towards nurses can also disrupt the functioning of the health care system as exemplified in staff illness and absenteeism (Rix 1987) or in cases of industrial compensation (Bensley, Nelson et al. 1997).

Nurses in various settings are subjected to high rates of aggression. A recent cross sectional survey in Switzerland has demonstrated that $72 \%$ of nurses working in psychiatric settings felt seriously threatened and $70 \%$ have reported being attacked at least once during their nursing career (Abderhalden, Needham et al. 2002). An investigation on 340 workers in care institutions for the elderly by Sprenger demonstrated that $69 \%$ of them are confronted with verbal aggression and $50 \%$ with physical aggression on a regular basis (Sprenger 2001).

All types of nurses are subjected to patient aggression and nursing students experience such incidents at a very early stage in their career. Given that nursing students have the least professional experience and that they are generally younger in age it follows that they are in a very vulnerable position regarding patient violence. Hence, educational measures - such as training courses in aggression management - aiming at ameliorating nursing students' capacity to handle patient aggression will be welcomed by themselves and their patients alike. This study is a first step in this direction and reports on the effect of a training course in aggression management on nursing students' confidence and their perception of aggression.

\section{Literature review}

Some studies demonstrate that young or inexperienced nurses (Whittington \& Wykes 1994; Flannery, Stone et al. 2001) are more frequently subjected to patient aggression and are thus at special risk (Wondrak \& Dolan 1992; Beech 1999). In a Swiss study $47.4 \%(\mathrm{n}=114)$ of nursing students employed in psychiatry reported having been threatened and physically attacked $(36.9 \%)$ once or more (Abderhalden, Needham et al. 2002). In the same study the frequency of threats and attacks on nursing students is below that of nursing aides and trained nurses. However, given the short duration of their nursing career this is an alarming rate evoking suffering and in some cases leading to burnout or to quitting the profession. Therefore nursing students' preparation for handling situations in which aggression occurs is a 
challenge to nurse educators (Whitley, Jacobson et al. 1996; Taylor 2000) and nurse managers alike.

One possible way to equip nurses to deal with patient aggression is to train them in aggression management (Chervinski 1995; Bin Abdullah, Khim et al. 2000). Such courses are implemented frequently and are expected to be effective on a various outcome variables. Some studies have measured the effectiveness of training courses in aggression management on the frequency of aggressive incidents (Hagen \& Sayers 1995; Maxfield, Lewis et al. 1996; Shah \& De 1998), on job satisfaction (Paterson, Turnbull et al. 1992; Goodridge, Johnston et al. 1997) or on the quality of nursing (Goodridge, Johnston et al. 1997; Arnetz \& Arnetz 2001). Other authors have tested the effect of training courses in aggression management on participants' perceived confidence, the reduction of anxiety, and the capacity to defend themselves. In most cases the educational measures led to an intensification of perceived efficacy and competence. Generally nurses felt safer and more comfortable after training. Some training sessions in aggression management are also capable of influencing nurses' attitude: Assistant nurses working in nursing homes viewed aggressive residents in a less paternalistic fashion (Goodridge, Johnston et al. 1997), they deemed aggressive patients more accountable (Collins 1994), or adopted a more positive attitude towards aggressive residents (Feldt \& Ryden 1992).

Given the prevalence and the negative consequences of patient aggression on nurses it is laudable that interventions aiming to equip nurses to deal with the problem are being developed and used. Although research demonstrates that such training courses may have positive effects on nurses, little is known on how nursing students respond to such trainings in general and especially on the effects of a training course currently being used in Switzerland on nursing students' confidence and attitude. This regrettable lack of evidence is the basic motivation for this study, because equipping nurses at a very early stage in their career could be instrumental in avoiding many negative experiences.

In this quasi-experimental study we expected the nursing students in the intervention group to perceive themselves more confident in dealing with aggressive patients and to adopt a more positive attitude and perception of aggression. We thus set out to investigate the influence of a training course currently being evaluated in Switzerland on a) perceived confidence, b) attitudes towards aggression, and c) the perception of aggression on students of nursing. For the purpose of this investigation confidence is defined as "selfattributed ability, preparation, and comfort in safely and effectively" dealing with aggressive patients (Thackrey 1987) and attitude is taken to be the sum of convictions, views, prejudices, and values of a person (Seel 2003). 


\section{Method}

Design: A quasi-experimental pre-post-test design employing a control group (Polit \& Hungler 1999) was conducted to investigate the influence of a training course in the management of aggression on the nursing students' perceived confidence in handling patient aggression, and on their attitudes towards aggression. The measurements of both groups were conducted three times: 1) at baseline (pre-test), 2) the final day of the training course (posttest), and 3) three months after the training course (follow-up). This design allows the measurement of a short and a long term effect.

Sample: After receiving ethical consent form local review boards one hundred and seventeen nursing students (57 in the experimental and 60 in the control group) from two nursing schools in eastern Switzerland participated in the study. The training course was administered on an experimental basis at one school and was integrated into the curriculum with course participation being fully acknowledged part of nursing education. The other school did not offer the training course. All participating students were female except for 6 men in the intervention group as depicted in Table 1. Each student was assigned a code number to guarantee anonymity. All participants in the sample were of Swiss origin excepting eight in the experimental group originating from Belgium, Croatia, Germany (2), Kosovo Albania (2), the Principality of Lichtenstein, and Turkey. The 117 students were distributed across all four years of training with the majority being in the first $(\mathrm{n}=55)$ or last $(\mathrm{n}=32)$ year.

Table 1: Distribution of nursing students according to educational year

\begin{tabular}{lcccccc} 
& \multicolumn{3}{c}{ Age } & \multicolumn{2}{c}{ Gender } \\
\hline Group & $\mathrm{n}$ & range & mean & st-dev & female & male \\
\hline Experimental & 57 & $19-43$ & 22.2 & 4.44 & 51 & 6 \\
Control & 60 & $18-24$ & 21.3 & 1.80 & 60 & 0 \\
\hline Total & 117 & $18-43$ & 21.7 & 3.38 & 111 & 6 \\
\hline
\end{tabular}

Mann-Whitney U test of asymptotic significance between groups: Age $=0.700$, gender $=0.01$

Intervention: The training program in the management of aggression developed by Nico Oud (Oud 1997) consisted of 24 lessons each lasting 50 minutes administered on four consecutive days. Although this course is currently being employed on a broad basis in Switzerland this is the first study to test its effect of nursing trainees. The course aimed to provide knowledge, skills and techniques to the students. The following areas were treated: Types and causes of aggression, the genesis of aggression, reflection on one's own aggressive components, theory on the various stages of aggressive incidents, behaviour during aggressive situations, types of conflict management, communication and interaction, post aggression procedures, workplace safety, prevention of aggression, breakaway techniques. Various educational forms such as role-play, group discussion, self reflection and hands-on skills training were used. The course was administered by a nurse 
instructor qualified in the education of the management of patient aggression. The three classes in the intervention group consisted of between 11 and 17 students. This training course corresponds approximately to a training course being administered in other nursing settings in Switzerland and to a recently identified core curriculum regarding control and restraint (Lee, Wright et al. 2001). However, to date no scientific investigations on the effectivity of the training course have been conducted.

Instruments: The students were administered a questionnaire comprised of demographic items (age, gender, stage of professional education) and questions on their experiences of aggression (frequency of experiences of verbal and physical aggression and of threat).

After having received approval by the author the "Confidence in Coping with Patient Aggression" instrument developed was used. This instrument is a one-dimensional, ten item construct demonstrating a high degree of internal consistency (Cronbach's alpha $=0.92$ ) and precision (standard error $=1.5)($ Thackrey 1987). This scale includes items such as: "How comfortable are you working with an aggressive patient?", "How able are you to intervene physically with aggressive patient?", or "How self-assured do you feel in the presence of an aggressive patient?" (Thackrey 1987) The instrument has demonstrated the capacity to monitor change on a short and long term basis of 18 months and is used here to monitor the nurses' confidence in dealing with aggressive patients. The scale employs a Likert-type answer format with five responses (very comfortable, comfortable, undecided, not comfortable and very uncomfortable) with high markings denoting comfortableness.

The nursing students were asked to indicate the position on a straight horizontal $100 \mathrm{~mm}$ line which corresponds to their opinion regarding patient aggression. The degrees of opinion range from "not at all" to "agree fully". The visual analogue scales (VAS) used represent aggression as a "comprehensible, purposeful" and as a "senseless, unacceptable" behaviour were used to assess the participants' attitudes toward aggression. To date of the VAS used in this study have not been subjected to rigorous testing of their psychometric properties. However, visual analogue scales are recognised as a scale to represent opinion and are increasing used to measure subjective experiences (Polit \& Hungler 1999).

For ascertaining and monitoring nurses' aggression perceptions the POAS-S - a short version of the "Perception of Aggression Scale" - was used (Needham, Abderhalden et al. 2004). This instrument was derived from the original "Perception of Aggression Scale" (POAS) encompassing 32 statements on aggression to measure nurses' views regarding patient aggression (Jansen, Dassen et al. 1997). In a recent study on 729 Swiss nurses working in psychiatric settings factor analysis revealed two factors: 1) aggression as a dysfunctional / undesirable and 2) as a functional / comprehensible phenomenon (Abderhalden, Needham et al. 2002). The 12 item POAS-S (Needham, Abderhalden et al. 2004) demonstrates the same factor structure as the previous Swiss study. This instrument has demonstrated good internal consistency (Cronbach's Alpha of 0.69 for factor one and 0.67 for factor two) an average 
retest reliability across 4,14 and 70 days of $r=0.76$ and $r=0.77$ for factors one and two respectively (Needham, Abderhalden et al. 2004). The items of the POAS-S (Table 2) use a Likert type format with 5 possible responses ranging from "completely disagree" to "completely agree". Higher pointing represents higher item agreement.

\section{Table 2: Items of the POAS-S}

\begin{tabular}{ll}
\hline $\begin{array}{l}\text { Factor 1: Aggression as a dysfunctional/ } \\
\text { undesirable phenomenon }\end{array}$ & $\begin{array}{l}\text { Factor 2 Aggression as a functional / } \\
\text { comprehensible phenomenon }\end{array}$ \\
\hline Aggression is... & $\begin{array}{l}\text { Aggression is... } \\
\text { - mental or physical harm to others }\end{array}$ \\
- a mean to dominate others & $-\quad$ a help for new nursing perspective \\
- physical violence & - an emotional outlet \\
- conscious battery & - the opening of new pathways in \\
- violence towards self or others & nursing care \\
- an expression rendering others insecure or & $-\quad \begin{array}{l}\text { an expression of protection of private } \\
\text { sphere }\end{array}$ \\
\hline
\end{tabular}

\section{Data analysis}

The two groups were analysed regarding their equivalence at baseline using the Chi-Square and Mann-Whitney tests (due to skewed age distribution in the intervention group). A repeated measures design (univariate analysis of variance across three points in time) was used to monitor effects on the items regarding confidence in handling aggressive situations of attitude, on the attitude towards aggression, and on the summed items of the POAS-S factors measuring the perception of aggression (Tabachnick \& Fidell 1996). In all cases a two-way type I error probability of less than 0.05 was considered to indicate statistical significance. All data were analyzed using the SPSS 11 software.

\section{Results}

Testing of group differences: The control and case groups did not differ significantly on age but highly significantly on gender (Mann-Whitney $\mathrm{U}$ test of asymptotic significance $=0.70$ and $=0.01$ respectively). The age and gender distribution of the sample are demonstrated in Table 1. No significant differences were found regarding nurses' experience with patient aggression (frequency of incidents, threats, attacks, verbal aggression) with all Pearson Chi Square $>0.19$.

a) Perceived confidence in dealing with aggression: The nursing students in the intervention group demonstrated a highly significant rise in self confidence compared with the controls with both within and between subject factors $(\mathrm{p}<0.001)$. The "perceived confidence in dealing with aggression" instrument demonstrated a very good (Dukes 1998) internal consistency of 0.93 . 
b) Attitude toward aggression on the visual analogue scales: Using the repeated measures design both VAS measuring the attitude towards aggression proved non-significant on both the within and between subjects measures (time* group and group) with all $p>0.24$. Because of the sharp increase of the score on the VAS representing aggression as a "comprehensible, purposeful behaviour" immediately after the training course, the intervention group was analysed to assess attitude change under the impression of the educational package. The paired $\mathrm{t}$-test proved highly significant $(\mathrm{t}=-4.51, \mathrm{df}$ $=53, \mathrm{CI} 95 \%-22.7$ to $-8.8, \mathrm{p}=0.001)$ in comparison to the control group $(\mathrm{t}=$ $0.301, \mathrm{df}=53, \mathrm{CI} 95 \%-4.73$ to $-6.40, \mathrm{p}=0.765$ ).

c) Perception of aggression on the POAS-S: The mean scores of the POAS-S factors showed no overall changes on the two factors. On factor 1 (aggression as a negative, dysfunctional behaviour) the within subject factors on time by group contrast (mean square $=0.658, \mathrm{df}=1, \mathrm{~F}=4.673$, sig $=$ 0.033 ) was significant but the between subject factor (mean square $=1.639$, $\mathrm{df}=1, \mathrm{~F}=2.271 \mathrm{sig}=0.980$ ) non significant. On factor 2 (aggression as a positive, functional behaviour) neither the within subject factors on time by group contrast (mean square $=0.006, \mathrm{df}=1, \mathrm{~F}=0.058, \mathrm{sig}=0.810$ ) nor the between subject factor (mean square $=0.0003, \mathrm{df}=1, \mathrm{~F}=0.001$, sig $=0.980$ ) were significant.

\section{Discussion}

This study set out to test the impact of a four day educational package on nursing students' confidence in handling situations involving aggressive patients, their attitude towards aggression, and perception of aggression.

The nursing students' perceived confidence in handling aggressive situations increased significantly suggesting a great benefit for the participants. It must be stressed that the self reported enhanced confidence in dealing with aggressive patients does not necessarily demonstrate any practical changes such as better performance in "real" situations involving aggressive patients. However, we do believe that the perception of enhanced confidence per se is an objective worthy of achievement.

In the long term the effect of the training course on the attitude towards aggression as measured by the visual analogue scales remained unchanged but in the short term the perception of aggression as a "comprehensible, purposeful behaviour" increased in a highly significant fashion in the intervention group. This short term effect accrues from the immediate impression the training made on the students demonstrating that attitudes can be influenced in a positive fashion. It order to produce a more permanent change it seems that further interventions (such as follow-up educational measures) are necessary.

The training course had no significant impact on nursing students' perception of aggression as measured by the POAS-S. This non-significant result is in keeping with the similar studies. In one study paternalistic attitudes (Goodridge, Johnston et al. 1997) remained unchanged and in a further 
investigation (Feldt \& Ryden 1992) the authors registered a trend towards a change in attitude regarding positive views on home residents but no statistically significant results.

The changes in the perception of aggression as measured by the POAS-S of this sample across time are minimal in our sample - representing at the most 0.3 on a Likert scale of 5 points. Factor 1 - aggression as "negative, dysfunctional behaviour" - demonstrates a rising trend in the intervention group. This trend suggests that the training programme tends to lead to an increase in the "negative" perception of aggression. During the course the participants are prompted to reflect their positions regarding the acceptance or non-acceptance of patient aggression as part of the job. Some authors have demonstrated that nurses having been subjected to patient aggression may regard such behaviour as acceptable and as part of the job (Whittington \& Wykes 1989; Adams \& Whittington 1995). Given that patients' accountability for their aggression is discussed in the training course it seems plausible that the acceptance of aggressive behaviour by nursing students may diminish. The perception of aggression as a "positive, functional behaviour" developed in a parallel fashion in both groups. The trend toward an increase in the controls may represent an artefact of the questionnaire (habituation to the items). Given the almost identical development in both groups we conclude that the educational measure had no impact on the perception of aggression as a positive behaviour.

The lack of a significant impact of the training course on nurse trainees' perception of aggression may be attributed to several causes. This is the first study using the short version of the Perception of Aggression Scale (POAS-S) for this purpose and on nursing students and it may be that the instrument is not sensitive enough to detect change on this population. Bearing in mind that the POAS-S is comprised of items which remain stable over time (Needham, Abderhalden et al. 2004) it is possible that the POAS-S may measures traits (stable motivational characteristics or attributes) as opposed to states (views or feelings which fluctuate according to specific situations or to particular contexts).

The three month period may influence the results. Whittington found in an investigation of attitude on experienced psychiatric nurses that the length of nursing experience was associated with a more tolerant attitude with staff who had been in the job for more than 15 years demonstrating more tolerance towards aggression (Whittington 2002). In the light of this finding it would appear three months between the training course and the final measure was insufficient to allow for changes in attitude and perception. Another possible explanation is the content or "dosage" of the training. Possibly a more persistent educational measure - with follow-up interventions in the "real world" are necessary to change perceptions of aggression and attitude.

This study suggests that the training course used here is capable of improving this sample of nursing students' self reported confidence regarding the management of patient aggression without having to change their fundamental views. 


\section{Limitations}

An obvious limitation of this study is the non-randomisation. Randomisation leads to the equal distribution of all characteristics of the subjects and offers the statistically most robust results. Given the practical constraints and the logistic difficulties in conducting a randomised controlled trial the quasi-experimental design employing a control group was, however, the best design available.

Methodologically, we strongly emphasise that the findings are highly dependent on the quality of the instruments in use. Whereas the psychometric properties of the "Confidence in Coping with Patient Aggression" instrument and the POAS-S are well established, the two VASs have been used for the first time here and thus the results are to be interpreted with caution.

The gender of the participants differed significantly in the control and intervention groups with no males at all in the intervention group. In Switzerland it is not unusual to find wholly female classes in nursing schools. We therefore conclude that the unequal gender distribution in the groups does not jeopardise the generalisability of these results to a predominantly female profession.

A further major limitation of is the lack of knowledge about the students' actual performance in the "real nursing world" during the three months following the training course. Because no data were collected on the nursing students' actual exposure to patient aggression and because of the fact that it is impossible to hold co-variables constant in domain of daily nursing practice the conclusions drawn here must be of a tentative nature. Furthermore the outcome variable on confidence is based on self reporting further studies are needed to monitor changes in actual performance in real life situations.

\section{Implications}

The results suggest that the training course in aggression management is justified by the enhanced self perceived confidence of the participants in this study population. This study leads to the tentative conclusion that it is possible to successfully enhance nursing students' self confidence in dealing with aggressive incidents involving patients without having to intervene in attitudinal processes at trait level. However, further testing of this implication on populations in other educational and cultural settings are necessary before generalisations are made. 


\section{References}

Abderhalden C, Needham I, Friedli TK, Poelmans J, Dassen T (2002) Perception of aggression among psychiatric nurses in Switzerland. Acta Psychiatrica Scandinavica 106 Supplementum (412): 110-117

Adams J, Whittington R (1995) Verbal aggression to psychiatric staff: Traumatic stressor or part of the job? Perspectives in Psychiatric Care 2(2):171-74

Arnetz JE, Arnetz BB (2001) Violence towards health care staff and possible effects on the quality of patient care. Social Science and Medicine 52(3):417-27.

Beech B (1999) Sign of the times or the shape of things to come? A 3-day unit of instruction on 'aggression and violence in health settings for all students during pre-registration nurse training'. Nurse Education Today 19(8):610-6.

Bensley L, Nelson N, Kaufman J, Silverstein B, Kalat J, Shields J (1997) Injuries due to assaults on psychiatric hospital employees in Washington State. American Journal of Industrial Medicine 1(1):92-9

Bin Abdullah AM, Khim LYL, Wah LC, Bee OG, Pushpam S (2000) A study of violence towards nursing staff in the emergency department. Singapore Nursing Journal 27(3):30-37

Carmel H, Hunter M (1993) Staff injuries from patient attack: five years' data. The journal of the American Academy of Psychiatry and the Law 21(4):485-493

Chervinski D (1995) Workplace violence. Canadian Journal of Medical Technology 57(3):1325 .

Collins J (1994) Nurses' attitudes towards aggressive behaviour, following attendance at "The prevention and management of aggressive behaviour programme". Journal of Advanced Nursing 20:117-131

Dukes K (1998) Encyclopedia of biostatistics. In: Armitage P, Colton T (Eds), Chichester, John Wiley and Sons.

Feldt K, Ryden M (1992) Aggressive behavior. Educating nursing assistants. Journal of Gerontological Nursing 18(5):3-12

Flannery RB, Jr., Stone P, Rego S, Walker AP (2001) Characteristics of staff victims of patient assault: Ten year analysis of the Assaulted Staff Action Program (ASAP). Psychiatric Quarterly 72(3):237-248

Goodridge D, Johnston P, Thomsen M (1997) Impact of a nursing assistant training program on job performance, attitudes, and relationships with residents. Educational Gerontology $23: 37-51$

Hagen B, Sayers D (1995) When caring leaves bruises. The effects of staff education on resident aggression. Journal of Gerontological Nursing 21(11):7-16

Hubschmid T (1996) Erfahrungen im Umgang mit Gewalttätigkeit in der psychiatrischen Klinik. Psychiatrische Praxis 3(1):26-8

Jansen G, Dassen T, Moorer P (1997) The perception of aggression. Scandinavian Journal of Caring Sciences 11(1):51-55

Lanza M, Kayne H, Hicks C, Milner J (1991) Nursing staff characteristics related to patient assault. Issues in Mental Health Nursing 12(3):253-265

Lee S, Wright S, Sayer J, Parr A-M, Gray R, Gournay K (2001) Physical restraint training for nurses in English and Welsh psychiatric intensive care and regional secure units. Journal of Mental Health 10(2):151-162

Maxfield MC, Lewis RE, Cannon S (1996) Training staff to prevent aggressive behavior of cognitively impaired elderly patients during bathing and grooming. Journal of Gerontological Nursing 22(1):37-43. 
Needham I, Abderhalden C, Dassen T, Haug HJ, Fischer JE (2004) The perception of aggression by nurses: Psychometric scale testing and derivation of a short instrument. Journal of Psychiatric and Mental Health Nursing 11(1):36-42

Oud NE (1997) Aggression and psychiatric nursing. Amsterdam, Broens and Oud: Partnership for consulting and training

Paterson B, Tumbull J, Aitken I (1992) An evaluation of a training course in the short-term management of violence, Nurse Education Today 12(5):368-375

Polit D, Hungler B (1999) Nursing Research. Philadelphia, Lippincott

Rippon TJ (2000) Aggression and violence in health care professions. Journal of Advanced Nursing 31(2):452-60

Rix G (1987) Staff sickness and its relationships to violent incidents on a regional secure psychiatric unit. Journal of Advanced Nursing 12(2):223-228

Rix G, Seymour D (1988) Violent incidents on a regional secure unit. Joumal of Advanced Nursing 13(6):746-51

Seel N (2003) Psychologie des Lernens. München, Reinhardt

Shah A, De T (1998) The effect of an educational intervention package about aggressive behaviour directed at the nursing staff on a continuing care psychogeriatric ward. International Journal of Geriatric Psychiatry 13(1):35-40

Sprenger R (2001) Aggressives Verhaiten von Patienten gegenüber Pflegenden, Fortbildungsbedarf im Zusammenhang mit Aggression. Universität Maastricht, Maastricht

Tabachnick B, Fidell L (1996) Using multivariate statistics. (3. edition) New York, Harper Collins

Taylor D (2000) Student preparation in managing violence and aggression. Nursing Standard 14(30):39-41

Thackrey M (1987) Clinicial confidence in coping with patient aggression: Assessment and enhancement. Professional Psychology: Research and Practice 18(1):57-60

Whitley GG, Jacobson GA, Gawrys MT (1996) The impact of violence in the health care setting upon nursing education. Journal of Nursing Education 35(5):211-8.

Whittington R (2002) Attitudes toward patient aggression amongst mental health nurses in the 'zero tolerance' era: associations with burnout and length of experience. Journal of Clinical Nursing 11(6):819-25

Whittington R, Shuttleworth S, Hill L (1996) Violence to staff in a general hospital setting. Journal of Advanced Nursing 24:326-333

Whittington R, Wykes T (1989) Invisible injury. Nursing Times 85(42):30-32

Whittington R, Wykes T (1994) Violence in psychiatric hospitals: are certain staff prone to being assaulted? Journal of Advanced Nursing 19(2):219-25

Wondrak RF, Dolan BM (1992) Dealing with verbal abuse: evaluation of the efficacy of a workshop for student nurses. Nursing Education Today 12(2):108-15 


\title{
CHAPTER 7
}

\author{
THE EFFECT OF A TRAINING COURSE IN AGGRESSION \\ MANAGEMENT ON MENTAL HEALTH NURSES' PERCEPTION \\ OF AGGRESSION: A CLUSTER RANDOMISED CONTROLLED \\ TRIAL
}

Needham I, Abderhalden C, Halfens RJG, Dassen T, Haug HJ, Fischer JE. The effect of a training course in aggression management on mental health nurses' perceptions of aggression: a cluster randomised controlled trial. Accepted for publication in the International Journal of Nursing Studies. 


\begin{abstract}
In inpatient psychiatric settings nurses are often confronted with the problem of patient aggression. Nurses' attitudes towards patient aggression may influence their behaviour towards such patients. Interventions able to ameliorate the nurses' capacity to cope with aggressive patients may lead to more positive attitudes and alleviate adverse feelings emanating from patient aggression. In this multi centre randomised controlled trial the hypotheses were tested that a five day training course in aggression management would positively influence nurses' perception of aggression, their tolerance towards patient aggression and their adverse feelings. After randomisation at ward level 30 nurses participated in the intervention and 28 in the control group. The groups were comparable regarding their demographic characteristics. A repeated measures design was employed to monitor change in the groups. After statistical testing no significant differences were found between the groups on the outcome variables. The results suggest that the training course had no effect on the outcome measures. Possible reasons are the short time frame of three months between the training course and the follow up measurement or non responsiveness of the measurement instruments.
\end{abstract}

Keywords: aggression, attitude, perception of aggression, psychiatric nurses, training in aggression management

Acknowledgement

This study was supported by grant number $3251 \mathrm{~B} 0-100710$ of the Swiss National Science Foundation. 


\section{Introduction}

Patient aggression in mental health settings is well recognised as a major problem (Whittington \& Wykes 1994; Arnetz \& Arnetz 2000) and is according to some authors (Hansen 1996) on the increase. Rates of patient aggression in psychiatric settings range from 0.07 (Steinert, Vogel et al. 1991; Richter 1998) to 0.25 aggressive incidents per bed and year (Cooper \& Mendonca 1989). According to a single centre study conducted at the Psychiatric University Clinic in Zurich $10 \%$ of newly admitted patients were aggressive (Geser 1999). Injuries may reach as many as 16 injuries per 100 staff (Carmel \& Hunter 1989). Because nurses provide a 24-hour care service they take the brunt of such aggression (Vanderslott 1998). This considerable source of stress on nurses and may even lead to considering leaving the nursing profession (Arnetz, Arnetz et al. 1998; Ito, Eisen et al. 2001). Thus dealing with aggressive or violent patients and coping with the sequelae thereof is a major challenge for nurses.

Patient aggression may be mediated by various influencing factors such as ward crowding (Palmstierna, Huitfeldt et al. 1991; Nijman \& Rector 1999), or ward culture (Morrison 1990; Morrison 1998), or interactional style of the personnel (Blair 1991; Whittington \& Wykes 1994). Training courses in aggression management have been suggested as appropriate way to equip personnel to deal with patient aggression in mental health settings (Cahill 1991). Such training courses have lead to changes in variables like a reduction of the use of seclusion (Ramirez, Bruce et al. 1981; Morales \& Duphorne 1995), staff confidence (Turnbull, Aitken et al. 1990; McGowan, Wynaden et al. 1999), knowledge on topics concerning the management of aggression (Rice, Helzel et al. 1985; Calabro, Mackey et al. 2002), or nurses attitudes on aggression (Beech 1999; Calabro, Mackey et al. 2002).

Nurses' attitudes towards patient aggression may be linked to actual behavioural performance (Collins 1994; Whittington \& Higgins 2002) in dealing with aggressive patients. Some studies have demonstrated that attitudes toward patient aggression such as a "tradition of toughness" (Morrison 1990 ) or staff's views regarding the genesis of aggression (Duxbury 2002) influence their interactional style. These studies support the position that viewing aggression as positive behaviour in certain circumstances (e.g. the enhancement of assertiveness, the capacity to accomplish one's goals) one is inclined to react to aggression in a more permissive fashion (Whittington 2002). A training course tested by Collins demonstrated the capacity to increase nurses' comprehension for patients' aggressive behaviour immediately after the training course but not a follow up after six months (Collins 1994). In the same study a greater proportion of nurses disagreed that patients "threaten staff to get their own way" after the training. In spite of the small sample $(\mathrm{n}=22)$ this study shows that educational measures may lead to attitude change. For these reasons investigations into attitudinal change following courses in aggression management are necessary (Collins 1994). 
Dealing with aggressive incidents involving patients often leaves carers with adverse feelings such as guilt or self blame (Ryan \& Poster 1989; Murray \& Snyder 1991; Hauck 1993; Gates, Fitzwater et al. 1999; O'Connell, Young et al. 2000), compassion with the aggressor (Murray \& Snyder 1991; Arnetz \& Arnetz 2001), avoiding the perpetrator (Adams \& Whittington 1995; Chambers 1998; Richter 1999), or the perception of an impaired relationship (Chambers 1998; Levin, Hewitt et al. 1998; Gates, Fitzwater et al. 1999; Arnetz \& Arnetz 2001). Carers may also feel insecure in dealing with the patients (Hauck 1993; Poster 1996; Bin Abdullah, Khim et al. 2000; O'Connell, Young et al. 2000; Fry, O'Riordan et al. 2002), or doubts regarding their professional competency (Lanza, Kayne et al. 1991; Hauck 1993; Flannery, Hanson et al. 1995; Bin Abdullah, Khim et al. 2000), or even provoke feelings of being a failure (Hauck 1993). Sometimes nurses may become angry towards the hospital they are working in (Lanza, Kayne et al. 1991; Hauck 1993; Chambers 1998) and even ask themselves if they are working in the right profession (Lanza, Kayne et al. 1991; Hauck 1993; Bin Abdullah, Khim et al. 2000; O'Connell, Young et al. 2000).

Given the capacity of such trainings to influence attitude towards patient aggression we devised this study to investigate the effects of a training course being offered currently in Switzerland. We hypothesised that a training course in the management of aggressive behaviour (the independent variable) will lead to a) a more positive perception of aggression, b) to higher tolerance towards patient aggression, and c) a reduction of adverse feelings on dealing with aggressive patients of nurses working in psychiatric acute in-patient settings (Figure 1).

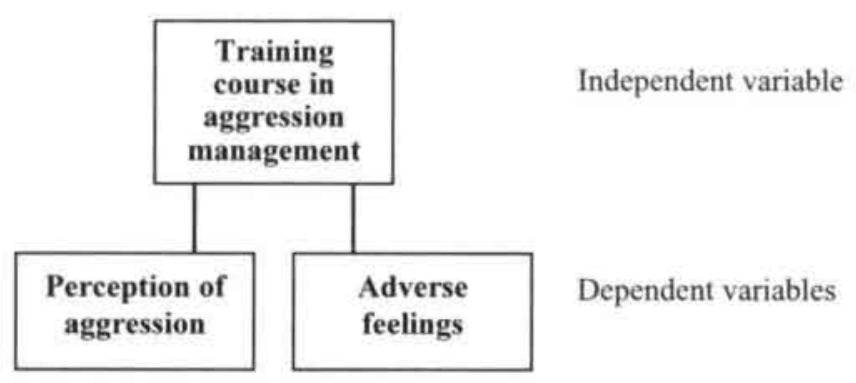

Figure 1: Research model 


\section{Method}

Design: This multi centre randomised control trial (Figure 2) was designed to test the effectiveness of a training programme in aggression management to influence nurses' perception of and attitude on patient aggression. All 87 acute psychiatric wards in the German speaking part of Switzerland were invited to participate in the study. The six wards recruited for this study agreed to waiting list randomisation. Three wards were randomly allocated to the intervention group and the remaining three to the control group. The control group received the training after completion of this study.

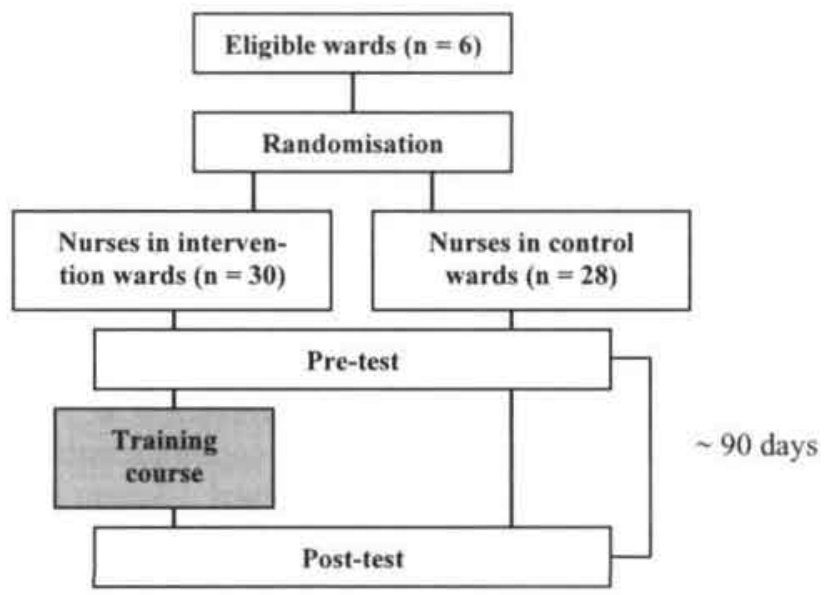

Figure 2: Study design

Sample: All 114 nurses working on the six participating wards were invited to participate in the study. Participants completed the questionnaire before the intervention (the training course in aggression management) and a second time after three months. The characteristics of the participating nurses are demonstrated in Table 1.

Table 1: Demographic characteristics of the groups

\begin{tabular}{lccc}
\hline Variable & Control & Intervention & P \\
\hline Gender (females, males) & 14,14 & 18,12 & $0.444^{\dagger}$ \\
Mean age (SD) & $39.21(8.7)$ & $36.47(8.7)$ & $0.288^{\prime}$ \\
Nursing experience in years (SD) & $12.62(7.9)$ & $9.85(8.5)$ & $0.423^{\dagger}$ \\
Nursing experience in psychiatry in years (SD) & $11.83(7.6)$ & $7.48(6.8)$ & $0.598^{\dagger}$ \\
Career prevalence of attack (SD) & $6.93(8.2)$ & $3.03(2.6)$ & $0.480^{\dagger}$ \\
\hline
\end{tabular}

${ }^{\dagger}$ Pearson $x^{2}$ test: ${ }^{\ddagger}$ Mann Whitney $U$ test 
Intervention: The training program in the management of aggression developed by Nico Oud (Oud 1997) consisted of 20 lessons each lasting 50 minutes administered on five consecutive days. The course aimed to provide knowledge, capabilities and techniques to the students. The following areas were treated: Types and causes of aggression, the genesis of aggression, reflection on one's own aggressive components, theory on the various stages of aggressive incidents, behaviour during aggressive situations, types of conflict management, communication and interaction, post aggression procedures, workplace safety, prevention of aggression, breakaway techniques, and role play. The standardised intervention was administered to complete nursing teams of wards by experienced psychiatric nurses who had previously completed an educational measure to train the teams. The teachers played no part in the randomisation process, the study design, data collection and analysis or other study activities.

Instruments: The nurses completed a questionnaire containing of socio-biographic items (age, gender, and years of professional experience) and questions on their experiences of aggression (frequency of experiences of verbal and physical aggression and of threat).

Perception of aggression: To ascertain the perception of aggression the short version of the Perception of Aggression Scale (POAS-S) was employed (Needham, Abderhalden et al. 2004). This scale is derived from the "Perception of Aggression Scale" (Jansen, Dassen et al. 1997). It shows a two factor solution - aggression as "functional, comprehensible" and as "dysfunctional, undesirable" behaviour. The shortened 12 item version has demonstrated similar psychometric properties to the full instrument (Needham, Abderhalden et al. 2004). Possible scores range from 6 to 30 points with high scores indicating high agreement to the factors (aggression as "functional, comprehensible" and "dysfunctional, undesirable" behaviour).

Tolerance measure: The "Tolerance Scale" (Whittington 2002) uses 12 items of the "Perception of Aggression Scale" (Jansen, Dassen et al. 1997) representing neutral, non-condemnatory or positive statements concerning patient aggression. This instrument has been employed in a cross sectional survey on of predominantly mental health nurses in the United Kingdom. To our knowledge it has not been used to monitor change in conjunction with an intervention designed to influence attitude. Possible scores range from 12 to 60 points with high scores indicating high tolerance towards patient aggression.

IMPACS: The "Impact of Patient Aggression on Carers Scale" (IMPACS) is an instrument designed to measure adverse feelings of carers in handling incidents involving aggressive patients (Needham, Abderhalden et al. 200x). The three factors - "impairment of relationship between patient and carer", "adverse moral emotions", and "adverse feelings to external sources" demonstrate satisfactory internal validity with Cronbach's alphas of 0.78 , 0.69 and 0.60 respectively. The possible scores range from 4 to 20 points on the first two and from 2 to 20 on the third factor. 
Data Analysis: Chi-Square and Mann-Whitney tests and independent samples t-tests were conducted to test the comparability of the two groups at baseline. A repeated measures design (univariate analysis of variance of the two measurements) was used to monitor change between baseline and follow up measurements conducted three months after the intervention.

Outcome variables were perception of aggression, tolerance towards patient aggression, and adverse emotions in dealing with aggressive patients. In all cases the items were aggregated into the dimensions or factors of the employed scales. A two-way type I error probability of less than 0.05 was considered to indicate statistical significance. All data were analyzed using the SPSS 12 software.

\section{Results}

Demographics: Fifty eight nurses completed the questionnaires (30 in the intervention and 28 in the control group) rendering an overall response rate of $51 \%$. No significant differences were found between the groups regarding gender, age, nursing experience, experience in psychiatry, and the career prevalence of attack (Table 1).

Testing of group differences at baseline: All comparisons of the means of the variables of the control and intervention groups were nonsignificant (positive perception of aggression $=0.679$, negative perception of aggression $=0.315$, the tolerance scale $=0.498$, "impairment of relationship between patient and carer" $=0.469$, "adverse moral emotions" $=0.055$, "adverse feelings to external sources" $=0.731$ ).

Post intervention effects: No statistically significant differences of the means were found between the intervention and control groups on the positive perception of aggression, the negative perception of aggression, the tolerance scale, the "impairment of relationship between patient and carer", "adverse moral emotions", and "adverse feelings to external sources" (Table 2 ). The only trend towards change was on the mean of the item "impairment of relationship between patient and carer". The mean fell slightly in the intervention group (from 8.0 to 7.6 points) but rose slightly in the control group (from 7.6 to 8.0 points). However, with a $p=$ of 0.233 this result is well out of the range of statistical significance. 
Table 2: Pre and post scores on all variables

\begin{tabular}{lllll}
\hline Item & Group & Pre score' & Post score' & $\mathbf{P}^{t}$ \\
\hline $\begin{array}{l}\text { Perception of aggression (POAS-S) } \\
\text { "positive" }\end{array}$ & Control & $16.7(3.5)$ & $16.3(2.9)$ & 0.912 \\
\hline $\begin{array}{l}\text { Perception of aggression (POAS-S) } \\
\text { "negative" }\end{array}$ & Contervention & $17.1(4.2)$ & $16.8(3.7)$ & \\
\hline Tolerance scale & Intervention & $17.3(3.7)$ & $17.7(4.2)$ & \\
\hline $\begin{array}{l}\text { IMPACS: "Impairment of } \\
\text { relationship between patient and } \\
\text { carer" }\end{array}$ & Control & $34.5(6.3)$ & $32.4(5.4)$ & 0.614 \\
\hline $\begin{array}{l}\text { IMPACS: "Adverse moral } \\
\text { emotions" }\end{array}$ & Intervention & $35.7(7.2)$ & $34.5(6.6)$ & \\
\hline IMPACS: "Adverse feelings to & Control & $7.6(2.3)$ & $8.0(2.0)$ & 0.233 \\
external sources" & Intervention & $7.7(2.1)$ & $8.0(1.6)$ & \\
\hline
\end{tabular}

${ }^{\dagger}$ Mean (SD): ' Test of within-subjects contrasts using the repeated measures design

\section{Discussion}

In this study we tested the hypotheses that a training course in aggression management would positively influence a) nurses' perception of aggression, b) tolerance towards patient violence and c) adverse feelings on dealing with aggressive patients. None of the variables tests reached statistical significance and therefore, none of the three hypotheses can be accepted.

The perception of aggression as measured by the "Tolerance Scale" remained unchanged. The participants in this study had higher mean tolerance scores of $35.1(\mathrm{sd}=6.8)$ compared with $34.2(\mathrm{sd}=7.1)$ in the British study (Whittington 2002). Whittington describes tolerance as a "relatively stable positive or negative evaluation of a phenomenon involving cognitive, affective and behavioural concepts" (Whittington 2002, p. 820). The generally higher tolerance of the Swiss nurses and the stability of attitudes may contribute to the explanation the negative results. The "Tolerance Scale" has to our knowledge never been used in a longitudinal design to monitor attitude change before. As no extensive testing of its psychometric properties has been conducted it is possible that the instrument is insensitive to change.

The testing of change employing the POAS-S also proved statistically insignificant. It is surprising how stable the scores in the control and intervention groups are (Table 2). This result leads us to suspect that derivates of the POAS measure only the most stable attitudinal items at trait level. The findings here are in keeping with a recent Swiss quasi experimental study using an instrument to monitor nurses' attitudes towards possible causes of patient aggression in which also no significant changes transpired after visiting the same training course (Hahn 2003).

None of the three dimensions of the "Impact of Patient Aggression on Carers Scale" (IMPACS) demonstrated any change. The slight change 
regarding the "impairment of relationship between patient and carer" is, however, so far off statistical significance that the conclusion must be drawn that the training course does not lead to a change in the expected direction. Due to the novelty of the scale we have no reference data on the levels of nurses' adverse feelings in the area under scrutiny. It is striking that the means for both groups are clustered at the low end of the scale. For example the combined control and intervention group scores a mean of $7.8(\mathrm{SD}=2.1)$ from a range of 4 to 20 points on the dimension "impairment of relationship between patient and carer". With such low scores at the onset only a very potent intervention would have to capacity to produce a statistically significant change. In order to rule out the probability of a type II error we would have needed approximately 65 respondents in each group. This is the first study to employ the IMPACS and further testing of the instrument's capacity to detect change is obviously necessary.

The non-significant results may be attributable to several issues. In spite of block randomisation the sample size of 28 and 30 persons in the control and intervention group respectively was small. Due to the repeated measures design some attrition occurred by persons not completing the questionnaires in both rounds. The final return rate of $51 \%$ lay under our expectations. It is also possible that the instrumentation was inadequate. The scales have been employed for the first time and it is possible that they are not sensitive enough to detect small differences. Possibly the instruments may detect modifications in a population with a greater potential for change such as nurses less experienced in the management of patient aggression.

Alternatively the lack of change may be an expression of the incapacity of the training course to induce change. Although the training course contained many important elements deemed capable of influencing the participants' attitudes it may have failed to address the variables in an adequate manner in terms of impact or "dosage". Interestingly, on an anecdotal basis all the nurses were laudable of the training course and they considered it to be of great practical value.

Another possible explanation for the statistically non significant results is that attitude only changes after implementing the techniques of the training on a long term basis. This hypothesis assumes an inverse model of causation with behaviour leading to attitude change and not - as assumed at the onset of this study - that the training course mediates attitude change. In the case of this hypothesis being true the time frame of three months seems too optimistic to allow for change. Furthermore, the mean age of the nurses lies around 38 years with nursing experience in a psychiatric nursing setting being about 9 years. It is possible, than a change agent may have a greater impact on a younger group.

The results of this study suggest that the attitudinal variables measured here are much more stable than we had previously envisaged. Whereas other instruments measuring attitude may include items such as patients' responsibility for aggressive action (Ryan \& Poster 1989) or nurses' reactions to patient aggression (Collins 1994) the POAS-S focuses solely on care workers views on patient aggression (Needham, Abderhalden et al. 2004). To 
date we have no data on actual changes regarding the management of aggressive patients so we cannot test the hypothesis that attitudinal change is a necessary prerequisite for behavioural change.

On the basis of these results we conclude that attitudes are more stable than expected and we question the capacity of short interventions to induce attitude changes at the level addressed here. 


\section{References}

Adams J, Whittington R (1995) Verbal aggression to psychiatric staff: Traumatic stressor or part of the job? Perspectives in Psychiatric Care 2(2):171-74

Arnetz J, Arnetz B, Soderman E (1998) Violence toward health care workers. Prevalence and incidence at a large, regional hospital in Sweden. American Association of Occupational Health Nurses Journal 46(3):107-114.

Arnetz JE, Arnetz BB (2000) Implementation and evaluation of a practical intervention programme for dealing with violence towards health care workers. Journal of Advanced Nursing 31(3):668-80

Ametz JE, Ametz BB (2001) Violence towards health care staff and possible effects on the quality of patient care. Social Science and Medicine 52(3):417-27.

Beech B (1999) Sign of the times or the shape of things to come? A 3-day unit of instruction on 'aggression and violence in health settings for all students during pre-registration nurse training'. Nurse Education Today 19(8):610-6.

Bin Abdullah AM, Khim LYL, Wah LC, Bee OG, Pushpam S (2000) A study of violence towards nursing staff in the emergency department. Singapore Nursing Journal 27(3):30-37

Blair D (1991) Assaultive behavior. Does provocation begin in the front office? Journal of Psychosocial Nursing and Mental Health Services 9(5):21-6

Calabro K, Mackey TA, Williams S (2002) Evaluation of training designed to prevent and manage patient violence. Issues in Mental Health Nursing 23(1):3-15

Carmel H, Hunter M (1989) Staff injuries from inpatient violence. Hospital Community Psychiatry $40(1): 41-46$

Chambers N (1998) 'We have to put up with it--don't we?' The experience of being the registered nurse on duty, managing a violent incident involving an elderly patient: a phenomenological study. Journal of Advanced Nursing 27(2):429-36

Collins J (1994) Nurses' attitudes towards aggressive behaviour, following attendance at "The prevention and management of aggressive behaviour programme". Journal of Advanced Nursing 20:117-131

Cooper A, Mendonca J (1989) A prospective study of patient assaults on nursing staff in a psychogeriatric unit. Canadian Journal of Psychiatry 34(5):399-404.

Duxbury J (2002) An evaluation of staff and patient views of and strategies employed to manage inpatient aggression and violence on one mental health unit: a pluralistic design. Journal of Psychiatric and Mental Health Nursing 9(3):325-37

Flannery R, Hanson M, Penk W (1995) Patients' threats. Expanded definition of assault. General Hospital Psychiatry 17(6):451-3

Fry AJ, O'Riordan D. Turner M. Mills KL (2002) Survey of aggressive incidents experienced by community mental health staff. International Journal of Mental Health Nursing 11(2):11220

Gates DM, Fitzwater E, Meyer U (1999) Violence against caregivers in nursing homes: Expected, tolerated, and accepted. Journal of Gerontological Nursing(4):12-22

Geser AM (1999) Aggressionen von hospitalisierten psychisch Kranken: Eine systematische Evaluation von knapp 2000 Aggressionsfallen. Unpublished Inaugural-Dissertation zur Erlangung der Doktorwürde, Universität Zürich, Zürich

Hahn S (2003) Effekt einer Schulung auf die Haltung von Pflegepersonen zu Ursache und Management von Patientenaggression. Unpublished Masters thesis, Rijksuniversiteit Limburg. Maastricht

Hansen B (1996) Workplace violence in the hospital psychiatric setting. An occupational health perspective. American Association of Occupational Health Nurses Journal 4(12):575-580 
Hauck M (1993) Die Wut bleibt - Gewalt von Patienten gegenüber Pflegenden (The anger remains - patient violence towards nurses). Unpublished Thesis, Kaderschule für die Krankenpflege, Aarau

Ito H, Eisen SV, Sederer LI, Yamada O, Tachimori H (2001) Factors affecting psychiatric nurses' intention to leave their current job. Psychiatric Services 52(2):232-234

Jansen G, Dassen T, Moorer P (1997) The perception of aggression. Scandinavian Journal of Caring Sciences 11(1):51-55

Lanza M, Kayne H, Hicks C, Milner J (1991) Nursing staff characteristics related to patient assault. Issues in Mental Health Nursing 12(3):253-265

Levin PF, Hewitt JB, Misner ST (1998) Insights of nurses about assault in hospital-based emergency departments. Image Journal of Nursing Scholarship 30(3):249-54

McGowan S, Wynaden D, Harding N, Yassine A, Parker J (1999) Staff confidence in dealing with aggressive patients: a benchmarking exercise. Australian and New Zealand Journal of Mental Health Nursing 8(3):104-8.

Morales E, Duphorne PL (1995) Least restrictive measures: alternatives to four-point restraints and seclusion. Journal of Psychosocial Nursing and Mental Health Services 33(10):13-6

Morrison EF (1990) The tradition of toughness: a study of nonprofessional nursing care in psychiatric settings. Image Journal of Nursing Scholarship 22(1):32-8

Morrison EF (1998) The culture of caregiving and aggression in psychiatric settings. Archives of Psychiatric Nursing 12(1):21-31

Murray G, Snyder JC (1991) When staff are assaulted. A nursing consultation support service. Journal of Psychosocial Nursing and Mental Health Services 29(7):24-29

Needham I, Abderhalden C, Dassen T, Haug HJ, Fischer JE (2004) The perception of aggression by nurses: Psychometric scale testing and derivation of a short instrument. Journal of Psychiatric and Mental Health Nursing 11(1):36-42

Needham I, Abderhalden C, Halfens R, Dassen T, Haug H, Fischer J O The impact of patient aggression on carers scale (IMPACS): Instrument derivation and psychometric testing. Submitted

Nijman H, Rector G (1999) Crowding and aggression on inpatient psychiatric wards. Psychiatric Services 50(6):831-831

O'Connell B, Young J, Brooks J, Hutchings J, Lofthouse J (2000) Nurses' perceptions of the nature and frequency of aggression in general ward settings and high dependency areas. Journal of Clinical Nursing 9(4):602-10.

Oud NE (1997) Aggression and psychiatric nursing. Amsterdam, Broens and Oud: Partnership for consulting and training

Palmstierna T, Huitfeldt B. Wistedt B (1991) The relationship of crowding and aggressive behavior on a psychiatric intensive care unit. Hospital Community Psychiatry 42(12):12371240

Poster EC (1996) A multinational study of psychiatric nursing staffs' beliefs and concerns about work safety and patient assault. Archives of Psychiatric Nursing 10(6):365-73

Ramirez LF, Bruce J, Whaley M (1981) An educational program for the prevention and management of disturbed behavior in psychiatric settings. Journal of Continuing Education in Nursing 12(5): 19-21

Rice MF, Helzel MF, Varney GW, Quinsey VI (1985) Crisis prevention and intervention training for psychiatric hospital staff. American Journal of Community Psychology 13:289-304

Richter D (1998) Gewalt und Gewaltprävention in der psychiatrischen Pflege- eine Ubersicht über die Literatur. In: Sauter D, Richter D (Hrsg). Gewalt in der psychiatrischen Pflege Bern, Huber.

Richter D (1999) Patientenübergriffe auf Mitarbeiter psychiatrischer Kliniken: Häufigkeit, Folgen, Präventionsmöglichkeiten. Freiburg im Breisgau, Lambertus 
Ryan JA, Poster EC (1989) The assaulted nurse: short-term and long-term responses. Archives of Psychiatric Nursing 3(6):323-31

Steinert T, Vogel W, Beck M, Kehlmann S (1991) Aggressionen psychiatrischer Patienten in der Klinik: Eine 1-Jahres-Studie an vier psychiatrischen Landeskrankenhäusern. Psychiatrische Praxis 18(5):155-161

Turnbull J, Aitken I, Black L, Patterson B (1990) Turn it around: Short-term management for aggression and anger. Journal of Psychosocial Nursing and Mental Health Services 28(6):6-10, 13

Vanderslott J (1998) A study of incidents of violence towards staff by patients in an NHS Trust hospital. Journal of Psychiatric and Mental Health Nursing 5(4):291-298

Whittington R (2002) Attitudes toward patient aggression amongst mental health nurses in the 'zero tolerance' era: associations with burnout and length of experience. Journal of Clinical Nursing 11(6):819-25

Whittington R, Higgins L (2002) More than zero tolerance? Burnout and tolerance for patient aggression amongst mental health nurses in China and the UK. Acta Psychiatrica Scandinavia 106 Supplementum (412):37-40

Whittington R, Wykes T (1994) An observational study of associations between nurse behaviour and violence in psychiatric hospitals. Journal of Psychiatric and Mental Health Nursing $1(2): 85-92$. 


\section{CHAPTER 8}

\section{THE EFFECTIVENESS OF TWO INTERVENTIONS IN THE MANAGEMENT OF PATIENT VIOLENCE IN PSYCHIATRY: REPORT ON A PILOT STUDY}

Needham I, Aberhalden C, Meer R, Dassen T, Haug HJ, Halfens RJG, Fischer JE. 2004. The effectiveness of two interventions in the management of patient violence in acute mental inpatient settings: Report on a pilot study. Journal of Psychiatric and Mental Health Nursing 11(5):595-601. 


\begin{abstract}
In this dual centre prospective, non-randomised pre and post-test feasibility study on two 12-bed psychiatric acute admission wards in Switzerland, the hypothesis that two interventions will reduce the frequency and severity of violent events and reduce coercion was tested. A systematic aggression risk assessment alone and in combination with a standardised training course in aggression management comprised the interventions with the frequency and severity of aggressive incidents and the frequency of coercive measures as the main outcomes. Incidence rates per 100 hospitalisation days of 3.51 for aggressive incidents, 1.68 for attacks against persons, and for coercion 3.05 were found. After introduction of the interventions no significant reduction of the incidence rates of aggressive events and attacks occurred. However the rates of coercive measures per 100 hospitalisation days declined significantly. The incident severity as measured by SOAS-R remained unchanged whilst the subjective severity declined after the training course. We conclude that a systematic risk assessment and a training course may assist in reducing the incidence rate of aggressive incidents and coercive measures on psychiatric acute admission wards. Further testing in a randomised controlled study is necessary to substantiate these preliminary findings and to measure the effect of the training course alone.
\end{abstract}

Key words: Aggression, violence, psychiatry, intervention

Acknowledgements

This study was supported by research grant BK $361 / 01$ of the Swiss Academy of Medical Science and by a financial contribution of the Swiss Association of Nursing Experts. 


\section{Introduction}

Aggressive incidents perpetrated by patients are a major concern in psychiatric acute admission wards. It has been estimated that more than half of the physicians, psychologists and social workers in German psychiatric hospitals have been subjected to serious injury induced by patient violence during their career (Steinert, Beck et al. 1995). Amongst these psychiatric care providers, almost all nurses have experienced patient violence (Carmel \& Hunter 1989) in their career. A recent survey in psychiatric institutions in the German speaking part of Switzerland corroborates these data: Seventy percent of 729 responding psychiatric nurses reported being physically attacked at least once in their career (Abderhalden, Needham et al. 2002).

A frequent reaction to patient aggression is the implementation of coercive measures. However, this practice has recently become the target of intense public criticism (Gebhardt \& Steinert 1998) and of scientific scrutiny. Thus, a major challenge for quality improvement is to prevent aggressive incidents and to reduce the need to employ coercive measures simultaneously. Various measures have been proposed to solve this problem such as the use of systematic risk assessments to foresee aggressive behaviour or special methods for handling aggressive patients (Fisher 1994; Chervinski 1995; Nijman, Merckelbach et al. 1997). In the Netherlands, the Scandinavian countries and Great Britain, such training courses for handling aggressive patients were introduced and implemented more than a decade ago. The rationale behind these interventions is to increase the predictability of patient aggression, hereby assisting to appropriately adapt staff-patient interactions. The training aims to avoid eruptions of violence, to minimise the risk of injury, and to reduce the need for harsh coercive measures.

Despite their widespread use in the aforementioned countries and the considerable resources devoted to training of the psychiatric staff, these interventions have never been systematically assessed as to their efficacy in reducing the incidence rate of aggressive events or the use of coercive measures. A recent cross sectional survey on the management of patient aggression in Switzerland revealed considerable heterogeneity in the management of aggressive patients (Needham, Abderhalden et al. 2002) and sub optimal use of systematic risk assessment or staff training in aggression management. This unique situation offers a pristine research environment in which both interventions can be implemented within the framework of a multi-centre randomised controlled trial.

Here we report on a dual centre feasibility study replicating the intended study design in a 1:1 fashion, exempt for randomisation. We included one urban and one rural acute psychiatry admission ward to cover the expected heterogeneity in patient populations and ward characteristics. We sequentially introduced risk prediction by the nursing staff and standardised staff training during a 10-month study period. The primary focus of interest was the incidence rate of aggressive events and coercive measures across the 
baseline period, the introduction of a systematic risk prediction and the additional training of the staff.

\section{Methods}

Study sites: The study was conducted on two 12-bed acute admission wards (an urban and a rural area) of the German speaking part of Switzerland. The study was approved the institutional review boards and the local ethical committees. All patients admitted to these wards during the study period were included.

Study design: We conducted a prospective non-randomised intervention study with before-after comparisons during 10 months. Following a three month baseline period, the first intervention was introduced (risk prediction). During the seventh month, the nursing staff on both wards received one week of training in aggression management. Thus, both interventions were implemented together during the final four month period of the study.

Interventions: The risk prediction consisted of an extended version of the Brøset-Violence-Checklist BVC (Almvik \& Woods 1998; Almvik, Woods et al. 2000). The extended version BVC-R requires nurses to rate six patient behaviours (confused, irritable, boisterous, verbally threatening, physically threatening and attacking objects) as being present (1) or absent (0). In combination with this scale a rating based on the nurses experience using a visual analogue scale (VAS) in the form of a slide rule was conducted. Nurses were requested to assess the probability that a given patient will become aggressive before the next half daily rating. The combined ratings produce a score between 0 (very low risk) and 12 (high risk). All patients are assessed at admission and twice daily for the three following days. A natural-frequency interpretation of the scoring results is provided comprising the following risk categories for a physical patient attack against staff: $<1$ in 100 (score 0-3), 1 in 100 (score 4-6), 1 in 10 (score 7-9) and 1 in 4 patients (score 10-12). For patients obtaining scores above 7 we recommended the discussion of preventive measures corresponding to general practice (e.g. observation, relaxation) and to consider immediate measures after multidisciplinary discussion for patients with scores of 10 or more. Further details on the psychometric properties of the instrument will be reported elsewhere (Abderhalden, submitted).

The standardised aggression management training followed the course devised by Oud in the Netherlands (Oud 1997). The five-day course is a skill-oriented, action-centred and problem-centred participating learning and includes experiential and knowledge based elements (e.g. the nature and prevalence of aggression, violence and sexual harassment, the use of aggression scales, preventive measures and strategies, de-escalation techniques, post-incident care and support, ethical aspects of violence management and safety management) and practical "hands-on" techniques such as holding methods, break-away techniques, control and restraint. The course content corresponds well to a recently suggested core curriculum for dealing with 
aggressive patients in psychiatry (Lee, Wright et al. 2001). The underlying principle of this training is the intent to minimise the risk of injury and harm on either side and to reduce the humiliating aspect of overwhelming aggressive patients. The approach includes the use of a team of three persons with clearly assigned roles (similar to the unambiguous role definition in cardiac arrest resuscitation) when dealing with patient aggression.

Outcome measures: The primary outcomes were the frequency of aggressive events and of coercive measures using a standardised reporting from. Event categories were: any aggressive event including verbal aggression, physical attacks against persons, any coercive measure. Aggressive incidents were recorded by the revised Staff Observation Aggression Scale (SOAS-R) (Nijman, Muris et al. 1999). The SOAS-R allows the registration of the provoking factor, the means used by the patient, the target of aggression, the consequence for victims, and the measures to terminate aggression. The scorings range from 0 to 22 points. Attacks were defined as recordings on the SOAS-R fulfilling the two criteria 1 ) the means of aggression = objects OR dangerous objects OR parts of the body AND 2) the target of the aggression $=$ a person other than the patient her- or himself. Coercive measures were recorded on a form developed on the basis of existing formats in general use in the area. Coercive measures were further categorised as a) coercive measures without prior aggression, and b) coercive measures following an aggressive incident. Incident rates were expressed as events per 100 hospitalisation days (unit of analysis $=$ occupied beds) and as days with event per ward (unit of analysis = ward). Secondary outcomes were the severity of aggressive events, measured by the SOAS-R, and by a visual analogue scale.

Data recording: The outcomes were recorded on specifically designed forms for three months at baseline and thereafter in the two intervention phases. Risk predictions were also recorded on specific report forms. A ruler for risk assessment was provided, which carried a simple visual analogue scale of $100 \mathrm{~mm}$ length on one side, and allowed to view the resulting score on the back. The nursing staff was instructed during several sessions about the correct use of forms and the ruler. Repetitive site visits were carried out to check compliance and consistency of reporting.

Data analysis: We report simple descriptive statistics with $95 \%$ confidence intervals for event ratios across the three study periods. Chisquare tests were employed to compare events rates, using hospitalisation days as the unit of analysis. Because this analysis does not account for the more nested nature of the data (i.e. patients nested within wards) we repeated the analysis with ward-days as the unit of analysis. In these calculations we determined whether the ward had remained event-free or one or more attacks / coercive measures had occurred on a given calendar day. We also repeated the analysis after excluding those two patients, who perpetrated an excessive number of attacks as compared to other patients committing violence. Severity of aggression was compared across periods by the Student's t-test. A twosides type I error probability of less than 0.05 was considered to indicate statistical significance. Analyses were carried out using SAS software (version 8.2 , SAS Inc, Cary, North Carolina, USA). 


\section{Results}

Patients: During the 10 month study period 576 patients $(41.3 \%$ females, mean age 38 years, range $15-88$ years) accounted for 721 admissions to the two acute psychiatric wards. These hospitalisations comprised of $38.5 \%$ voluntary and $61.5 \%$ involuntary admissions giving rise to a total of 7732 hospitalisation days. The length of stay ranged between one and 367 days (median 5, Mean 11.3) with some patients having been admitted prior to the start of the study. The ICD-10 diagnoses comprised of schizophrenia, schizo-type and delusional disorders $(38.3 \%)$, mood (affective) disorders $(15.6 \%)$, mental and behavioural disorders due to psychoactive substance use $(23.9 \%)$, neurosis and personality disorders $(14.9 \%)$, and other psychiatric ICD-10 categories $(7.3 \%)$.

Aggressive incidents: The 273 reported aggressive incidents included 131 physical attacks against persons and 14 events of auto-aggression. This corresponded to overall incidence rates of 3.51 (95\% CI $3.10-4.00$ ) aggressive incidents per 100 hospitalisation days, and 1.68 (95\% CI 1.41 $2.00)$ attacks against persons, respectively. The rate of days with occurrence of a violent attack against persons amounted to $15.6 \%$ per ward, or approximately one attack every six days. Sixty-seven individuals perpetrated the total of 131 attacks; two patients contributed 12 and 13 attacks. Thus, incidence rates across study periods were calculated including and excluding these two patients.

Coercive measures: The number of coercive measures amounted to 237 rendering an incidence rate per 100 hospitalisation days of $3.05(95 \%$ $2.67-3.46)$, of which 137 were undertaken in conjunction with an aggressive incident (rate $1.76,95 \% \mathrm{Cl} 1.46-2.10$ ).

Effect of interventions: The crude analysis including all patients and using hospitalisation days as the unit of analysis showed no significant reduction in the incidence rate of aggressive events and attacks against persons from baseline over the introduction of risk prediction to training the staff (Table 1). However, the rates of coercive measures per 100 hospitalisation days significantly declined from 4.0 , to 2.9 , and to 2.3 over the three study periods (Chi-square $\mathrm{p}=0.0008$, Mantel-Haenszel-trend-test $\mathrm{p}=0.0002$ ). The trend remained significant when the two most violent patients were excluded from the analysis, giving rise to rates of $3.2,3.0$ and 2.3 , respectively (chisquare $\mathrm{p}=0.09$, trend-test $\mathrm{p}=0.03$ ).

Table 1: Incidence rates per 100 hospitalisation days $(95 \% \mathrm{CI})$

\begin{tabular}{llllr}
\hline & Baseline & Risk prediction & Staff training & \multicolumn{1}{c}{$\mathbf{X}^{2} \mathbf{P}$} \\
\hline $\begin{array}{l}\text { All aggressive } \\
\text { incidents }\end{array}$ & $3.7(2.99$ to 4.44$)$ & $3.7(2.90$ to 4.56$)$ & $2.8(2.18$ to 3.47$)$ & 0.11 \\
$\begin{array}{l}\text { Attacks } \\
\begin{array}{l}\text { Coercive } \\
\text { asures }\end{array}\end{array}$ & $1.5(1.10$ to 2.04$)$ & $2.4(1.82$ to 3.17$)$ & $1.3(0.90$ to 1.80$)$ & 0.006 \\
\hline
\end{tabular}


Using the ward as the unit of analysis, we observed a significant reduction as to the days with occurrence of attacks again persons (trend-test p $=0.04)$ and as to the days with implementation of coercive measures against any patient (trend-test $\mathrm{p}=0.01$; Figure 1 ).

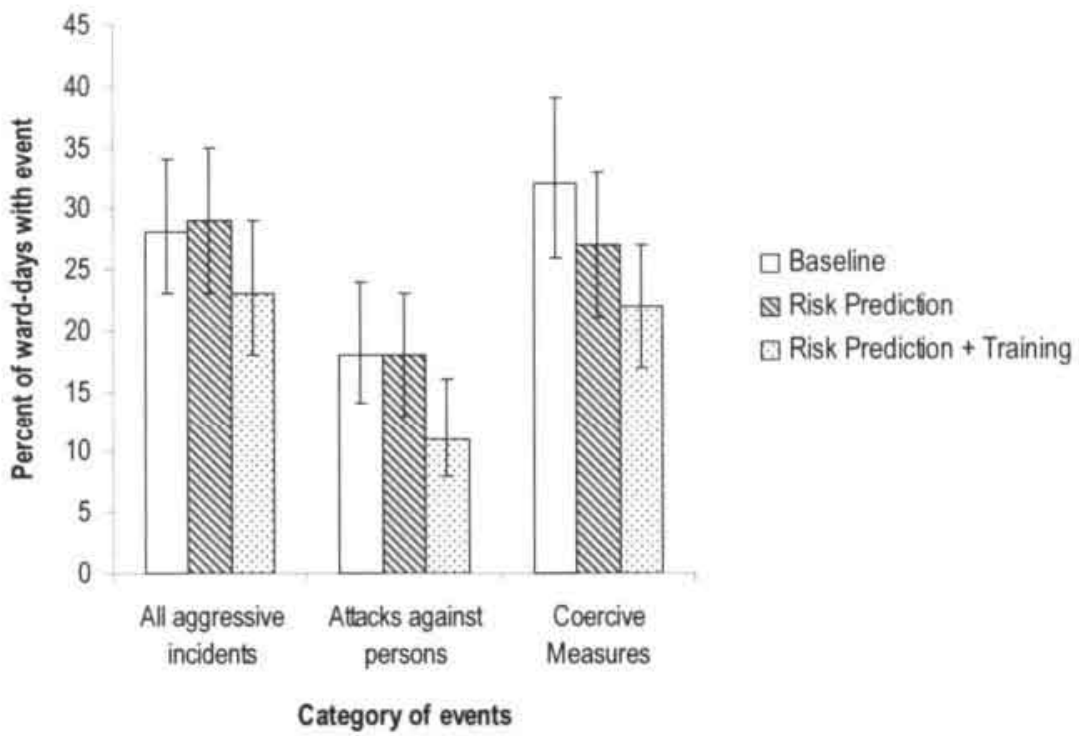

Figure 1: Percentage of hospitalisation days with events in the three study phases

It should be noted, that the two participating wards showed considerable differences as to the effects of the interventions. In one ward we observed a significant decline in days with occurrence of attacks against persons from $17.8 \%$, to $13.8 \%$, to $5.7 \%$ (trend-test $p=0.005$ ), while the rate of days with implementation of coercive measures remained similar (trend-test $\mathrm{p}=$ $0.24)$. On the other ward, the days with occurrence of coercive measures declined $(42.2 \%$ to $28.7 \%$, trend-test $p=0.03)$, while the rate of days with attacks against persons remained unchanged (trend-test $\mathrm{p}=0.72$ ).

The severity of all aggressive incidents as assessed by the SOAS-R remained unchanged across the three study periods (mean score 9.8 vs. 10.1 vs. $10.5, p=0.59$ ), as well as the SOAS-R score of those incidents identified as attacks against persons also remained unchanged (mean 12.9 vs. 13.2 vs. $11.8, \mathrm{p}=0.35$ ). However the subjective perception of severity as indicated on the visual analogue scale significantly declined after the training (mean 42.3 vs. 41.5 vs. 27.8 , chi-square $\mathrm{p}=0.005$ ). 


\section{Discussion}

We conducted a prospective intervention study on a rural and urban acute psychiatric ward to test the effect of two interventions on the incidence rate of aggressive events, attacks against persons and incidence rate of coercive measures. The primary aim of the present study was to achieve a more accurate estimate of the possible effect size of the interventions in preparation for a multi-centre randomised trail. Bearing the non-randomised nature of our study in mind, our data suggest the following tentative interpretations.

The rate of coercive measures steadily declined during the study period. After introducing the systematic risk prediction and the staff training in the management of aggression the incidence rate of coercive measures dropped considerably compared to that of the baseline period. This result remained consistent across all modes of calculation. In contrast the rate of attacks remained unaltered if hospitalisation days were the unit of analysis, but showed a significant trend towards reduction with ward as the unit of analysis. The ward perspective accounts for the fact that hospitalisation days are not truly independent events, but that the probability of aggressive events may correlate amongst patients being hospitalized on the same ward during the same calendar day. Finally, the severity of attacks as recorder by the SOAS-R remained unchanged, while the subjective severity as recorded on the visual analogue scale significantly declined after training the staff.

Converting our observed incidence rates to events per year per occupied bed, we observed 12.8 ( $95 \%$ CI 11.3 - 14.4) aggressive incidents, and $6.1(95 \% \mathrm{Cl} 4.9-7.3)$ attacks against persons. The rate of coercive measures per year and occupied bed amounted to $11.1(95 \% \mathrm{Cl} 9.7-12.6)$, and to 4.7 $(95 \%$ CI 3.7 - 5.5) undertaken without prior occurrence of an aggressive event. These figures are well within the range reported from other studies using the SOAS-R for reporting events (Nijman, Allertz et al. 1997). Our findings also corroborate other Swiss data reporting that $10 \%$ of patients on admission wards are responsible for all aggressive incidents (Geser 1999). For a 12-bed ward with a $95 \%$ occupancy rate the observed numbers correspond to about 2.8 aggressive incidents per week, 1.3 attacks against persons per week and 2.4 coercive measures per week. These are small numbers and, therefore, it is unlikely that staff will not note changes in the incidence rates unless large effect sizes are observed. It is also unlikely that the burden of recording these relatively rare events will cause a large reporting bias.

To our knowledge, this is the first study investigating the effect of a systematic risk prediction on the incidence rate of coercive measures and patient aggression on acute psychiatric wards. It is also the first study to investigate the combined effect of systematic risk prediction and staff training. Both interventions aim to augment the staff's ability to deal with potentially aggressive patients. Hereby, we hoped to alter staff-patient interactions in such a way that patients can be hospitalised with a minimised necessity to resort to coercion and with a reduced risk of violent outbursts. The data from the present study suggest that the rate of coercive measures declines, while the data on violent outbursts remain inconclusive. Moreover, given the non- 
randomised nature of our study, several limitations must be considered before the observed changes may be attributed to the specific interventions.

The major limitation of the present study is its intended nonrandomised nature. We carried out this study to obtain reasonable estimates for sample size considerations of the intended multi-centre randomised trial. The following biases may have distorted the results: First, selection bias, e.g. the admission of patients with differing aggressive potential during the study period. We attempted to correct this by excluding the two patients contributing the most numerous amounts of aggressive incidents. The consequence for the larger study is to increase the sample size by factor 10 and to assure that enrolment is spread out over calendar months to avoid seasonal biases. Second, reporting biases: During the 10 month study period, staff may have become more reluctant to record less severe events of aggression. We consider this a possibility that escaped out scrutiny during site visits and double checking of patient records. Third, attribution bias: It remains conceivable that other external factors (e.g. staff characteristics, occupancy rates, treatment regimen of the physicians, hospital policies, and season) confounded the results. While we recorded a large number of these variables (data not shown), to test for reporting compliance in the intended multi-centre trial, it remains impossible to discern these effects in the present design. Fourth, we treated hospitalisation days as independent events, omitting within-patient co linearity. While we attempted to acknowledge this by introducing an additional analysis based on the ward perspective, the fully appropriate handling would be nested design. These shortcomings, therefore, call for a considerably larger sample allowing multilevel-hierarchical modelling with hospitalisation days nested within patients nested within wards nested within hospitals. We suggest a multi-centre trial with a two-by-two factorial design to allow discerning the effects of either intervention alone and a combination thereof. This pilot study has shown that such a trial is feasible and that staff complies with the required additional effort towards recording events and data. The personnel participating in the trail has remarked on the practical value of the interventions in terms of enhanced capacities to manage violence and subjective feelings of greater confidence in treating potential and manifest aggressive patients. In the planned study these factors will be subjected to recording and testing.

We conclude that the training of staff in patient aggression management combined with a systematic recording of events and with a systematic risk prediction enhances the reduction of the incidence rate of coercive measures and may reduce the rate of violent patient attacks against persons. 


\section{References}

Abderhalden C, Needham I, Friedli TK, Poelmans J, Dassen T (2002) Perception of aggression among psychiatric nurses in Switzerland. Acta Psychiatrica Scandinavica 106 Supplementum (412):110-117

Almvik R, Woods P (1998) The Broset Violence Checklist (BVC) and the prediction of inpatient violence: Some preliminary results. Perspectives of Psychiatric Care 5(6):208-211

Almvik R, Woods P, Rasmussen K (2000) The Broset Violence Checklist: Sensitivity, Specificity and Interrater Reliability. Journal of Interpersonal Violence 15(12):1284-1296

Bensley L, Nelson N, Kaufman J, Silverstein B, Shields J (1995) Patient and staff views of factors influencing assaults on psychiatric hospital employees. Issues in Mental Health Nursing 16( 5):433-446

Blair D (1991) Assaultive behavior. Does provocation begin in the front office? Journal of Psychosocial Nursing and Mental Health Services 9(5):21-6

Carmel H. Hunter M (1989) Staff injuries from inpatient violence. Hospital Community Psychiatry $40(1): 41-46$

Chervinski D (1995) Workplace violence. Canadian Journal of Medical Technology 57(3):1325.

Chou KR, Lu RB, Mao WC (2002) Factors relevant to patient assaultive behavior and assault in acute inpatient psychiatric units in Taiwan. Archives of Psychiatric Nursing 16(4):187-95

Fisher WA (1994) Restraint and seclusion: A review of the literature. American Journal of Psychiatry 151:1584-1591

Gebhardt RP, Steinert T (1998) Innere Struktur der stationären psychiatrischen Krankenhausversorgung 22 Jahre nach der Psychiatrie-Enquete. Nervenarzt 69(9):791-8.

Geser AM (1999) Aggressionen von hospitalisierten psychisch Kranken: Eine systematische Evaluation von knapp 2000 Aggressionsfällen. Unpublished Inaugural-Dissertation zur Erlangung der Doktorwürde, Universität Zürich, Zürich

Grassi L, Peron L, Marangoni C, Zanchi P, Vanni A (2001) Characteristics of violent behaviour in acute psychiatric in-patients: a 5-year Italian study. Acta Psychiatrica Scandinavica 104(4):273-9

Kho K, Sensky T, Mortimer A, Corcos C (1988) Prospective study into factors associated with aggressive incidents in psychiatric acute admission wards. British Joumal of Psychiatry $172: 38-43$

Lanza M, Kayne H, Hicks C, Milner J (1994) Environmental characteristics related to patient assault. Issues in Mental Health Nursing 15( 3):319-35

Lee S, Wright S, Sayer J, Parr A-M, Gray R, Goumay K (2001) Physical restraint training for nurses in English and Welsh psychiatric intensive care and regional secure units. Journal of Mental Health 10(2):151-162

Needham 1, Abderhalden C. Dassen T. Haug HJ, Fischer JE (2002) Coercive procedures and facilities in Swiss psychiatry. Swiss Medical Weekly 132(19:20):253-258

Nijman HLI, Allertz WWF, à Campo JLMG, Ravelli DP (1997) Aggressive behavior on an acute psychiatric admission ward. European Journal of Psychiatry 11(1):104-114

Nijman HLI, Merckelbach HLGJ, Allertz WFF, à Campo JML (1997) Prevention of aggressive incidents on a closed psychiatric ward. Psychiatric Services 48(5):694-8

Nijman HLI, Muris P, Merckelbach HLGJ, Palmstierna T, Wistedt B, Vos AM, van Rixtel A, Allertz WWF (1999) The Staff Observation Aggression Scale - Revised (SOAS-R). Aggressive Behavior 25:197-209

Oud NE (1997) Aggression and psychiatric nursing. Amsterdam, Broens and Oud: Partnership for consulting and training 
Smith AD, Humphreys M (1997) Characteristics of in-patients transferred to a locked ward in a Scottish psychiatric hospital. Health Bulletin 55(2):77-82

Steinert T, Beck M, Vogel W, Wohlfahrt A (1995) Gewalttätige Patienten: Ein Problem für Therapeuten an psychiatrischen Kliniken? Nervenarzt 66:207-211

Steinert T, Vogel W. Beck M, Kehlmann S (1991) Aggressionen psychiatrischer Patienten in der Klinik: Eine 1-Jahres-Studie an vier psychiatrischen Landeskrankenhäusern. Psychiatrische Praxis 18(5):155-161 


\title{
CHAPTER 9
}

\author{
THE EFFECT OF A TRAINING COURSE IN AGGRESSION \\ MANAGEMENT ON THE PREVALENCE OF AGGRESSION AND \\ COERCIVE MEASURES IN INPATIENT PSYCHIATRIC SETTINGS: \\ A RANDOMISED CONTROLLED TRIAL
}

Needham I, Abderhalden C, Haug HJ, Dassen T, Halfens RJG, Fischer JE. Submitted for publication 


\section{Introduction}

Patient aggression in psychiatric institutions is a longstanding and common problem. In Swiss psychiatry approximately $10 \%$ of newly admitted patients in acute psychiatry are aggressive (Geser 1999). A recent Swiss study revealed a rate of 12.8 aggressive incidents per occupied bed per year (Needham, Abderhalden et al. 2004). Whereas on individual wards such incidents are relatively rare events a crude estimate using the above rates renders a total of approximately 18.700 aggressive incidents per annum for the 86 acute psychiatric wards in the area under investigation.

Patient aggression often leads to adverse consequences such as physical injury (Noble \& Rodger 1989) or physio-biological, emotional, emotional, cognitive and social sequelae (Needham, Abderhalden et al. 2004) with the recipients being predominantly nursing staff Geser 1999). According to the British Crime Survey (Budd 1999) the nursing profession is the second most vulnerable group, second only to the security and protective services. Coercion is a major intervention for handling patient aggression in psychiatry (Visalli, McNasser et al. 1997). Hence, patients may also suffer the consequences of their own behaviour. For these reasons approaches to reduce patient aggression and its consequences will be welcomed by patients and carers alike.

Staff training courses have been suggested and introduced as possible non-pharmacological interventions to reduce aggression. Numerous studies have been conducted on the efficacy of training courses in psychiatric settings using outcome measures such as rates of reduction of staff injury (Forster, Cavness et al. 1999), the severity of staff assaults (Ramirez, Bruce et al. 1981), enhanced knowledge regarding the management of aggression (IlkiwLavalle, Grenyer et al. 2002), physical skills of staff (Rice, Helzel et al. 1985), or more safety for patients (Turnbull, Aitken et al. 1990). A Dutch research group investigated the effect of the "threatening and destructive behaviour" training programme in a psychiatric setting and found a reduction of aggressive events by $46 \%$ in the intervention group compared with a reduction of $33 \%$ in the control group (van Rixtel, Nijman et al. 1997). In another study the implementation of a 5 day crisis prevention and intervention training produced favourable results regarding aggression rates in a psychiatric in-patient setting (Rice, Helzel et al. 1985). Also in a recently conducted non-randomised study in Switzerland no significant reduction of the incidence rates of aggressive events and attacks occurred after subjecting staff to a five day training course in aggression management (Needham, Abderhalden et al. 2004).

Coercive measures such as seclusion, restraint, or involuntary medication are common interventions used in the treatment and management of disruptive and violent behaviour (Sailas \& Fenton 2000). Thus, coercion is often used as an outcome variable of training courses in aggression management. A 50\%-reduction of patients' time spent in seclusion and/or restraint was observed after training staff in the early recognition of anxiety and agita- 


\section{Introduction}

Patient aggression in psychiatric institutions is a longstanding and common problem. In Swiss psychiatry approximately $10 \%$ of newly admitted patients in acute psychiatry are aggressive (Geser 1999). A recent Swiss study revealed a rate of 12.8 aggressive incidents per occupied bed per year (Needham, Abderhalden et al. 2004). Whereas on individual wards such incidents are relatively rare events a crude estimate using the above rates renders a total of approximately 18.700 aggressive incidents per annum for the 86 acute psychiatric wards in the area under investigation.

Patient aggression often leads to adverse consequences such as physical injury (Noble \& Rodger 1989) or physio-biological, emotional, emotional, cognitive and social sequelae (Needham, Abderhalden et al. 2004) with the recipients being predominantly nursing staff Geser 1999). According to the British Crime Survey (Budd 1999) the nursing profession is the second most vulnerable group, second only to the security and protective services. Coercion is a major intervention for handling patient aggression in psychiatry (Visalli, McNasser et al. 1997). Hence, patients may also suffer the consequences of their own behaviour. For these reasons approaches to reduce patient aggression and its consequences will be welcomed by patients and carers alike.

Staff training courses have been suggested and introduced as possible non-pharmacological interventions to reduce aggression. Numerous studies have been conducted on the efficacy of training courses in psychiatric settings using outcome measures such as rates of reduction of staff injury (Forster, Cavness et al. 1999), the severity of staff assaults (Ramirez, Bruce et al. 1981), enhanced knowledge regarding the management of aggression (IlkiwLavalle, Grenyer et al. 2002), physical skills of staff (Rice, Helzel et al. 1985), or more safety for patients (Turnbull, Aitken et al. 1990). A Dutch research group investigated the effect of the "threatening and destructive behaviour" training programme in a psychiatric setting and found a reduction of aggressive events by $46 \%$ in the intervention group compared with a reduction of $33 \%$ in the control group (van Rixtel, Nijman et al. 1997). In another study the implementation of a 5 day crisis prevention and intervention training produced favourable results regarding aggression rates in a psychiatric in-patient setting (Rice, Helzel et al. 1985). Also in a recently conducted non-randomised study in Switzerland no significant reduction of the incidence rates of aggressive events and attacks occurred after subjecting staff to a five day training course in aggression management (Needham, Abderhalden et al. 2004).

Coercive measures such as seclusion, restraint, or involuntary medication are common interventions used in the treatment and management of disruptive and violent behaviour (Sailas \& Fenton 2000). Thus, coercion is often used as an outcome variable of training courses in aggression management. A 50\%-reduction of patients' time spent in seclusion and/or restraint was observed after training staff in the early recognition of anxiety and agita- 
tion and the offering of choices to potentially aggressive patients (Morales \& Duphorne 1995). Another research group found a 13\% decrease in the use of restraints and a $55 \%$ reduction of duration in seclusion after implementing a aggression management training (Forster, Cavness et al. 1999) and Ramirez et al. also registered a $30 \%$ reduction in hours spent in restraint and seclusion (Ramirez, Bruce et al. 1981).

In spite of the important research work conducted, the generalisability of these studies is limited due to methodological shortcomings such as small sample sizes, the lack of utilisation of control groups and the lack of randomisation. In a comprehensive literature review on aggression management in mental health settings conducted by the Royal College of Psychiatry found from a data base of 10.000 publications only 68 rendering a satisfactory quality to be deemed as evidence. However, only 11 of these met the basic requirements for randomised controlled studies. The author group infers that no strong evidence-based conclusions can be drawn from the current studies on the effect of training courses on the rates of aggression (Royal College 1998).

Against this background a multi-centre randomised controlled trial was devised to evaluate the effect of an aggression-management training on the incidence and severity of aggressive events, attacks against persons and coercive measures. Here, we report on the first wave of recruitment.

\section{Method}

Study design: We conducted a prospective multi-centre randomised controlled trial employing waiting list randomisation. The study included data acquisition and data verification procedures pilot tested in an independent study involving two wards (Needham, Abderhalden et al. 2004). Ethical approval was granted by the local ethics committees.

In the present study we employed a pre-post design. The participating wards were randomly allocated to the intervention or to the control group. Randomisation was carried out by drawing previously prepared lots from closed envelopes. The control arm continued to acquire data on aggressive incidents for an additional three months observing the same procedures as during the baseline period. During a four-week period in the intervention wards, all staff members participated in the one-week aggression management course. The three months following the training month were regarded as the intervention period. The study design is depicted in Figure 1. The primary outcomes were rates of aggressive incidents, severe aggressive incidents, attacks against persons and coercive measures per 100 hospitalisation days. We tested the hypotheses that the intervention would reduce aggression rates and severity and coercion rates compared to the baseline period in the treatment group after adjusting for rate changes in the control group.

The intervention did not allow blinding staff receiving the intervention. Patients were solely informed about the data collection, but not about the nature of the intervention provided to staff members. 


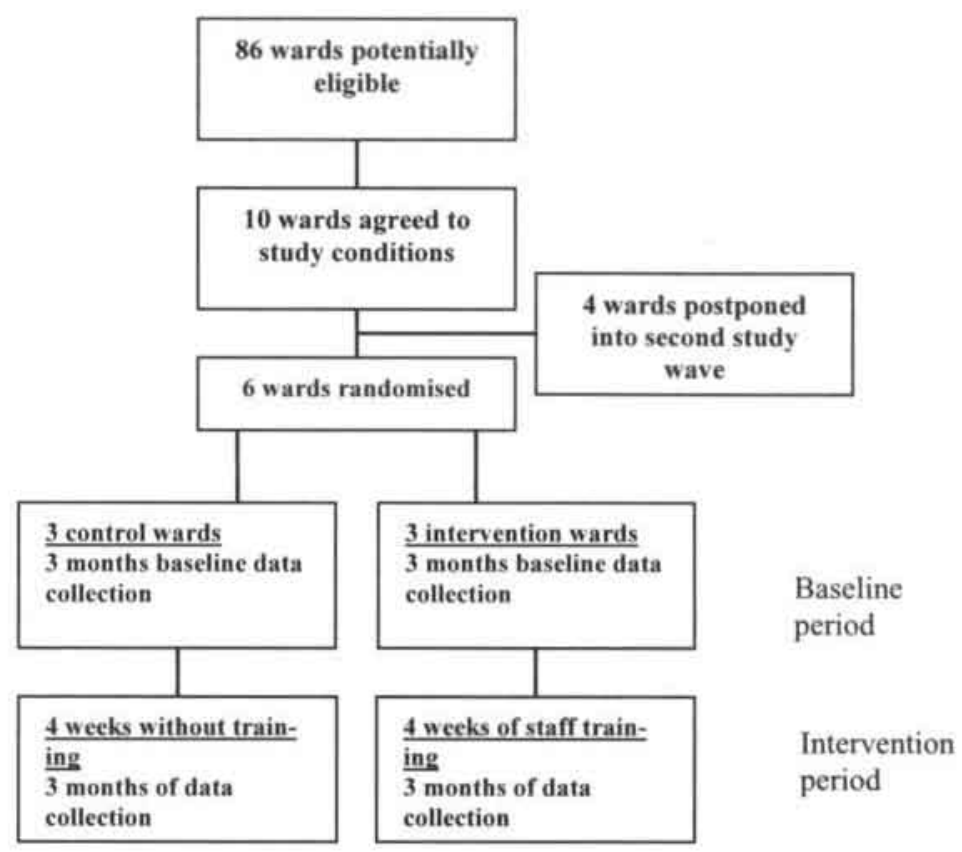

\section{Figure 1: Flow-chart of study}

Setting: To be eligible, acute psychiatric wards had to meet the following criteria for inclusion: The majority of patients have an acute psychiatric disorder, they are admitted directly onto the ward, they usually are discharged within less than three months, patients are between 18 and 65 years of age, and the ward is not specialised in the treatment of particular disorders (e.g. addiction). These conditions were met by 86 acute psychiatric admission wards in the German speaking part of Switzerland. Of these 10 consented to partake in the study and to adhere to the protocol. Due to financial constraints the first wave of recruitment was limited to six of these wards from four psychiatric hospitals (Figure 1). A power calculation based on a prior pilot study and the incidence rates estimated from a prevalence study in Switzerland (Needham, Abderhalden et al. 2004) suggested an $80 \%$ power to detect a reduction by $1 / 3$ in the rate of aggressive incidents at a type I error level of $p$ $<0.05$, while the full sized study including 10 wards would have yielded a power of $95 \%$. Two of the participating wards are located in urban and the other four in rural regions. The wards have between 17 and 19 beds and offer their services to the general public.

Intervention: The training program in the management of aggression developed by Nico Oud (Oud 1997) consisted of 24 lessons each lasting 50 minutes administered on five consecutive days. Great care was undertaken to ensure involvement of all nurses of the wards providing acute care. In some 
the consistency of reporting were checked on the regular site visits on each ward.

Data analysis: Patient characteristics across the two groups of wards were compared by the Wilcoxon test for continuous measures and the Chi Square or Fisher's exact test for categorical data. All tests were two-tailed. A probability for the type I Error of less than 0.05 was considered to indicate statistical significance. The primary outcomes were calculated as incidence rates per 100 hospitalisation days (unit of analysis = occupied beds). In case more than one event occurred within a three-hour period, the most severe event was recorded, independently for aggressive events, coercive measures and attacks against persons. Crude frequency counts revealed that six patients were involved an excessive number of events $(>11$ or $22 \%$ of all aggressive events and $>12$ or $23 \%$ of all coercive measures). These patients were considered as outliers in the analysis of incidence rates. Hence, crude incidence rates were calculated for each group and each period after excluding the outliers.

In the first step of the analysis we calculated the risk ratio and risk difference comparing the baseline-period and the intervention-period independently for the treatment group and the control group. The analysis revealed a non-stationary pattern in the control group, suggesting a secondary analysis in which we calculated the adjusted risk ratio and adjusted risk difference after controlling for changes between baseline-period and intervention-period in the control group. The reasoning for this adjustment is derived from pre-post designs using quantitative measures, where changes in the treatment group between baseline-period and intervention-period are compared to changes in the control group between baseline-period and intervention-period. For statistical testing and for calculation of confidence intervals, we considered events as the nominator and hospitalisation days as the denominator. For the secondary analysis we adjusted the nominator in the treatment group during the intervention period by the risk ratio of the control group comparing baseline-period to intervention-period.

Calculations were carried out using SPSS (version 12.0, SPSS Inc, Chicago, IL), and STATA (version 8, Stata corporation, College Station, TX).

\section{Results}

Patients: During the 6 month study period 985 patients $(42.8 \%$ females, mean age 38.5 years, $\mathrm{SD}=13.7$, range $12-94$ years) accounted for 1200 hospitalisations and 21715 hospitalisation days. Almost two thirds $(65 \%)$ were admitted on a voluntary basis with an average length of stay of 16.9 days $(\mathrm{SD}=22.6$, range $1-189$ days). The rather high proportion of involuntary admissions of around one third is usual for the German speaking part of Switzerland.

The ICD-10 diagnoses of the patients were F1 disorders due to psychoactive substance use $(302=30.7 \%)$, F2 schizophrenia, schizo-type and delusional disorders $(278=28.2 \%), F 3$ mood (affective) disorders $(159=$ 
the consistency of reporting were checked on the regular site visits on each ward.

Data analysis: Patient characteristics across the two groups of wards were compared by the Wilcoxon test for continuous measures and the Chi Square or Fisher's exact test for categorical data. All tests were two-tailed. A probability for the type I Error of less than 0.05 was considered to indicate statistical significance. The primary outcomes were calculated as incidence rates per 100 hospitalisation days (unit of analysis = occupied beds). In case more than one event occurred within a three-hour period, the most severe event was recorded, independently for aggressive events, coercive measures and attacks against persons. Crude frequency counts revealed that six patients were involved an excessive number of events $(>11$ or $22 \%$ of all aggressive events and $>12$ or $23 \%$ of all coercive measures). These patients were considered as outliers in the analysis of incidence rates. Hence, crude incidence rates were calculated for each group and each period after excluding the outliers.

In the first step of the analysis we calculated the risk ratio and risk difference comparing the baseline-period and the intervention-period independently for the treatment group and the control group. The analysis revealed a non-stationary pattern in the control group, suggesting a secondary analysis in which we calculated the adjusted risk ratio and adjusted risk difference after controlling for changes between baseline-period and intervention-period in the control group. The reasoning for this adjustment is derived from pre-post designs using quantitative measures, where changes in the treatment group between baseline-period and intervention-period are compared to changes in the control group between baseline-period and intervention-period. For statistical testing and for calculation of confidence intervals, we considered events as the nominator and hospitalisation days as the denominator. For the secondary analysis we adjusted the nominator in the treatment group during the intervention period by the risk ratio of the control group comparing baseline-period to intervention-period.

Calculations were carried out using SPSS (version 12.0, SPSS Inc, Chicago, IL), and STATA (version 8, Stata corporation, College Station, TX).

\section{Results}

Patients: During the 6 month study period 985 patients $(42.8 \%$ females, mean age 38.5 years, $\mathrm{SD}=13.7$, range $12-94$ years) accounted for 1200 hospitalisations and 21715 hospitalisation days. Almost two thirds $(65 \%)$ were admitted on a voluntary basis with an average length of stay of 16.9 days $(\mathrm{SD}=22.6$, range $1-189$ days). The rather high proportion of involuntary admissions of around one third is usual for the German speaking part of Switzerland.

The ICD-10 diagnoses of the patients were F1 disorders due to psychoactive substance use $(302=30.7 \%)$, F2 schizophrenia, schizo-type and delusional disorders $(278=28.2 \%), F 3$ mood (affective) disorders $(159=$ 
$16.1 \%$ ), F4 to F6 neurotic, stress-related and somatoform disorders, behavioural syndromes associated with physiological disturbances and physical factors, and personality disorders of adult personality and behaviour $(171=$ $17.4 \%$ ), mental retardation, disorders of psychological development, behavioural and emotional disorders with onset occurring in childhood and adolescence $(60=6.1 \%)$, and missing $(15=1.5 \%)$. Patients in the control and intervention group were comparable in terms of age, length of stay, sex and admission mode (voluntary or involuntary). Table 1 compares patient characteristics across groups.

Aggressive events and coercive measures: During the six month study period in the six participating wards, a total of 409 aggressive events were recorded (control group 250, intervention group 159), of these 242 had a SOAS-R score above 9 (control group 139, intervention group 103). Patients perpetrated 139 attacks against persons (control group 78, intervention group 61 ), and staff induced 481 coercive measures (control group 145, intervention group 336).

During baseline, the treatment wards recorded fewer aggressive events $(p<0.05)$ and more coercive measures $(p<0.05)$, suggesting that the randomisation procedure failed to guarantee the even allocation of characteristics in the groups. Moreover, the crude analysis showed that a minority of patients were involved in an over proportionate number of aggressive events and coercive measures. Four patients exclusively belonging to the intervention group were subjected to $108(23 \%)$ of the 481 coercive measures. Two of these patients and another two from the control group contributed $91(22 \%)$ of all aggressive incidents. These six patients were excluded from further analysis. Figure 2 presents the incidence rates for the four outcome measures after excluding these patients with excessive numbers of aggressive events or coercive measures. 


\begin{tabular}{|c|c|c|c|}
\hline & $\begin{array}{l}\text { Control } \\
\text { group }\end{array}$ & $\begin{array}{c}\text { Intervention } \\
\text { group }\end{array}$ & Test \\
\hline Patients (n) & 450 & 535 & \\
\hline Hospitalisations (n) & 570 & 630 & \\
\hline Total hospitalisation days $(\mathrm{n})$ & 10600 & 9820 & \\
\hline Mean age of patients (SD) & $37.98(14.9)$ & $38.98(12.6)$ & p $=$ n.s. ${ }^{2}$ \\
\hline Mean length of stay in days (SD) & $18.6(26.5)$ & $15.6(18.4)$ & $\mathrm{p}=\mathrm{n} . \mathrm{s}^{\mathrm{t}}$ \\
\hline Sex (male / female) & $58.7 \% / 41.3 \%$ & $55.5 \% / 44.5 \%$ & $\mathrm{p}=\mathrm{n} . \mathrm{s}^{\prime}$ \\
\hline Voluntary / involuntary admission & $64.8 \% / 35.0 \%$ & $65.7 \% / 34.3 \%$ & $\mathrm{p}=\mathrm{n} . \mathbf{s}^{\prime}$ \\
\hline \multicolumn{4}{|l|}{ Psychiatric diagnoses (ICD 10) } \\
\hline FI disorders due to psychoactive substance use & $121(26.9 \%)$ & $181(33.8 \%)$ & \\
\hline $\begin{array}{l}\text { F2 schizophrenia, schizo-type and delusional } \\
\text { disorders }\end{array}$ & $140(31.1 \%)$ & $138(25.8 \%)$ & \\
\hline F3 mood (affective) disorders & $74(16.4 \%)$ & $85(15.9 \%)$ & \\
\hline $\begin{array}{l}\text { F4 to F6: neurotic, stress-related and somatoform } \\
\text { disorders, behavioural syndromes associated } \\
\text { with physiological disturbances and physical } \\
\text { factors, and personality disorders of adult per- } \\
\text { sonality and behaviour }\end{array}$ & $73(16.2 \%)$ & $98(18.3 \%)$ & \\
\hline $\begin{array}{l}\text { Other: mental retardation, disorders of psycho- } \\
\text { logical development, behavioural and emotional } \\
\text { disorders }\end{array}$ & $28(6.2 \%)$ & $32(6.0 \%)$ & \\
\hline Diagnosis missing & $14(3.1)$ & I $(0.2)$ & \\
\hline All diagnoses & $450(99.9 \%)$ & $535(100 \%)$ & p $=$ n.s. ${ }^{\dagger}$ \\
\hline
\end{tabular}

Chi Square, ${ }^{;}$Wilcoxon rank sum test

Aggressive events and coercive measures: During the six month study period in the six participating wards, a total of 409 aggressive events were recorded (control group 250, intervention group 159), of these 242 had a SOAS-R score above 9 (control group 139, intervention group 103). Patients perpetrated 139 attacks against persons (control group 78, intervention group 61 ), and staff induced 481 coercive measures (control group 145, intervention group 336).

During baseline, wards in the treatment group recorded fewer aggressive events $(\mathrm{p}<0.05)$ and more coercive measures $(\mathrm{p}<0.05)$, suggesting that the randomisation procedure failed to guarantee the even allocation of characteristics in the groups. Moreover, the crude analysis showed that a minority of patients were involved in an over proportionate number of aggressive events and coercive measures. Four patients exclusively belonging to the intervention group were subjected to $108(23 \%)$ of the 481 coercive measures. Two of these patients and another two from the control group contributed $91(22 \%)$ of all aggressive incidents. These six patients were excluded from further analysis. Figure 2 presents the incidence rates for the four outcome measures after excluding these patients with excessive numbers of aggressive events or coercive measures. 
Aggressive incidents

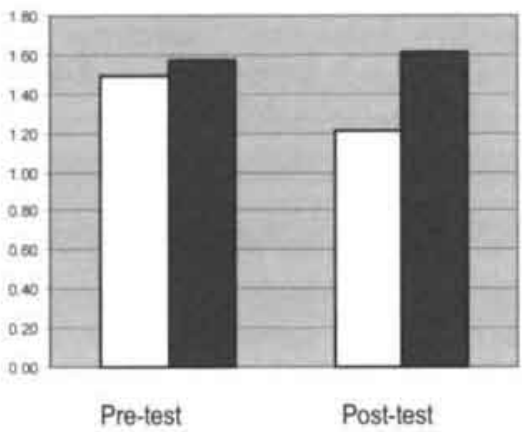

Attacks

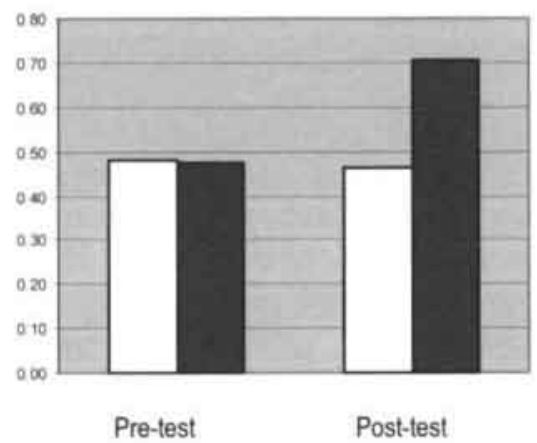

Aggressive incidents $>9$

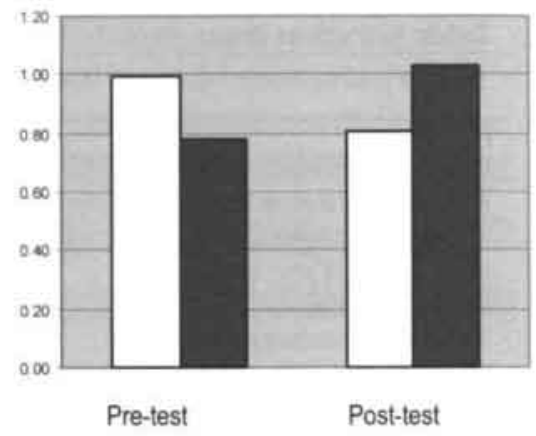

Coercive measures

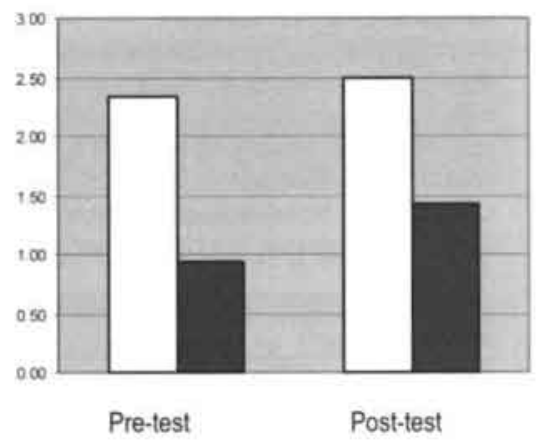

$\square=$ Intervention group $\square=$ Control group

Figure 2: Incidence rates of events per 100 hospitalisation days after exclusion of outliers

The incidence rate for aggressive events declined from baseline through intervention in the treatment group while it remained constant in the control group. However, the decline did not reach statistical significance (relative risk reduction $19.3 \%, 95 \% \mathrm{Cl}-16 \%$ to $44 \%$ ). The incidence rates of severe aggressive events decreased in the intervention group and increased in the control group, but neither change alone reached statistical significance. While attack incidence rates remained constant in the intervention group, they tended to increase in the control group $(p=0.11)$. Coercive measures were applied more often during the intervention period in the control group than at baseline $(\mathrm{p}=0.016)$.

Reasoning that without intervention incidence rates in the control group should remain stationary, we controlled for the observed trends in the control group in the secondary analysis. This secondary analysis - adjusting the rates observed during the intervention period in the treatment group for changes observed in the control group - revealed a non-significant reduction in aggressive events (adjusted risk ratio $=0.79,95 \% \mathrm{CI} 0.55-1.14, \mathrm{p}=$ 
0.19 ), a significant reduction in severe aggressive events (adjusted risk ratio $=$ $0.63,95 \% \mathrm{CI} 0.38-0.99, \mathrm{p}=0.048$ ), fewer attacks against persons (adjusted risk ratio $=0.63,95 \% \mathrm{CI} 0.29-1.28, \mathrm{p}=0.18)$ and a significant reduction in coercive measures (adjusted risk ratio $=0.70,95 \% \mathrm{Cl} 0.51-0.95, \mathrm{p}=0.017$ ). Figure 3 compares the adjusted risk ratios and their confidence intervals.

All aggression
Aggression $>9$

Attacks

Coercion

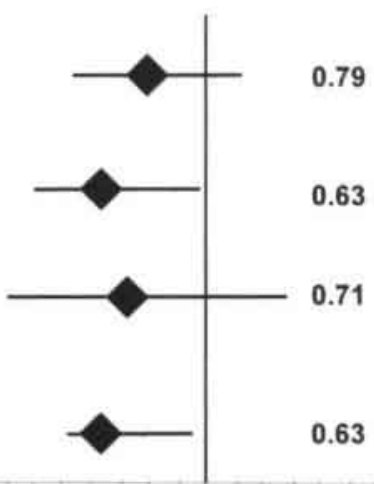

$\begin{array}{lllllllll}0 & 0.2 & 0.4 & 0.6 & 0.8 & 1 & 1.2 & 1.4 & 1.6\end{array}$

Figure 3: Risk ratios treatment vs. baseline after adjusting for changes in the control group

Severity of aggressive incidents: The mean severity of the aggressive incidents as measured by the SOAS-R remained constant in the intervention group $(\mathrm{t}=-0.6, \mathrm{p}=0.55)$ and increased in the control group $(\mathrm{t}=4.2, \mathrm{p}<$ 0.001 , Table 2). The mean of the visual analogue scale depicting nurses' subjective assessment of the severity of aggressive incidents markedly dropped in the intervention group $(\mathrm{t}=-3.0, \mathrm{p}=0.003)$ and remained constant in the control group $(\mathrm{t}=0.44, \mathrm{p}=0.66)$.

Table 2: Severity of aggressive incidents

\begin{tabular}{lcccc} 
& \multicolumn{2}{c}{ Mean of SOAS-R (SD) } & \multicolumn{2}{c}{ Mean of VAS (SD) } \\
\hline & $\begin{array}{l}\text { Baseline } \\
\text { period }\end{array}$ & $\begin{array}{l}\text { Intervention } \\
\text { period }\end{array}$ & $\begin{array}{l}\text { Baseline } \\
\text { period }\end{array}$ & $\begin{array}{l}\text { Intervention } \\
\text { period }\end{array}$ \\
\hline Intervention wards $(\mathbf{n}=\mathbf{3})$ & $11.0(5.2)$ & $10.6(4.6)$ & $40.2(24.7)$ & $28.2(22.2)$ \\
Control wards $(\mathbf{n}=\mathbf{3})$ & $7.5(4.4)$ & $10.0(4.7)$ & $16.8(18.1)$ & $17.9(21.5)$ \\
\hline
\end{tabular}




\section{Discussion}

This prospective multi-centre randomised controlled clinical trial was conducted to test the effect of a training course in aggression management administered to the personnel on the rates of aggressive incidents, attacks, coercive measures and on the severity of the aggressive incidents. The main findings can be summarised as following: After adjusting the rates in the intervention group for the change in incidence rates in the control group, significant reductions of severe aggressive incidents and coercive measures were observed. The severity of aggressive incidents as measured by the SOAS-R remained stable in the intervention group and rose in the control group. However, the estimation of the severity by the nurses employing the more subjective Visual Analogue Scale dropped sharply in comparison to the control group.

After adjusting the event rates a change in rates of all aggressive incidents was found but failed to reach statistical significance $(p=0.19)$. However, one must bear in mind that aggressive behaviour of a more "minor" nature (shouting or swearing without consequences for other persons) is included in this incidence rate. The incidence rate including aggressive events expressed as frequencies of aggressive incidents per bed per year of 6.3 in the baseline and 6.2 in the intervention period are considerably lower than Swedish rates of 13.8 (Palmstierna, Huitfeldt et al. 1991), Dutch rates of 17.8 (Nijman, Allertz et al. 1997), or Swiss rates of 12.8 (Needham, Abderhalden et al. 2004). It should be noted that the adjusted estimate of risk reduction for all aggressive events is within the vicinity of the effect size deemed clinically relevant when designing the study. The considerably lower aggression rate than anticipated in the present trial impeded the chance to achieve statistical significance with the given sample size. It could also be argued that effect of the training course may be more pronounced when tested in settings with higher prevalence rates of aggression.

The decline in the rates of coercive measures in the intervention group as opposed to a slight rise in the control group after adjustment is in keeping with other studies reporting coercion rates after trainings (Ramirez, Bruce et al. 1981; Morales \& Duphorne 1995; Forster, Cavness et al. 1999; Needham, Abderhalden et al. 2004). This decline may well be attributed to deescalation techniques treated in the training and to the general sensitisation of staff towards aggression. However, one must bear in mind that the initial coercion rates in the intervention group were much higher than in the control group. Obviously, a reduction of coercion from a high rate is easier to achieve than from a low one.

The average severity of aggressive incidents in this study ranged from $7.5(\mathrm{SD}=4.4)$ to $11.0(\mathrm{SD}=5.2)$ with an average of $9.6(\mathrm{SD}=4.9)$ across groups and study periods. These scores correspond to results derived from psychiatric hospitals in the Netherlands and Belgium (Nijman, Evers et al. 2002) with an observed an average severity of $10.4(\mathrm{SD}=5.0)$ on the SOAS-R. Although the intervention produced only minor changes in the severity of aggression as recorded by the SOAS-R, the subjective appraisal of 
incident severity by the visual analogue scale decreased dramatically in the intervention group. This may reflect an attitudinal change pointing to more subjective security in dealing with aggression or may possibly indicate less stress on part of the nurses during occurrence of aggressive events. This is a positive development given the adverse consequences of patient aggression on nurses such as symptoms of Post Traumatic Stress Disorder (Richter \& Berger 2000) or some psychiatric nurses' intentions to leave the profession altogether (Lanza 1983). Originally we had hypothesised that the reduction of severity of incidents would be attributable to enhanced de-escalating skills. We conclude after statistical adjustment that the training does reduce the rates of the more severe aggressive events but - once patients have engaged in aggressive behaviour - not the objective severity.

Several caveats pertain to the present study. In spite of randomisation the overall incidence rates of aggression and coercive measures markedly differed between the groups in the baseline period of the study. The increase of severe aggressive events in the control group in the post-test period revealed an unexpected pattern for which we have no explanation. An inspection of the temporal distribution of the incidents to detect any seasonal variation of aggression (Morken \& Linaker 2000) offered no insight into this erratic arrangement of incidents. A similar phenomenon (an increase in the number of difficult patients in the intervention period) has been reported elsewhere (Rice, Helzel et al. 1985) and may be indicative of the unpredictable distribution of aggression in acute psychiatry.

Due to the small number of participating wards randomisation was unable to guarantee approximately equal rates in the intervention and control groups. Because patients in the two groups were comparable as to the distribution of gender, admission status and psychiatric diagnosis, these differences most likely reflect variation in treatment regimes as to patients at risk of aggressive behaviour. Although this study employs one of the largest sample sizes in the field, randomisation failed to safeguard against these problems.

A further limitation is the existence of an unknown external factor which caused an increase in aggressive events in the control group wards during the study period. The standard statistical procedure to control the data in the intervention group with the data of the control group rests on the assumption that the unknown external factor causing an increase in aggressive events in the control group equally affects the intervention group. The increase in the control group may also be due to unexpectedly large random fluctuations in the distribution of aggressive events. The present study revealed both a smaller incidence rate of aggressive events and a considerably larger heterogeneity in distribution as observed during our pilot studies assessing the feasibility of the protocol and during our pilot study evaluating incidence rates and distribution amongst Swiss psychiatry hospitals. Only a substantial increase in sample size (about 3 fold) would remedy this problem.

Finally, whilst numerous measures were conducted to assure compliance to the study protocol (standardised instruction of the nursing staff, control visits, plausibility checks of the incoming data) it is still possible that 
some reporting bias may have occurred. It is conceivable that wards differed as to their tendency to report all minor incidents. For these reasons it appears more appropriate to consider aggressive incidents scoring more than 9 points on the SOAS-R as a more objective measure. Furthermore, in spite of standardisation of the training course in aggression management and of two follow up sessions by the trainers in the individual wards, it is also possible that the staff may have responded in different ways to the education measure.

Bearing the mentioned caveats in mind, an interpretation of the findings suggest that the training course employed for aggression-management may yield an influence on aggression and coercion rates and on the subjective perception of aggression severity. Converting the adjusted risk ratios to "numbers needed to treat" (NNT) yields estimates of one severe aggressive event prevented per 270 hospitalisation days or for the average sized ward with 17 beds in our study approximately 2 such events per month. This reduction occurs from a baseline of about 6 such events per month in an average sized ward (adjusted risk ratio 0.63). Clearly, these events are too rare for an individual staff member to be able to notice the reduction as clinically relevant. However, extrapolating this estimate to the 86 acute admission wards in the German speaking part of Switzerland (a catchment area of about 5 million inhabitants) renders the grand total of approximately 2000 avoided severe aggressive incidents per annum. It should also be noted that the training ensued in a marked decline in subjective perception of the severity of aggressive events. This perception may indicate a possible subjective effect which transcends the results derived with the quantitative methods employed in this study. 


\section{References}

Budd T (1999) Violence at work: Findings from the British Crime Survey. London, Home Office: 76

Forster PL, Cavness C, Phelps MA (1999) Staff training decreases use of seclusion and restraint in an acute psychiatric hospital. Archives of Psychiatric Nursing 13(5):269-271

Geser AM (1999) Aggressionen von hospitalisierten psychisch Kranken: Eine systematische Evaluation von knapp 2000 Aggressionsfallen. Unpublished Inaugural-Dissertation zur Erlangung der Doktorwürde, Universität Zürich, Zürich

Ilkiw-Lavalle O, Grenyer BF, Graham L (2002) Does prior training and staff occupation influence knowledge acquisition from an aggression management training program? International Journal of Mental Health Nursing 11(4):233-9

Lanza ML (1983) The reactions of nursing staff to physical assault by a patient. Hospital Community Psychiatry 34(1):44-7.

Morales E, Duphorne PL (1995) Least restrictive measures: alternatives to four-point restraints and seclusion. Journal of Psychosocial Nursing and Mental Health Services 33(10):13-6

Morken G, Linaker OM (2000) Seasonal variation of violence in Norway. American Journal of Psychiatry 157(10):1674-8

Needham I, Abderhalden C, Halfens R, Fischer J, Dassen T O Non somatic effects of patient aggression on nurses: A systematic literature review. Accepted

Needham I, Abderhalden C, Meer R, Dassen T, Haug HJ, Halfens RJG, Fischer JE (2004) The effectiveness of two interventions in the management of patient violence in acute mental inpatient settings: Report on a pilot study. Journal of Psychiatric and Mental Health Nursing. Journal of Psychiatric and Mental Health Nursing 11(5):595-601

Nijman H, Evers C, Merckelbach H, Palmstierna T (2002) Assessing aggression severity with the revised staff observation aggression scale. Journal of Nervous and Mental Disease 190(3): 198-200

Nijman HLI, Allertz WWF, à Campo JLMG, Ravelli DP (1997) Aggressive behavior on an acute psychiatric admission ward. European Journal of Psychiatry 11(1):104-114

Nijman HLI, Muris P, Merckelbach HLGJ, Palmstierna T, Wistedt B, Vos AM, van Rixtel A, Allertz WWF (1999) The Staff Observation Aggression Scale - Revised (SOAS-R). Aggressive Behavior 25:197-209

Noble P, Rodger S (1989) Violence by psychiatric in-patients. British Journal of Psychiatry $155 ; 384-390$

Oud NE (1997) Aggression and psychiatric nursing. Amsterdam, Broens and Oud: Partnership for consulting and training

Palmstierna T (2003) Cut-off point of SOAS-R. Personal Communication

Palmstierna T, Huitfeldt B, Wistedt B (1991) The relationship of crowding and aggressive behavior on a psychiatric intensive care unit. Hospital Community Psychiatry 42(12):12371240

Ramirez LF, Bruce J, Whaley M (1981) An educational program for the prevention and management of disturbed behavior in psychiatric settings. Journal of Continuing Education in Nursing 12(5):19-21

Rice MF, Helzel MF, Varney GW, Quinsey VI (1985) Crisis prevention and intervention training for psychiatric hospital staff. American Journal of Community Psychology 13:289-304

Richter D, Berger K (2000) Physische und psychische Folgen bei Mitarbeitern nach einem Patientenübergriff: Eine prospektive Untersuchung in sechs psychiatrischen Kliniken. Arbeitsmedizin, Sozialmedizin, Umweltmedizin 35(8):357-362 
Royal College of Psychiatrists (1998) Management of imminent violence: clinical practice guidelines to support mental health services. Occasional Paper OP41. London, Royal College of Psychiatrists College Research Unit

Sailas E, Fenton M (2000) Seclusion and restraint for people with serious mental illnesses. Cochrane Database of Systematic Reviews(2):CD001163

Turnbull J, Aitken I, Black L, Patterson B (1990) Turn it around: Short-term management for aggression and anger. Joumal of Psychosocial Nursing and Mental Health Services 28(6):6-10, 13

van Rixtel A, Nijman H, Jansen A (1997) Agressie en psychiatrie. Heeft training effect? Verpleegkunde 12(2):111-119

Visalli H, McNasser G, Johnstone L, Lazzaro C (1997) Reducing high-risk interventions for managing aggression in psychiatric settings. Journal of Nursing Care Quality 11(3):54-61 


\section{ChaPter 10}

GENERAL DISCUSSION 
This final chapter summarises the main findings and critically reflects methodological and theoretical aspects of the dissertation. Implications are stated, and finally areas for further research delineated.

\section{Main findings}

This study set out to test the following hypotheses:

- The training course will lead a) to a more positive perception of aggression, b) to nurses experiencing patient aggression in a less severe way, and c) to a rise in confidence in handling situations involving aggressive patients by the individual nurses.

- The training course will reduce a) aggressive incidents, b) attacks against persons and c) coercive measures.

Hypothesis testing in the various studies led to the following results.

\section{The influence of the training course on nurses}

The training course had no effect on the perception of aggression as measured by the shortened Perception of Aggression Scale (Needham, Abderhalden et al. 2004) on nurse trainees or on experienced psychiatric nurses (Chapters 6 and 7 respectively). Similarly, no training course effect was found on nurses' adverse feelings (Chapter 8). However, indirect indications for a change in perception were found regarding the perception of the severity of aggression: The subjective severity of aggressive events as recorded on a visual analogue scale (VAS) - as compared with the objective measure employing the scoring system of the SOAS-R - declined after completing the training course (Chapters 8 and 9). A confidence change was observed in the student nurses having absolved the training course compared with the control group (Chapter 6).

\section{The influence of the training course on patients and on nursing practice}

The pilot study on two acute admission wards (Chapter 8) demonstrated a statistically significant reduction of coercion rates but not of aggression rates or rates of attacks against persons. However, a trend towards reduction of aggressive incidents across the three study periods (baseline, the utilisation of a systematic risk assessment for patient aggression, and after the training course) was registered (Chapter 8 ). Despite various caveats (for example non-randomisation, small number of wards, or the inclusion of a second intervention rendering the interpretation of the training course alone difficult) the study results were encouraging enough to engage on the randomised controlled trail.

The results of the randomised controlled trial (Chapter 9) demonstrate effects attributable to the training course. After excluding outliers and adjusting the event rates in the intervention group to the pattern observed in the control group statistically significant reductions of severe aggressive incidents and coercive measures were found in the intervention group compared with the control group. No statistically significant effects were found on all 
aggressive events (including "minor" patient aggression such as shouting or swearing without consequences for other persons) or on attacks against persons. The "objective" measure of the severity of aggressive incidents remained stable but the subjective assessment of incident severity decreased significantly in the intervention group. The study results suggest that the training course contributes to a reduction of severe aggression, the subjective perception of aggression by the nurses, and coercion. These results are illustrated graphically in Figure 1.

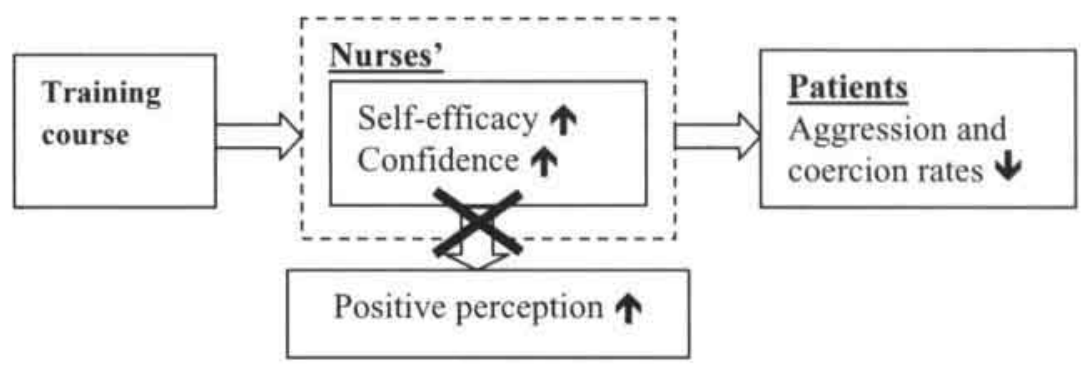

Figure 1: The effects of the training course in aggression management

\section{Methodological reflections}

The following considerations refer to the adequacy of the procedures employed in the studies.

\section{The effects of the training course on the nurses}

The lack of attitude change after the training course as measured by the POAS-S on student nurses (Chapter 6) and on experienced psychiatric nurses (Chapter 7) may reflect the real results or be attributed to various methodological difficulties or shortcomings. These study findings point to the assumption that scales based on the POAS (Jansen, Dassen et al. 1997) such as the POAS-S and the Tolerance Scale measure traits (stable or consistent characteristics or attitudes) and not states (states of mind which fluctuate or change as a result of the momentary context). This difficulty is especially pronounced in the case of the POAS-S (Needham, Abderhalden et al. 2004) which was developed on the basis of its stability over time. Thus the time frame of three months was probably too optimistic to expect any kind of change.

The lack of change on experienced mental health nurses' adverse feelings as measured by the IMPACS (Chapter 4) may be attributable to various methodological issues. The investigation of the effect of the training of carers' adverse feelings unfolded in three stages starting with a systematic review of adverse effects (Chapter 3), through the development of an appropriate instrument (Chapter 4) and finally the randomised controlled trial 
(Chapter 7). Reasons for the non significant findings may thus be located in any one of these stages. One possible error was the inclusion of articles containing adverse experiences of nurses from domains other than psychiatric nursing in the systematic review. There are some indications - for example the low occurrence or the lack of some non-somatic effects e.g. frustration or powerlessness in psychiatric settings - that psychiatric nurses may react to patient aggression in a different way than nurses from other domains (Chapter 3 ). If the focus had been placed on psychiatric nurses only possibly more representative effects could have been identified. Whilst every effort was made to establish the validity and reliability of the "Impact of Patient Aggression on Carers Scale" (IMPACS) time and logistic restraints prevented the consolidation of its psychometric properties. The test and retest stability and its use on known groups would have been a great asset to assist the interpretation of the results found in the randomised controlled trial. Due to the fact that the IMPACS was used for the first time in this dissertation no comparative data is available assist the interpretation of the results. Furthermore, the IMPACS may lack responsiveness - the ability to detect clinically important changes (Moons, Marquet et al. 2004). Prima vista it would appear that the nurses in this sample score at the bottom end of the scale. Should this assumption be true - and the present knowledge base does not allow any discernment on this matter - then the scorings may be so low ("floor" effect) that little or no improvement is possible.

Furthermore, the time frame of three months may have been insufficient to allow for change.

The drop in the subjectively assessed severity of incidents of aggression using the VAS as compared with the concurrently registered more objective measure of the SOAS-R indicates some change to nurses' subjective experience of aggression. This change indicates a modification in the perception of aggression after the training course. The measurement of this perception change is possibly attributable to the fact that the nurses having experienced the aggressive incident made their assessment under the impression of the incident itself. The immediate assessment helps to avoid recall bias and is potentially a more robust measure of the perception of change than the administration of a questionnaire three months after termination of the training course. However, the fall in subjectively assessed severity is the average of all assessments in the intervention group is not strictly comparable to the measurements of perception of the nurses on an individual basis and using a repeated measure design.

\section{The effect of the training course at the patient level}

Data analysis - after statistical adjustment - demonstrated that the training course led to a reduction of severe aggressive incidents and coercive measures. Also the nurses' subjective perception of the severity aggression sank. However, the course did not lead to a reduction of the objective severity of aggressive incidents or to a reduction in overall aggressive incidents and attacks against persons. In spite of these mainly positive results various methodological issues must be critically addressed. 
Whilst every effort was made to ensure the accurate registration of events such as the instruction of the personnel, cross checks to ascertain if aggressive events recorded in the nursing notes were also registered on the appropriate aggression forms, it is possible that reporting bias may have occurred.

Before consenting to participate in the studies hospital management agreed to refrain from inducing changes to practice for the duration of the study. During the pilot study (Chapter 8) one of the two participating acute admission wards replaced a senior physician. This change was accompanied by a fundamental change in the use of pharmacological substances with the new physician prescribing less medication than his predecessor. In the randomised controlled trial the rates of aggressive incidents and coercive measures varied significantly at baseline, very probably due to the fact that the unit of randomisation was the ward. The different prevalence rates of aggression and coercion were also probably attributable to the relatively short duration of the investigation. This duration of three months was a necessary trade off between an adequate time frame to record an ample amount of aggressive incidents and the condition sine qua non of holding all parameters bar the intervention stable. These remarks point to the logistic challenges and difficulties involved in conducting empirical research in a complex and dynamic environment such as an acute admission ward. If the characteristics of the wards had been more stable or the prevalence of events more balanced the results could have been more positive.

The decline in the subjective severity of aggressive events attributable to the training course may be interpreted in two possible ways. It is possible that the nurses underestimate the severity of aggression which could possibly be detrimental if nurses acted in a less cautious manner potentially endangering themselves and their patients. Alternatively, this result could suggest a rise in self confidence or a stress reduction on the part of the nurses.

One major methodological problem was the unpredictable distribution of aggressive and coercive events as observed in the randomised controlled trial (Chapter 9). The rates of aggressive incidents and coercive measures showed marked increases between the baseline and the second study phase although no intervention had been administered. For example after the exclusion of outliers the attack rates in the control group rose from 0.78 to 1.03 per 100 hospitalisation days. Inspection of the temporal distribution of the aggression data did not suggest any kind of seasonal variation as found in other studies (Morken \& Linaker 2000). It is quite probable that some extraneous variables had gone undetected. 


\section{Theoretical reflections}

The findings of the studies on the perception of aggression towards patient aggression and the effects of the training course on clinical practice call for some fundamental considerations regarding the theoretical basis of this dissertation.

The lack of change in nurses' perception of aggression may - as already referred to above - may be accounted for by erroneously measuring the nurses' traits instead of states. Another possible reason may lie in the number of aggressive incidents occurring in the study period. On the three intervention wards in the randomised controlled trial 59 aggressive incidents of a more severe nature (SOAS-R $>9$ ) were recorded before and 44 after the training course in each three month study period. Thus, the 50 or so nurses working on these three wards did not experience a dramatic reduction of severe incidents at the individual level. It is thus possible that the enhanced efficacy on employing the course contents was insufficient to influence the perception of aggression of the individual nurses. However, the aggregation of all data at ward level is sufficient to demonstrate enhanced self efficacy as measured by performance (the reduction of severe aggression).

If any attitude change were to accrue one could theoretically suspect such a modification in the group of student nurses. Their younger age and the shorter period of professional experience could be expected to render their attitudes more susceptible to change than the attitudes in the group of experienced mental health nurses. However, this was not the case. If the training course was unable to incite attitudinal change on the most "supple" group of nurses then it is difficult to imagine which modifications of the training course could make an impact. A possible explanation for the stable attitudes in the experienced psychiatric nurses is the probable selective turnover. It is known that some nurses leave psychiatric nursing or leave nursing altogether (Ito, Eisen et al. 2001) because of aggression rates. Hence, it is possible that the nurses continuing to work in acute psychiatric settings may have developed adequate coping strategies to deal with patient aggression on a long term basis. This proposed selective turnover would mean that only the most robust nurses remain in settings dealing with aggression on a frequent basis. Hence, one could hardly expect a change of perception of aggression within a time frame of three months in this population. These considerations were not sufficiently integrated into the theoretical reasoning at the onset of the study.

In spite of various authors suggesting relationships between attitude and performance regarding patient aggression (Collins 1994; Duxbury 2002; Whittington 2002; Whittington \& Higgins 2002) the role of attitude remains uncertain in the light of the findings in the studies in this dissertation. Whilst evidence was found for increased performance (reduction of coercion and aggression rates in nursing practice) no proof of the change in the perception of aggression was found. Thus, until robust evidence is produced on the relationship between the perception of aggression (attitude) and performance it is contended that such an association is questionable. 
On designing the randomised controlled trial in Chapter 9 various implicit theoretical assumptions were made. It was assumed for example that baseline measurement on wards of the same type (acute psychiatric admission wards) would render similar event rates at baseline or that the event rates in the control wards would remain stable when no intervention is administered. Although the study described in Chapter 9 is - with the participation of six wards - probably the largest study ever conducted in this area the randomisation of the wards did not guarantee the equal distribution of characteristics across the groups. With the study design demanding the ward as the unit of randomisation the number of six was too small and probably over 20 wards would be required to allow for the law of large numbers to apply. However, such a large sample would pose almost insurmountable financial and logistic demands. The erratic distribution of the aggressive incidents found in this study and the large number of variables in the "real word" of a psychiatric acute admission ward illustrate some of the difficulties of embarking on aggression research in such a setting.

On considering the effect of the training course on aggressive incidents and coercive measures one must take into consideration that a certain amount of patients will not be affected. Patients with serious disorders of impulse control, patients demonstrating very disturbed behaviour, or persons endangering themselves in such a way as to need coercive measures as protection belong to this group. It is therefore highly improbable that all types of aggression and coercion are avoidable and manageable with the contents of the training course. In some extreme cases no type of intervention or combinations of interventions may be effective. This consideration is reflected by patients who accounted for multiple aggressive incidents or those subjected to repeated coercive measures.

These theoretical considerations point to areas of research which should be addressed in future investigations (see below).

\section{Implications and recommendations}

It has been demonstrated that patient aggression is a significant problem in psychiatric inpatient health care settings, with patient aggression having a negative impact on patients' and carers alike. The clinical studies have demonstrated the capacity of the training course to reduce coercive measures and some types of aggression and. Hence, given the negative effects of coercion on patients (Sagduyu, Hornstra et al. 1995; Greenberg, Moore-Duncan et al. 1996; Martinez, Grimm et al. 1999; Olofsson \& Norberg 2001) and the adverse effects of patient aggression (Lanza 1983; Hauck 1993; Richter \& Berger 2001) it is most probable that the effects of the training course will be welcomed by patients and carers alike.

The techniques offered in the training course are expected to promote the safer handing of aggressive patients. Various complications such as asphyxiation or heart arrest (Busch \& Shore 2000) have accrued from handling aggressive patients. Such findings come as no great surprise, given the lack of 
training in the handling of aggression (Cannon, Sprivulis et al. 2001; Needham, Abderhalden et al. 2002). The use of the best known techniques addressed in the training courses such as techniques employed to guarantee adequate breathing during physical restraint will probably minimise such complications and thus diminish distress to nurses and patients alike.

Aggressive incidents and coercive measures are known to be associated with workplace stress (Caldwell 1992; Fagin, Carson et al. 1996; Rodney 2000 ) in psychiatric nursing. Thus, the reduction of such incidents as demonstrated in this dissertation may help render the psychiatric ward less stressful for all concerned. Possibly, in the long term some nurses previously leaving acute psychiatric nursing or leaving the profession altogether because of the obligation to handle patient aggression (Ito, Eisen et al. 2001) may opt to continue their work in such settings.

The handling of patient aggression has given rise to a negative reputation of psychiatry in the public eye (Gebhardt \& Steinert 1998) and in the media (Steinert \& Gebhardt 2000). The reduction of aggression and coercion may therefore benefit not only patients and carers, but may also assist psychiatry in becoming more humane and thus deemed more respectable by persons outside.

The rise in nursing students' reported confidence after visiting the training course in aggression management is a very encouraging result. As already mentioned, this finding does not necessarily imply better performance or higher confidence in actual situations requiring the handling of aggressive patients. Obviously, further research is needed to produce robust evidence on these matters. However, the findings of this research work suggest that the training course used here is beneficial to nursing students' and should thus become an integral part of nursing education. Boosting nursing students' confidence may pave the way to a better management of aggression and to less suffering.

In the light of these findings the further propagation and dissemination is recommended. It is especially recommended that nursing trainees should be recipients of the intervention in preparation for their deployment in all nursing domains. However, alternative approaches to attitude research should be considered (see below).

\section{Suggestions for further research}

This study has answered two questions and has generated other important issues which could not be addressed in the framework of this project. Here are a few suggestions for further research in the area.

Long term monitoring of the training is suggested to investigate its long term consequences on nursing practice. The short term effect may be attriutable to better sensitisation to the problem and to initial successes. In order to facilitate a sustainable effect a network of trainers and educational courses to train the trainers have been established in Switzerland. In the light of the incapacity of the training course to influence nurses' perception of 
aggression long term studies should test the hypothesis that long periods of enhanced clinical performance will lead to perception change.

Many nurses praised the training course and remarked that the course contents were capable of making a considerable impact on nursing practice. In the clinical studies only a few variables were addressed (rates of aggressive incidents, attacks, and coercive measures). Anecdotally some teams reported positive effects on the team culture or on patients. Such changes should ideally be captured by qualitative studies which allow the inductive discovery of various effects on clinical practice.

The voice of the patients themselves, as the "recipients" of the intervention, was fully neglected in this dissertation. Anecdotally some patients commented that the carers react in a more positive fashion after the implementation of the training course. A vigorous investigation of the patient perspective, perhaps using focus groups, may help establish the social acceptability of the intervention and possibly reduce tension between patients and carers on this sensitive matter. If the approaches addressed by the training programme should be deemed positive by the patients this would lend credibility to the training course and possibly assure carers that they are employing basically sound methods.

From a financial perspective one should consider developing shorter courses than the one used here. For a high wage country such as Switzerland the price of the course under scrutiny in this dissertation is quite cheap. However, many institutions do not have the resources to send their personnel to a five day course. The role of nursing scientists would be to develop short courses for other caring settings such as accident and emergency nursing, intensive care, or residential settings. Apart from the scientific investigation of their effectivity in comparison to the longer and thus more costly courses cost-benefit analyses should be conducted to furnish policy makers with information on how to invest their scarce resources in the best possible manner. It has been estimated that the loss of manpower in Switzerland due to aggressive incidents is higher than due to other accidents (SFr. 1'504.- and SFr. 884.- respectively (Giovannini, Bergoignan et al. 1993; Ferrero \& Kaision 1995). Hence, such research should investigate the financial justification of the training in aggression management. 


\section{References}

Busch AB, Shore MF (2000) Seclusion and restraint: a review of recent literature. Harvard Review of Psychiatry 8(5):261-70

Caldwell MF (1992) Incidence of PTSD among staff victims of patient violence. Hospital and Community Psychiatry 43(8):838-9

Cannon ME, Sprivulis P, McCarthy J (2001) Restraint practices in Australasian emergency departments. Australian and New Zealand Journal of Psychiatry 35(4):464-7

Collins J (1994) Nurses' attitudes towards aggressive behaviour, following attendance at "The prevention and management of aggressive behaviour programme". Journal of Advanced Nursing 20:117-131

Duxbury J (2002) An evaluation of staff and patient views of and strategies employed to manage inpatient aggression and violence on one mental health unit: a pluralistic design. Journal of Psychiatric and Mental Health Nursing 9(3):325-37

Fagin L, Carson J, Leary J, De Villiers N, Bartlett H, O'Malley P, West M, McElfatrick S, Brown D (1996) Stress, coping and burnout in mental health nurses: findings from three research studies. International Journal of Social Psychiatry 42(2):102-11.

Ferrero F, Kaision JM (1995) Epidemiologie de la violence en psychiatrie. Schweizer Archiv für Neurologie, Neurochinurgie und Psychiatrie 146(3):121-5

Gebhardt RP, Steinert T (1998) Innere Struktur der stationären psychiatrischen Krankenhausversorgung 22 Jahre nach der Psychiatrie-Enquete. Nervenarzt 69(9):791-8.

Giovannini M, Bergoignan JP, Kaision JM (1993) Les accidents professionelles en psychiatrie: Statistiques et prévention. Unpublished Thesis, VESKA, Aarau

Greenberg WM, Moore-Duncan L, Herron R (1996) Patients' attitudes toward having been forcibly medicated. Bulletin of the American Academy of Psychiatry and Law 24(4):51324

Hauck M (1993) Die Wut bleibt - Gewait von Patienten gegenūber Pflegenden (The anger remains - patient violence towards nurses). Unpublished Thesis, Kaderschule für die Krankenpflege, Aarau

Ito H, Eisen SV, Sederer LI, Yamada O, Tachimori H (2001) Factors affecting psychiatric nurses' intention to leave their current job. Psychiatric Services 52(2):232-234

Jansen G, Dassen T, Moorer P (1997) The perception of aggression. Scandinavian Journal of Caring Sciences 11(1):51-55

Lanza ML (1983) The reactions of nursing staff to physical assault by a patient. Hospital Community Psychiatry 34(1):44-7.

Martinez RJ, Grimm M, Adamson M (1999) From the other side of the door: patient views of seclusion. Journal of Psychosocial Nursing and Mental Health Services 37(3):13-22

Moons P, Marquet K, Budts W, De Geest S (2004) Validity, reliability and responsiveness of the "Schedule for the Evaluation of Individual Quality of Life - Direct Weighting" (SEIQoL-DW) in congenital heart disease. Health and Quality of Life Outcomes 28(2)

Morken G, Linaker OM (2000) Seasonal variation of violence in Norway. American Journal of Psychiatry 157(10):1674-8

Needham I, Abderhalden C, Dassen T, Haug HJ, Fischer JE (2002) Coercive procedures and facilities in Swiss psychiatry. Swiss Medical Weekly 132(19:20):253-258

Needham I, Abderhalden C, Dassen T, Haug HJ, Fischer JE (2004) The perception of aggression by nurses: Psychometric scale testing and derivation of a short instrument. Journal of Psychiatric and Mental Health Nursing 11(1):36-42

Olofsson B, Norberg A (2001) Experiences of coercion in psychiatric care as narrated by patients, nurses and physicians. Journal of Advanced Nursing 33(1):89-97 
Richter D, Berger K (2001) Patientenübergriffe auf Mitarbeiter - Eine prospektive Untersuchung der Häufigkeit, Situation und Folgen. Nervenarzt 72(9):693-9

Rodney V (2000) Nurse stress associated with aggression in people with dementia: its relationship to hardiness, cognitive appraisal and coping. Journal of Advanced Nursing 31(1):172180

Sagduyu K, Hornstra RK, Munro S, Bruce-Wolfe V (1995) A comparison of the restraint and seclusion experiences of patients with schizophrenia or other psychotic disorders. Missouri Medicine 92(6):303-7

Steinert T, Gebhardt RP (2000) Erfolgen Zwangsmassnahmen willkürlich? Psychiatrische Praxis 27(6):282-5.

Whittington R (2002) Attitudes toward patient aggression amongst mental health nurses in the 'zero tolerance' era: associations with burnout and length of experience, Journal of Clinical Nursing 11(6):819-25

Whittington R, Higgins L (2002) More than zero tolerance? Burnout and tolerance for patient aggression amongst mental health nurses in China and the UK. Acta Psychiatrica Scandinavia 106 Supplementum (412):37-40 


\section{SUMMARY}

\section{A nursing intervention to handle patient aggression: The effectiveness of a training course in the management of aggression}

Aggressive behaviour is a major societal problem and also poses a challenge to carers in acute psychiatric in-patient settings. Aggression is a multi-faceted phenomenon representing various types of behaviour. No ubiquitously accepted definition of aggression exists and in the framework of this dissertation the definition proposed by Morrison is adopted: Aggression is "any verbal, non-verbal, or physical behaviour that is threatening (to self, others or property), or physical behaviour that actually does harm (to self, others, or property)." However, the focus of this research is on patient aggression towards staff.

In inpatient psychiatry aggression is multi-causal with reasons for such behaviour ranging from relatively "normal" frustration to psychopathology. Often interpersonal action (e.g. between patients and staff) contributes to the genesis of aggression.

This dissertation investigates the effect of a training course in aggression management on nurses' attitudes and on patient aggression. The choice of this nursing intervention was motivated by a various reasons: The paucity of robust evidence on such trainings, the lack of a standardised core nursing curriculum on the management of patient aggression in Switzerland, the need for the promotion of interventions for nurses developed by nurses, the necessity to introduce modes of managing patient aggression which may reduce coercive behaviour of the staff, and the reduction of humiliation to the patients.

The five day aggression management training course under investigation was developed by N. Oud in the Netherlands. It is a skill-oriented, action-centred and problem-centred participating learning package and includes aspects such as the nature and prevalence of aggression, violence and sexual harassment, the use of aggression scales, preventive measures and strategies, de-escalation techniques, ethical aspects of violence management and safety management. The primary goal of the course is the prevention and deescalation of aggression. However, techniques are also offered for aiding patients who are manifestly aggressive. Such skills include break-away techniques, control and restraint, and post-incident care. Course participants are introduced to the concept of "actors" in social interaction in order to avoid the "perpetrator vs. victim" dichotomy. Another important content of the course is the coordination and concertation of nurses or other carers in handling patient aggression. This training course has received anecdotal praise from participants but this is the first scientific investigation on its effects.

It was hypothesised that the training course would have an effect on the individual nurses in terms of their attitudes, their confidence in dealing 
with patient aggression, and their adverse feelings emanating from dealing with aggressive patients. A further effect of the training was expected at patient level. It was hypothesised that attitude and behaviour modifications would ameliorate nurses' capacities to assist aggressive patients and thus lead to reductions in aggression and coercion. These assumptions are derived partially from Bandura's concept of self-efficacy which maintains that people's judgements of their capabilities are instrumental in mediating performance.

In the light of this aspect of Bandura's theory the following objectives regarding the training course were developed:

1. To investigate the capacity of the training course to influence nurses' perceptions or opinions regarding patient aggression.

2. To test the efficacy of a training course in the management of patient aggression as observed in terms of the reduction of rates of aggression, attacks, coercive measures (seclusion, involuntary medication and mechanical restraint), and the severity of aggressive incidents.

These objectives lead to the following hypotheses of this dissertation:

1. The training course will lead a) to a more positive perception of aggression, b) to staff experiencing patient aggression in a less severe way, and c) to a rise in confidence in handling situations involving aggressive patients by the individual nurses.

2. The training course will a) reduce aggressive incidents, b) attacks against persons, and c) coercive measures.

Figure 1 represents graphically the expected effects. Enhanced capacities in dealing with patient aggression are mediated by self-efficacy and promote confidence in dealing with patient aggression. Enhanced selfefficacy and confidence are expected to foster a more positive perception of aggression. Improved skills in the better recognition of precursors of aggressive behaviour may avoid escalation and reduce the severity of some aggressive incidents or may avoid some events completely. Hence, enhanced performance in dealing with aggressive patients is expected to lead to reductions in aggression and coercion rates.

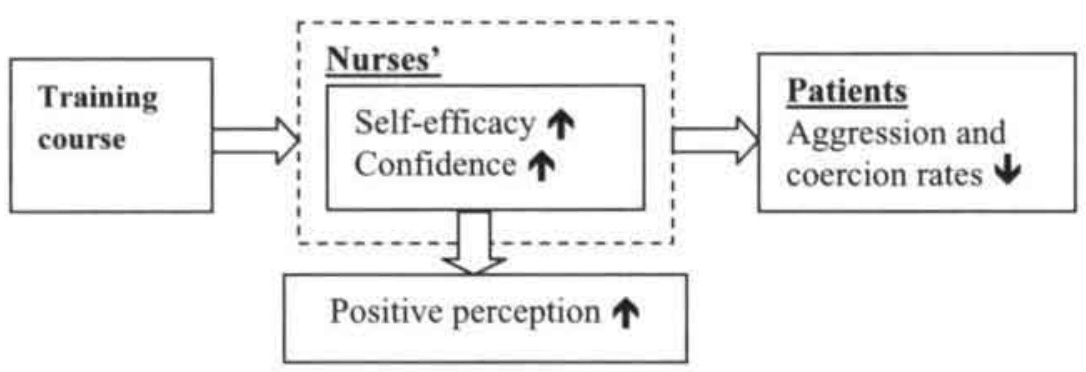

Figure 1: Expected effects of the training course 
The first part of the dissertation (chapters 2 to 5 ) is comprised of preparatory studies which pave the way for the main studies. The second part (chapters 6 to 9) deals with the two themes, notably the impact of the training course on nurses and on patients. All studies in this dissertation were, where necessary, approved by local and cantonal ethic committees and the data was handled to assure anonymity to the subjects involved. The following overview describes the various studies and their contribution to the study objectives,

Chapter 2 describes a survey conducted in the area under investigation. A questionnaire regarding coercive facilities and procedures was dispatched to the charge nurses of 86 acute psychiatric admission wards in German speaking Switzerland covering a catchment area of $75 \%$ of the Swiss population. $95 \%$ of all wards responded rendering the survey representative. The majority of wards have seclusion rooms and $55 \%$ of charge nurses perceive seclusion facilities as adequate. Two to twenty staff members are involved in overwhelming dangerous patients and some discontent is expressed at the haphazard fashion in which such events occur. Almost $70 \%$ of the wards use a form for reporting, $42 \%$ of wards keep statistics on violent incidents and $17 \%$ of wards have access to these data. Of all wards $84 \%$ register injections against patients' will, $83 \%$ seclusion, and $78 \%$ mechanical restraint and a minority of wards register the coercive administration of oral medication, forced nutrition, threats of coercive measures in case of pharmacological non-compliance. Deficits reported by the charge nurses point to the need for enhanced facilities and improved forms of coercion management such as training in the use of mechanical restraints and the overwhelming of dangerous patients.

Chapter 3 is a systematic review of the predominant non-somatic effects of patient assault on nurses. A systematic review of literature from 1983 to May 2003 was conducted using the Medline, CINAHL, PsychINFO and PSYINDEX databases. Articles from international journals in English or German and reporting at least three non-somatic responses to patient aggression were included. The electronic search produced 6616 articles. After application of the inclusion and exclusion criteria, 25 texts from 8 countries and 4 domains of nursing remained. Twenty-eight main effects were found, and these were categorised in terms of the bio-physiological, emotional, cognitive, and social dimensions. The predominant responses were anger, fear or anxiety, post-traumatic stress disorder symptoms, guilt, self-blame, and shame. These main effects occurred across most countries and nursing domains. Despite differing countries, cultures, research designs and settings, nurses' responses to patient aggression are similar. For future research standardised questionnaires could help improve estimations of the real prevalence of non-somatic effects. Given the suffering caused by non-somatic effects, research should be aimed at preventing patient aggression and at developing better ways to prepare nurses to cope with this problem. This systematic review forms the basis of chapter four.

Chapter 4 is a study designed to derive an instrument to monitor adverse effects on carers. The "Impact of Patient Aggression on Carers Scale" 
(IMPACS) is a short instrument intended for use in monitoring the negative consequences of such incidents. The items of the IMPACS were derived basically from a review of the literature on negative effects of patient aggression on nurses. The IMPACS was administered to a convenience sample of nurses working on 14 psychiatric acute admission wards in the German speaking part of Switzerland. Factor analysis led to the exclusion of three of the original items and thus to an interpretable three factor solution with all factors demonstrating Eigen values higher than 1. The factors demonstrate moderate to good internal consistency. Canonical correlation analysis using the dimensions of the Maslach Burnout Inventory (MBI) produced a correlation coefficient of 0.457 , thus demonstrating external reliability. In spite of some caveats such as possible response bias and the necessity of the investigation of the test retest stability of the scale this study suggests that the IMPACS is a good measure of adverse effects and thus merits further development.

The study presented in Chapter 5 was conducted to investigate the test-retest stability of the "Perception of Aggression Scale" (POAS) and to derive a shortened version. In order to test the reliability of the POAS items, three groups of psychiatric nurses were requested to fill in the POAS twice ( 30 student nurses after 4 days, 32 qualified nurses after 14 days and 36 qualified nurses after 70 days). The shortened version was derived from an independent dataset on 729 psychiatric nurses. The procedure employed principal component analysis, and aimed at maximising parsimony and Cronbach's alpha. Amongst competing short versions we selected those with the highest reliability at 70 or 14 day retest. A scale using 12 of the original 32 items was derived yielding alphas of $r=0.69$ and $r=0.67$ for the two POAS factors with retest reliabilities of $r=0.76$ and $r=0.77$. The shortened scale offers a practical and viable alternative to the longer version.

Chapter 6 is a quasi-experimental study investigating the effect of a training course in aggression management on student nurses confidence, attitude, and perception of aggression. Amongst all groups of nurses they are probably the most vulnerable to patient aggression. Training courses have been seen to promote greater confidence and to change attitude towards aggression. The intervention group demonstrated a higher confidence level but no change in attitude after the training course whilst the controls remained stable on all measures. The short time frame, the training itself, and the instruments used for monitoring attitude and the perception of aggression are seen as possible reasons for these results. It is tentatively concluded that in this sample it is possible to enhance nursing students' perceived confidence in dealing with aggressive patients without having to change their fundamental attitudes.

Chapter 7 reports on a multi centre randomised controlled trial testing the hypotheses that a five day training course in aggression management would positively influence nurses' perception of aggression, their tolerance towards patient aggression and their adverse feelings. The rationale for the study was derived from reports in the literature that nurses' attitudes towards patient aggression may influence their behaviour towards such patients. It was also hypothesised that interventions able to ameliorate the nurses' capac- 
ity to cope with aggressive patients may lead to more positive attitudes and may alleviate adverse feelings emanating from patient aggression. After randomisation at ward level 30 nurses participated in the intervention and 28 in the control group. The groups were comparable regarding their demographic characteristics. A repeated measures design was employed to monitor change in the groups. After statistical testing no significant differences were found between the groups on the outcome variables. The results suggest that the training course had no effect on the outcome measures. Possible reasons are the short time frame of three months between the training course and the follow up measurement or non responsiveness of the measurement instruments.

Chapter 8 reports on a dual centre prospective, non-randomised pre and post-test feasibility study on two 12-bed psychiatric acute admission wards in Switzerland. The hypothesis was tested that two interventions will reduce the frequency and severity of violent events and reduce coercion. The interventions were a systematic aggression risk assessment alone and in combination with a standardised training course in aggression management and the frequency and severity of aggressive incidents and the frequency of coercive measures were the main outcomes. Incidence rates per 100 hospitalisation days of 3.51 for aggressive incidents, 1.68 for attacks against persons, and for coercion 3.05 were found. After introduction of the interventions no significant reduction of the incidence rates of aggressive events and attacks occurred. However the rates of coercive measures per 100 hospitalisation days declined significantly. The incident severity as measured by SOAS-R remained unchanged whilst the subjective severity declined after the training course. The conclusion is that a systematic risk assessment and a training course may assist in reducing the incidence rate of aggressive incidents and coercive measures on psychiatric acute admission wards. However, further testing in a randomised controlled study is necessary to substantiate these preliminary findings and to measure the effect of the training course alone.

In chapter 9 a multi centre randomised controlled clinical trial derived to evaluate the effect of a training course in aggression management on the incidence and severity of aggressive events, attacks against persons and coercive measures is presented. The six participating wards were block randomised into the intervention or control group. The intervention was a five day training course in aggression management for complete nursing teams. Aggressive incidents and their severity and coercive measures were registered for three months before the intervention and three months in the second phase of the study. The patients' characteristics were comparable across the groups. After exclusion of a small number of patients who were involved in an over proportionate number of aggressive and coercive events and after adjusting for the incidence rates of the control group in the post intervention phase statistically significant reductions of severe aggressive incidents and coercive measures were found. A substantial reduction of the subjective severity of aggressive incidents occurred after the training course in the intervention group in comparison to the control group. No statistically significant changes were found regarding overall aggressive incidents, attacks against personnel, 
or the objective severity of aggressive incidents. The data suggest that the training course may exert an influence on severe aggression and coercion rates and on the subjective perception of aggression severity. However, various caveats such as the somewhat unpredictable distribution of aggressive and coercive events or the probable variation in responses to the training course across the wards must be considered.

Chapter 10 is a general discussion on the dissertation. After summarising the main results (Figure 2) at the level of the nurses (perception of aggression and confidence) and the patients (clinical changes in coercion and aggression rates and the severity of aggression) various methodological considerations are reflected. The lack of results indicating attitude change at the level of the individual nurses having completed the training course may be attributed to instrumentation problems or to the short time frame for the training to take effect. Possible methodological shortcomings of the clinical studies are reporting bias, changes in the regimen of the wards during the study, the short time frame of 6 months per trial, and the unpredictable distribution of aggressive events in the wards. The stationary perception of aggression may accrue from erroneously measuring traits instead of states, from poor responsiveness (the capacity of the instruments to detect change), or from the low incidence of aggressive incidents offering little sensory information to allow the individuals to register change. For the randomised controlled clinical trial assumptions based on the theory of large numbers were made. However, the small number of six wards trial was insufficient to render a similar distribution of aggression and coercion rates across the study sites. The clinical studies also demonstrated that not all patients - for example persons with serious impulse control disorders - can be affected by the skills acquired in the training. In spite of some caveats the training course is recommended to help reduce some forms of aggression and coercion. It is also recommended to nursing students to help boost their confidence. Finally some areas for future research - for example the monitoring of the long term effect of the training, studies to discover the patient perspective on the training course, or the qualitative investigations to reveal possible benefits for the nurses - are suggested.

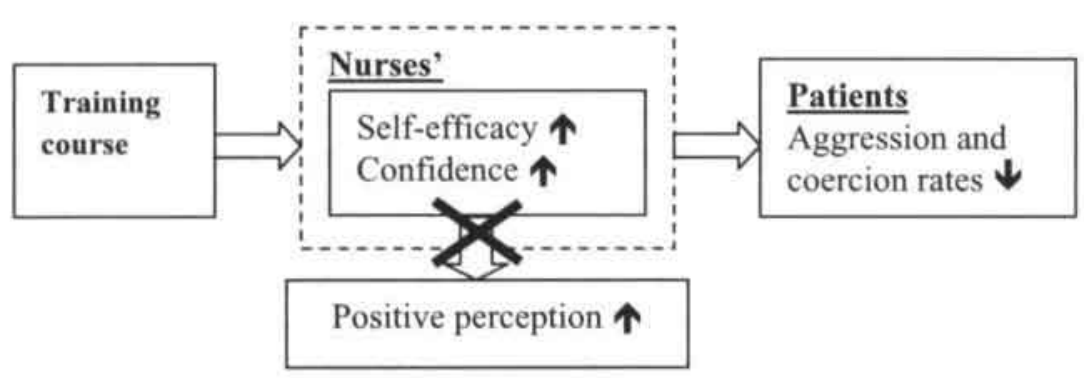

Figure 2: The effects of the training course in aggression management 


\section{SAMENVATTING}

\section{Een verpleegkundige interventie bij aggressie: De effectiviteit van een training in het omgaan met aggressie van patiënten}

Agressie is een groot maatschappelijk probleem en vormt voor hulpverleners in de acute klinische settings een uitdaging. Agressie is een verschijnsel met vele facetten, en met veel verschillende uitingsvormen. $\mathrm{Er}$ bestaat geen algemeen aanvaarde definitie van het begrip agressie. In het kader van dit proefschrift wordt de definitie van Morrison gehanteerd: agressie is "elk verbaal, nonverbaal, of fysiek gedrag dat bedreigend is (tegenover zichzelf, anderen of objecten)." In dit onderzoek zal de nadruk liggen op agressie van patiënten tegen stafleden.

Agressie in de klinische psychiatrie kent vele oorzaken, uiteenlopend van relatief "normale" frustratie tot psychopathologie. In veel gevallen speelt de interactie (b.v. tussen patiënten en stafleden) een rol bij het ontstaan ervan.

In dit proefschrift wordt het effect van een training in het omgaan met agressie op de attitude van verpleegkundigen en op de agressie van patiënten onderzocht. De keuze voor deze interventie komt voort uit verschillende overwegingen: het tekort aan bewijs voor de effectiviteit van dergelijke trainingen; het ontbreken in Zwitserland van een degelijk gestandaardiseerd lesprogramma voor verpleegkundigen voor agressiehantering; de behoefte om interventies - ontwikkeld door verpleegkundigen - in te voeren, de noodzaak om manieren van agressiehantering te introduceren die de toepassing van dwang terug kunnen dringen en vernedering van patiënten kunnen verminderen.

De vijfdaagse cursus "omgaan met agressie", die hier is onderzocht, is in Nederland ontwikkeld door N. Oud. De training is gericht op het aanleren van vaardigheden, waarbij concrete handelingen en problemen centraal staan. Het vraagt om een actieve deelname en omvat onderdelen als de aard en prevalentie van agressie, geweld en ongewenste seksuele intimiteiten en handtastelijkheden, het gebruik van lijsten om agressie te registreren, preventieve maatregelen en strategieën, deëscalatietechnieken, ethische aspecten van het omgaan met agressie en veiligheidsbeleid. Het primaire doel van de cursus is preventie en deëscalatie van dreigende agressie. Daarnaast wordt ook aandacht besteed aan technieken om in te grijpen bij patiënten die daadwerkelijk agressief zijn. Daarbij moet gedacht worden aan technieken om zichzelf te bevrijden uit de handen van de patiënt, aan technieken voor controle en fysieke overmeestering, en opvang na incidenten. De deelnemers aan de training maaken kennis met het verschijnsel "actor(en) in sociale interactie" teneinde de daderslachtoffer dichotomie te vermijden. Een ander belangrijk onderdeel van de cursus betreft de coördinatie en samenwerking tussen verpleegkundigen of andere hulpverleners bij agressie. Deze training is weliswaar positief beoordeeld 
door deelnemers, maar tot nu toe is geen wetenschappelijk onderzoek naar het effect verricht.

Als hypothese is aangenomen dat de training een effect heeft op de attitude van de individuele verpleegkundigen, op hun zelfvertrouwen in het kunnen omgaan met agressie van patiënten, en op hun negatieve gevoelens die het gevolg zijn van het omgaan met agressieve patiënten. Op patientniveau werd verwacht dat door de attitude- en gedragsveranderingen van de verpleegkundigen, zij beter met agressieve patiënten om zouden gaan, waardoor er een reductie van agressie en dwang zou plaats vinden. Deze aannames zijn deels afgeleid van Bandura's concept van self-efficacy, dat inhoudt dat het oordeel van mensen over hun eigen vaardigheden ten opzicht van het uiteindelijke gedrag, van invloed is op het gedrag.

De volgende doelen voor deze studie zijn geformuleerd:

- Onderzoeken in welke mate de training in het omgaan met agressie de perceptie en opvattingen van verpleegkundigen over agressie van patiënten beïnvloedt;

- Testen van de effectiviteit van de training in het omgaan met agressie op het aantal agressieve incidenten, aanvallen, dwangtoepassing (separatie, dwangmedicatie en fixatie), en op de ernst van de agressie-incidenten.

Op basis van deze doelstellingen zijn de volgende hypotheses van dit proefschrift geformuleerd:

1. de training leidt a) tot een meer positieve houding ten opzichte van agressie, b) ertoe dat stafleden agressie als minder ernstig gaan ervaren, en c) tot toenemend zelfvertrouwen onder individuele verpleegkundigen in het omgaan met situaties waarbij patiënten agressief zijn.

2. de training zal a) leiden tot vermindering van het aantal agressieve incidenten, b) tot minder aanvallen op personen gericht, en c) tot minder dwangtoepassing.

In Figuur 1 worden de verwachte effecten grafisch weergegeven. Verbeterde vaardigheden in het omgaan met agressie van patiënten bevordert self-efficacy en het vertrouwen in het kunnen omgaan met agressie. Verwacht wordt dat verhoogde self-efficacy en zelfvertrouwen een positieve bijdrage levert aan een meer positieve perceptie van agressie. Verbeterde vaardigheden in het herkennen van signalen van agressief gedrag kan escalatie voorkomen en de ernst van agressieve incidenten verminderen, of zelfs helemaal voorkómen. Vandaar dat de verwachting is dat verbeterde werkwijzen in het omgaan met agressieve patiënten zal leiden tot vermindering van agressie en dwangtoepassing. 


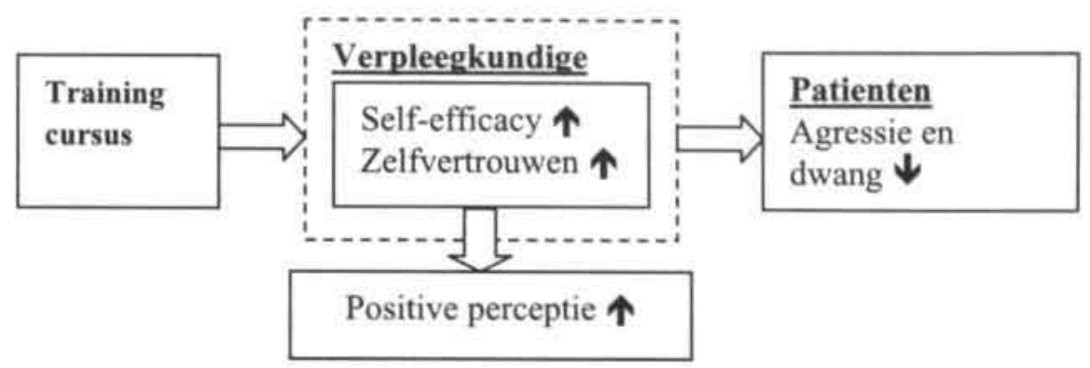

Figuur 1: Verwachte effecten van de training omgaan met aggressie

Het eerste deel van dit proefschrift (hoofdstuk 2 tot en met 5) behandelt onderzoeken die de basis leggen voor de hoofdstudie. Het tweede deel (hoofdstuk 6 tot en met 9) handelt over twee thema's, namelijk de invloed van de training op verpleegkundigen en op patiënten. Alle onderzoekingen uit dit proefschrift werden, voor zover noodzakelijk, goedgekeurd door lokale en kantonale medisch-ethische commissies en de gegevens werden zodanig verwerkt dat de anonimiteit van de bij het onderzoek betrokken personen werd gegarandeerd. Het navolgende overzicht beschrijft de verschillende studies en hun respectievelijke bijdragen aan de doelstellingen van het onderzoek.

In hoofdstuk 2 worden de resultaten van een enquête naar het gebruik van dwangmiddelen en -procedures beschreven. Een vragenlijst werd verspreid onder hoofdverpleegkundigen van 86 acute psychiatrische opnameafdelingen in het Duitstalige deel van Zwitserland, een verzorgingsgebied dat $75 \%$ van de Zwitserse bevolking omvat. De respons bedroeg $95 \%$ van alle aangeschreven afdelingen waardoor de representativiteit gegarandeerd is. Uit deze studie blijkt dat de meerderheid van de afdelingen de beschikking heeft over separeerkamers en $55 \%$ van de hoofdverpleegkundigen acht de separatiemogelijkheden op hun afdeling voldoende. Twee tot twintig stafleden zijn betrokken geweest bij de overmeestering van gevaarlijke patiënten en er werd enige onvrede geuit over de risicovolle wijze waarop met dergelijke situaties werd omgegaan. Bijna $70 \%$ van de afdelingen gebruiken een vorm van verslaglegging: $42 \%$ van de afdelingen houden een register bij met betrekking tot agressieve incidenten en $17 \%$ van de afdelingen hebben toegang tot deze gegevens. Van alle afdelingen houdt $84 \%$ een registratie bij van het gebruik van het toedienen van medicatie per injectie onder dwang; $83 \%$ van gedwongen separatie, en $78 \%$ van fixatie en een minderheid van de afdelingen houdt een register bij van gedwongen orale medicatie, gedwongen voeding, dreiging met dwangmiddelen in geval van medicatieweigering. De hoofdverpleegkundigen rapporteerden de behoefte aan betere faciliteiten en verbeterde vormen van dwangtoepassing zoals training in het gebruik van fixatie en overmeesteringstechnieken bij gevaarlijke patiënten. 
Hoofdstuk 3 bevat een systematische review van de literatuur over de meest voorkomende niet-lichamelijke gevolgen bij verpleegkundigen door agressie van patiënten. Deze review bestrijkt het tijdperk van 1983 tot mei 2003 en werd uitgevoerd met behulp van de databases van Medline, CINAHL, PsychINFO en PSYINDEX. Ook werden Engelstalige en Duitstalige tijdschriftartikelen in de zoekstrategie meegenomen als hierin tenminste drie niet-lichamelijke reacties op agressie van patiënten voorkwamen. Deze search leverde 6616 artikelen op. Na toepassing van de inclusie- en exclusiecriteria, bleven er 25 teksten uit 8 landen en 4 verpleegkundige domeinen over. Er werden 28 gevolgen gevonden, en deze werden gecategoriseerd op basis van hun bio-fysiologische, emotionele, cognitieve en sociale dimensies. De meest voorkomende reacties waren woede en boosheid, angst, symptomen van een post-traumatische stress stoornis, schuldgevoel, zelfverwijt en schaamte. Deze meest voorkomende reacties bleken te worden genoemd in de meeste landen en verpleegkundige domeinen. Ondanks de onderlinge verschillen tussen landen, culturen, onderzoeksopzetten en settings, bleken de reacties van verpleegkundigen op agressie van patiënten zeer vergelijkbaar. Dit betekent dat gestandaardiseerde vragenlijsten bij toekomstig onderzoek goed bruikbaar zijn om tot betere prevalentieschattingen te komen van niet-lichamelijke gevolgen. Gezien het leed dat wordt veroorzaakt door niet lichamelijke gevolgen, zou onderzoek zich meer dienen te richten op preventie van agressie van patiënten en op het ontwikkelen van betere manieren om verpleegkundigen voor te bereiden om dit probleem te hanteren. Deze systematische review vormt de basis van hoofdstuk 4.

Hoofdstuk 4 betreft een studie die tot doel had om een instrument te ontwikkelen waarmee de nadelige gevolgen van degelijke incidenten op hulpverleners systematisch kunnen worden bijhegouden. De IMPACS is een kort instrument dat de negatieve gevolgen van agressieve incidenten meet. De items van de IMPACS werden afgeleid uit een review van de literatuur over negatieve gevolgen van agressie van patiënten op verpleegkundigen. De IMPACS werd afgenomen bij een steekproef van verpleegkundgien die werkzaam waren op 14 verschillende acute psychiatrische opnameafdelingen in het Duitstalige deel van Zwitserland. Factoranalyse leidde tot uitsluiting van drie oorspronkelijke items en daarmee tot een interpreteerbare driefactorenoplossing die elk een Eigen Value hadden van hoger dan 1. De factoren laten een matige tot goede interne consistentie zien. Ondanks beperkingen, zoals mogelijke respons-bias en de noodzaak om de test hertest stabiliteit van de schaal te onderzoeken, maakt deze studie aannemelijk dat de IMPACS een goede maat is voor de negatieve gevolgen van agressieve incidenten.

In hoofdstuk 5 worden de resultaten gepresenteerd van een studie die tot doel had om de test-hertest stabiliteit van de "Perception of Aggression Scale" (POAS) nader te onderzoeken en hiervan een verkorte versie samen te stellen. Om de betrouwbaarheid van de POAS items te onderzoeken, werden drie groepen psychiatrisch verpleegkundigen gevraagd om de POAS tweemaal in te vullen ( 30 leerling-verpleegkundigen na 4 dagen; 32 
gediplomeerd verpleegkundigen na 14 dagen en 36 gediplomeerd verpleegkundigen na 70 dagen). De verkorte versie was afgeleid uit een onafhankelijke dataset over 729 verpleegkundigen. Hierbij werd gebruik gemaakt van principale componentenanalyse, met als doel om zo hoog mogelijke Cronbachs alfa's te bereiken met een minimale omvang van de itempool. Uit de verschillende verkorte versies werd de versie gekozen met de hoogste test hertest- betrouwbaarheid bij 7 of 14 dagen. Dit leverde een verkorte versie van de POAS op die bestond uit 12 van de 32 oorspronkelijke items, en liet alfa's zien van $r=0,69$ en $r=0,67$ voor de twee POAS-factoren met test-hertest betrouwbaarheden van $r=0,76$ en $r=0,77$. De verkorte schaal biedt daarmee een praktisch alternatief voor de langere versie.

Hoofdstuk 6 betreft het verslag van een quasi-experimentele studie naar het effect van de training in het omgaan met agressie op het zelfvertrouwen, de attitude en de perceptie van agressie bij student verpleegkundigen. Onder de verschillende groepen verpleegkundigen zijn zij waarschijnlijk degenen die met meeste risico lopen om aan agressie van patiënten blootgesteld te worden. Trainingen hebben laten zien dat het zelfvertrouwen verbeterd wordt, en de attitude ten aanzien van agressie verandert. De interventiegroep liet een verbetering in zelfvertrouwen zien, maar geen attitudeverandering na de training, terwijl de controlegroep gelijk bleef op alle uitkomstmaten. Mogelijke redenen voor het ontbreken van een attitudeverandering ten aanzien van agressie kunnen worden gezocht in de korte tijdspanne tussen de training en de nameting, de training zelf en in de gebruikte instrumenten waarmee de attitude en de perceptie van agressie werden gemeten. Voorzichtig kan geconcludeerd worden dat het mogelijk is om het zelfvertrouwen van verpleegkundigen in het omgaan met agressieve patiënten te vergroten, zonder dat dit noodzakelijkerwijs gepaard hoeft te gaan met verandering van hun basisattitude.

In hoofdstuk 7 wordt verslag gedaan van een multicenter gerandomiseerde gecontroleerde studie. Daarin wordt de hypothese getoetst dat een vijfdaagse training in het omgaan met agressie een positieve invloed heeft op de perceptie van agressie, op een grotere tolerantie tegenover agressie en op negatieve gevoelens bij verpleegkundigen. Uit de literatuur kwam naar voren dat de houding van verpleegkundigen ten aanzien van agressie van patiënten hun gedrag tegenover agressieve patiënten kan beïnvloeden. Verder werd de hypothese gesteld dat interventies die het vermogen van verpleegkundigen om beter met agressie van patiënten om te gaan, kan leiden tot een meer positieve houding en minder negatieve gevoelens ten gevolge van agressie van patiënten. Na randomisatie op afdelingsniveau deden 30 verpleegkundigen mee in de interventie, en 28 in de controlegroep. De groepen waren vergelijkbaar wat betreft hun demografische eigenschappen. Hierbij werd gebruik gemaakt van een design met herhaalde metingen om veranderingen binnen de groepen te kunnen vastleggen. $\mathrm{Na}$ statistische toetsing werden geen significante verschillen gevonden tussen de groepen op de uitkomstmaten. Mogelijke redenen hiervoor zijn het korte tijdsbestek van drie maanden tussen de training en de follow-up meting, of de ongevoeligheid van de gebruikte meetinstrumenten. 
In hoofdstuk 8 wordt verslag gedaan van een prospectief, nietgerandomiseerde studie in twee acute opnameafdelingen van elk twaalf bedden in Zwitserland. Het betrof een haalbaarheidsstudie met pré en post metingen. Daarin werd de hypothese getoetst dat twee interventies de frequentie en ernst van geweldsincidenten zullen doen verminderen, evenals de toepassing van dwang. De interventies betroffen: alleen een systematische assessment van risico's op agressie en dit in combinatie met de gestandaardiseerde training in agressiehantering. De centrale uitkomstmaten waren de frequentie en ernst van agressie-incidenten en de frequentie van toepassing van dwangmaatregelen. $\mathrm{Bij}$ aanvang bleken er per honderd opnamedagen gemiddeld 3,51 agressie-incidenten, waaronder 1,68 agressieincidenten gericht tegen personen voor te komen, en 3,05 dwangmaatregelen te worden toegepast. $\mathrm{Na}$ invoering van de twee interventies werd geen significante daling gevonden van agressieve incidenten, noch van agressie gericht tegen personen. Echter, de toepassing van dwangmiddelen per honderd opnamedagen daalde wel significant. De gemiddelde ernst van de incidenten, zoals gemeten met de SOAS-R, bleef ongewijzigd terwijl de subjectieve ernst verminderde na de training. De conclusie is dat systematische risicotaxatie plus een training kunnen bijdragen aan een vermindering van de frequentie van agressieve incidenten en dwangmiddelengebruik op acute opnameafdelingen. Toch is verder onderzoek middels een gerandomiseerde en gecontroleerde studie nodig om deze voorlopige bevindingen te onderbouwen en om het effect van de training op zich te kunnen meten.

In hoofdstuk 9 wordt een multicenter gecontroleerde klinische trial gepresenteerd waarmee het effect van een training in het omgaan met agressie op de incidentie en ernst van agressieve incidenten, aanvallen op personen en dwangmiddelen werd geëvalueerd. Daartoe werden zes deelnemende afdelingen bloksgewijs gerandomiseerd toegewezen aan de interventie- of controlegroep. De interventie bestond uit een vijfdaagse training in het omgaan met agressie voor de totale verpleegkundige teams. Gedurende de drie maanden voorafgaand aan de interventie en gedurende de drie maanden van de tweede fase van het onderzoek werden de agressieve incidenten, de ernst ervan en het dwangmiddelengebruik geregistreerd. De patiëntkenmerken waren tussen de groepen onderling vergelijkbaar. Na exclusie van een klein aantal patiënten die bovenmatig betrokken waren bij agressie-incidenten en dwangtoepassing, en na correctie van de incidentiematen van agressie-incidenten bij de controlegroep in de postinterventiefase werden er statistisch significante dalingen gevonden wat betreft ernstige agressie-incidenten en wat betreft het toepassen van dwangmiddelen. Verder deed zich in de interventiegroep een substantiële daling voor in de subjectieve beleving van de ernst van de agressie na de training in vergelijking tot de controlegroep. $\mathrm{Er}$ werden geen statistisch significante veranderingen gevonden wat betreft het gemiddelde aantal agressieve incidenten, aanvallen tegen personeelsleden, of de objectieve ernst van de agressieve incidenten. De data suggereren dat de training van invloed zou kunnen zijn op de ernst van de agressie en de mate van dwangtoepassing 
en op de subjectieve beleving van de ernst van de agressie. Hierbij dienen echter enkele kanttekeningen geplaatst te worden, zoals de enigszins onvoorspelbare verdeling van de agressieve incidenten en gevallen van dwangtoepassing of de mogelijke variatie in respons op de training tussen de verschillende afdelingen.

Hoofdstuk 10 bevat de algemene discussie van dit proefschrift. $\mathrm{Na}$ een opsomming van de algemene resultaten (figuur 2) op het niveau van de verpleegkundigen (de perceptie van agressie en zelfvertrouwen) en de patiënten (klinische veranderingen in dwangtoepassing en de mate en ernst van agressie) wordt stilgestaan bij enkele methodologische overwegingen. Het ontbreken van resultaten die wijzen op een attitudeverandering op het niveau van de individuele verpleegkundigen die de training hebben gevolgd, zou kunnen worden toegeschreven aan problemen met de gebruikte meetinstrumenten, of aan de te korte tijdspanne van het onderzoek om die veranderingen te kunnen bewerkstelligen.

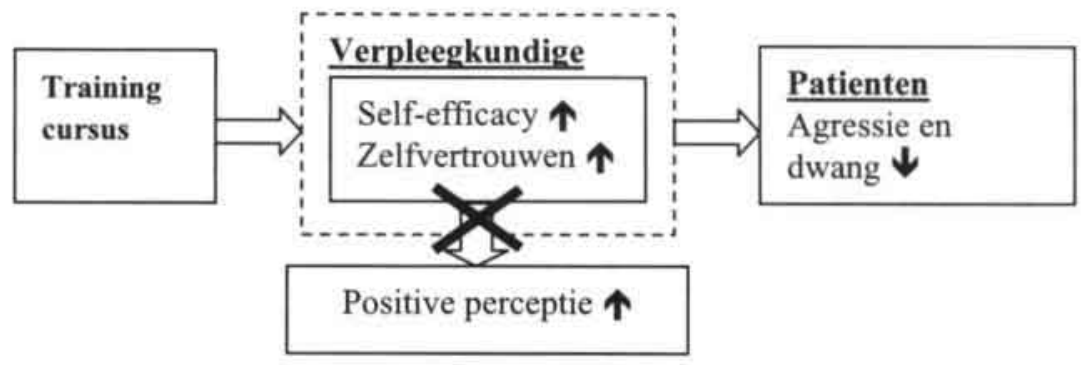

Figuur 2: De effecten van de training omgaan met aggressie

Mogelijke methodologische tekortkomingen van de klinische studies zijn response bias, veranderingen in het regime van de onderzochte afdelingen gedurende de looptijd van het onderzoek, het korte tijdsbestek van zes maanden per trial, en de onvoorspelbare verdeling van agressieve incidenten op de afdelingen. Het feit dat er geen verandering in de perceptie van agressie werd gevonden op het individueel niveau van de verpleegkundigen kan voortkomen uit het ten onrechte meten van 'traits' in plaats van 'states', uit gebrekkige sensitiviteit (responsiveness) van de gebruikte instrumenten voor het meten van verandering, maar ook uit de geringe incidentie van agressieve incidenten die daarmee weinig gelegenheden krijgen om veranderingen bij zichzelf waar te nemen. De assumpties voor de gerandomiseerde gecontroleerde klinische trial waren gebaseerd op de theorie van grote getallen. Echter, het kleine aantal van zes deelnemende afdelingen aan het onderzoek was onvoldoende om een vergelijkbare verdeling tussen de verschillende onderzoekslocaties op te leveren wat betreft de mate waarin agressie en dwang voor kwam. De klinische studies lieten ook zien dat niet alle patiënten - bijvoorbeeld personen met ernstige impulscontrolestoornissen - kunnen worden beïnvloed met de vaardigheden die werden verkregen tijdens de training. Ondanks enige voorbehouden wordt de training wel aanbevolen om bij te dragen aan het 
verminderen van een aantal vormen van agressie en dwangtoepassing. De training wordt ook aanbevolen aan verpleegkundigen om hun zelfvertrouwen te vergroten. Tenslotte worden voor toekomstig onderzoek enige onderzoeksterreinen aanbevolen, zoals het monitoren van de lange termijneffecten van de training, onderzoek naar de effecten van de training vanuit het patiëntperspectief, en kwalitatief onderzoek naar de mogelijke positieve effecten voor de betrokken verpleegkundigen. 


\section{ZUSAMMENFASSUNG}

Eine Pflegeintervention zur Handhabung von Patientenaggression: Die Auswirkung eines Trainingskurses in Aggressionsmanagement

Aggressives Verhalten stellt ein schwerwiegendes gesellschaftliches Problem dar. Für BetreuerInnen in Institutionen des Gesundheitswesens bedeutet aggressives Verhalten eine grosse Herausforderung. Aggression ist ein vielschichtiges Phänomen und zeigt sich in verschiedenen Verhaltensweisen. Es gibt keine allgemein akzeptierte Definition von Aggression. In der vorliegenden Dissertation wird die Definition von Morrison verwendet: „Jegliche Form von verbalem, nonverbalem oder körperlichem Verhalten, welches für den Patienten/die Patientin selbst, andere Personen oder deren Eigentum bedrohlich ist, oder körperliches Verhalten, wodurch der Patient selbst, andere Personen oder deren Eigentum zu Schaden gekommen ist/sind“".

In der stationären Psychiatrie ist Aggression multikausal. Die Ursachen reichen von ,gewöhnlicher" Frustration bis hin zu psychopathologischen Ursachen. Vielfach tragen Interaktionen (etwa zwischen PatientInnen und Personal) zur Entstehung von Aggression bei.

In vorliegender Dissertation wird der Effekt eines Trainingskurses zu Aggressionsmanagement auf die Einstellung Pflegender und auf die Aggression von PatientInnen untersucht. Unterschiedliche Gründe führten zur Wahl der Pflegeintervention: Der Mangel von robuster Evidenz zur Wirksamkeit solcher Trainings, das Fehlen standardisierter Curricula zum Aggressionsmanagement in der Schweiz, die Notwendigkeit durch Pflegende entwickelte Pflegeinterventionen zu fördern und die Erfordernis, Methoden des Aggressionsmanagements einzuführen, die möglicherweise den Einsatz von Zwangsmassnahmen reduzieren, sowie eine Reduktion von erniedrigenden Erfahrungen der PatientInnen bewirken.

Der hier untersuchte fünftägige Trainingskurs in Aggressionsmanagement wurde von $\mathrm{N}$. Oud in den Niederlanden entwickelt. Es handelt sich um eine fertigkeitsorientierte, aktions- und problemzentrierte Schulung und umfasste Elemente wie Wesen und Vorkommen von Aggression, Gewalt und sexueller Belästigung, Anwendung von Aggressionsskalen, vorbeugende Massnahmen und Strategien, Techniken der Deeskalation, Ethik des Managements der Aggression und Sicherheitsaspekte. Prävention und Deeskalation der Aggression stellten das primäre Ziel der Schulung dar. Für den Fall, dass PatientInnen manifest aggressiv sind, wurden Hilfen angeboten. Diese Fertigkeiten umfassen Losreiss-Techniken, Festhaltegriffe, und Nachsorge von PatientInnen nach aggressiven Vorfällen. Die Schulung basiert auf dem Modell der „Akteure“ in einer sozialen Interaktion und nicht auf der TäterOpfer"-Dichotomie. Ein anderes wichtiges Merkmal des Trainings ist die Koordination und "Choreographie" der Pflegenden oder Betreuenden bei der Handhabung von Aggression bei PatientInnen. Der Trainingskurs wurde bis- 
lang von Kursabsolvent/innen zunächst anekdotisch gelobt. Dies ist jedoch die erste wissenschaftliche Untersuchung zu seinen Auswirkungen.

Es wurde angenommen, dass der Trainingkurs sich auf die einzelnen Pflegenden mit Blick auf deren Einstellung, Selbstvertrauen bei der Handhabung von Aggression von PatientInnen und durch Aggressionsmanagement ausgelöste negative Gefühle auswirken würde. Eine weitere Auswirkung wurde bei den PatientInnen erwartet. Es wurde angenommen, dass die Einstellungs- und Verhaltensänderungen der Pflegenden zu verbesserten Fähigkeiten in der Begleitung von PatientInnen und zur Reduktion von Aggression und Zwangsmassnahmen führen würden. Diese Annahmen beruhten teilweise auf Bandura's Konzept der Selbstwirksamkeit, welches davon ausgeht, dass die Einschätzung der eigenen Fähigkeiten das Verhalten massgeblich beeinflussen kann.

Aufgrund dieses Aspektes von Bandura's Theorie wurden die Forschungsziele hinsichtlich des Trainingskurses entwickelt: Die Studie untersuchte...

- das Vermögen des Trainingskurses, die Einstellungen der Pflegenden zu beeinflussen und

- den Effekt des Trainingskurses auf das Management von Aggression von PatientInnen hinsichtlich Aggressionsraten, Übergriffe, Zwangsmassnahmen (Isolierung, Zwangsmedikation und Fixierung) und den Schweregrad von Aggressionsereignissen.

Aus diesen Forschungszielen gingen folgende Hypothesen hervor:

- Der Trainingskurs führt a) zu einer positiveren Einstellung gegenüber Aggression, b) dazu, dass Pflegende Aggression von PatientInnen als weniger schwerwiegend erleben und c) zu einer Steigerung des Selbstvertrauens bei Pflegenden in der Aggressionshandhabung.

- Der Trainingskurs reduziert die Anzahl von a) aggressiven Ereignissen, b) Übergriffen auf Personen und c) Zwangsmassnahmen.

Abbildung 1 verdeutlicht die erwarteten Auswirkungen. Verbesserte Fähigkeiten im Umgang mit Aggression von PatientInnen erhöhen das Vertrauen im Umgang mit diesen. Dieser Zusammenhang wird durch Selbstwirksamkeitserwartungen mediiert. Verbesserte Selbstwirksamkeit und verbessertes Selbstvertrauen führen - so die Hypothese - zu einer positiveren Einstellung gegenüber Aggression. Verbesserte Fertigkeiten im Umgang mit Aggression und verbessertes Erkennen der Vorboten aggressiven Verhaltens verhindern möglicherweise eine Eskalation und tragen zur Senkung des Schweregrads mancher Ereignisse bei. In manchen Fällen können gegebenenfalls Aggressionsereignisse gänzlich vermieden werden. 


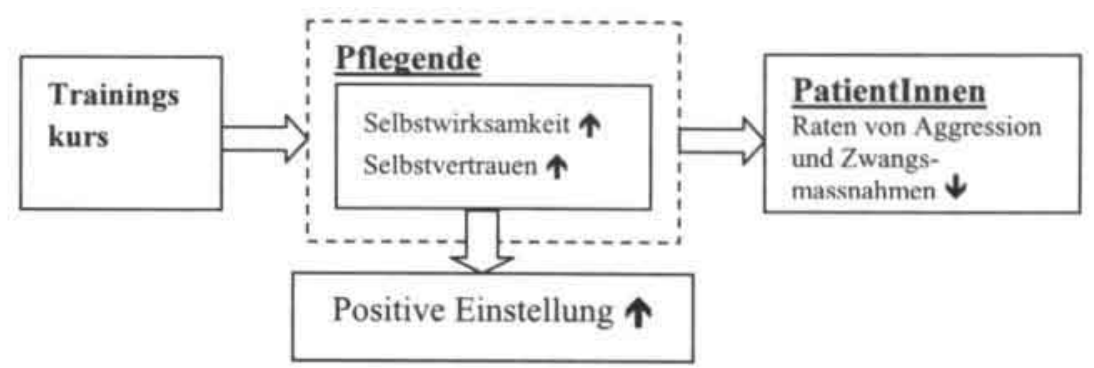

Abbildung 1: Erwartete Auswirkungen des Trainingskurses

Der erste Teil dieser Dissertation (Kapitel 2 bis 5) besteht aus zugrunde liegenden Studien. Der zweite Teil (Kapitel 6 bis 9) befasst sich mit zwei Themen, einerseits den Auswirkungen des Trainingskurses auf Pflegende und andererseits auf die PatientInnen. Alle Studien in dieser Dissertation wurden, wo erforderlich, von lokalen oder kantonalen Ethikkomitees bewilligt. Die Daten wurden gemäss den Richtlinien zur Wahrung der Anonymität der involvierten Personen behandelt. Die folgende Übersicht beschreibt die einzelnen Studien und deren Beitrag zur Erreichung der Studienziele.

Kapitel 2 beschreibt eine Umfrage im Untersuchungsgebiet. Ein Fragebogen über die Umsetzung von Zwangsmassnahmen wurde an die Stationsleitungen von 86 akutpsychiatrischen Aufnahmestationen im deutschsprachigen Teil der Schweiz verteilt. Dies entspricht einem Einzugsgebiet von $75 \%$ der Schweizer Bevölkerung. Da die Rücklaufquote $95 \%$ beträgt, kann die Umfrage als repräsentativ angesehen werden. Die Mehrheit der Stationen verfügt über Isolierungszimmer, $55 \%$ der Stationsleitungen betrachten die Möglichkeiten zur Isolierung als genügend. Zwei bis zwanzig Personen werden zur Überwältigung gefährlicher PatientInnen benötigt. Solche Aktionen laufen nicht selten unsystematisch ab und geben häufig Anlass zur Unzufriedenheit. Beinahe $70 \%$ der Station benutzten Formulare zur Erfassung aggressiver Ereignisse, $42 \%$ der Stationen führten eine diesbezügliche Statistik, $17 \%$ der Stationen haben Zugang zu diesen Daten. Registriert werden Zwangsinjektionen gegen den Willen der PatientInnen auf $84 \%$ der Stationen und Fixierung auf $78 \%$ der Stationen. Eine Minderheit der Stationen registriert perorale Zwangsmedikation, Zwangsernährung und die Androhung von Zwangsmassnahmen bei medikamentöser Noncompliance. Zu den durch die Stationsleitungen vermerkten Mängel, gehören infrastrukturelle Einrichtungen zur Durchführung von Zwangsmassnahmen, Formulare, Schulung in der Anwendung von Fixierungsmitteln und die Überwältigung gefährlicher PatientInnen.

Kapitel 3 ist eine systematische Übersicht von vorherrschenden nicht-somatischen Auswirkungen auf Pflegende nach Übergriffen durch PatientInnen. Eine systematische Übersicht der Literatur zwischen 1983 und Mai 2003 wurde unter Verwendung von MEDLINE, CINAHL, PsychINFO und PSYINDEX erstellt. Eingeschlossen wurden Artikel internationaler Fachzeitschriften in englischer oder deutscher Sprache mit mindestens drei nicht- 
somatischen Auswirkungen. Die elektronische Suche ergab 6616 Artikel. Nach Anwendung der Einschlusskriterien verblieben 25 Artikel aus 8 Ländern und 4 Pflegefachgebieten. Die 28 ermittelten Auswirkungen wurden nach den Unterkriterien bio-physiologisch, emotional, kognitiv und sozial kategorisiert. Die vorherrschenden Auswirkungen waren Wut, Angst oder Furcht, Symptome der posttraumatischen Stressreaktion, Schuldgefühl, Selbstvorwürfe und Scham. Diese Hauptauswirkungen kommen in den meisten Ländern und Pflegefachbereichen vor. Trotz verschiedener Länder, Kulturen, Forschungsanlagen und Pflegefachbereiche sind die Reaktionen Pflegender ähnlich. Für künftige Studien könnten standardisierte Fragebögen zur Ermittlung der tatsächlichen Raten von nicht-somatischen Auswirkungen dienen. Angesichts des durch nicht-somatische Auswirkungen verursachten Leidens sollten vermehrt Studien über die Vermeidung von Aggression von PatientInnen und zur besseren Vorbereitung der Pflegenden für den Umgang mit diesem Thema durchgeführt werden. Diese systematische Übersicht ist die Grundlage für Kapitel vier.

Kapitel 4 befasst sich mit einer Studie zur Entwicklung eines Instruments zur Messung von nachteiligen Auswirkungen von Aggression durch PatientInnen auf Pflegende. Die "Impact of Patient Aggression on Carers Scale" (IMPACS) ist ein kurzes Instrument zur Feststellung der Veränderung solcher Auswirkungen nach Patientenaggression. Die Items der IMPACS wurden hauptsächlich aus der Literaturübersicht über negative Auswirkungen auf Pflegende nach Aggressionsereignissen zusammengestellt. Die IMPACS wurde an einer Gelegenheitsstichprobe von Pflegenden auf 14 akutpsychiatrischen Stationen in der Deutschschweiz weiter entwickelt. Nach Faktorenanalyse wurden drei Items von der Skalenbildung ausgeschlossen. So ergab sich eine inhaltlich interpretierbare Faktorlösung. Alle Faktoren zeigten einen Eigen-Wert von über 1. Die Faktoren zeigten eine mässige bis gute interne Konsistenz. Kanonische Korrelation mit Verwendung der Maslach-BurnoutSkala (MBI) ergab ein Korrelationskoeffizient von 0.457 , was auf externe Zuverlässigkeit hinweist. Trotz einiger Einschränkungen, wie etwa eine mögliche Antwortverzerrung oder die Notwendigkeit der Untersuchung der TestRetest-Stabilität der Skala, weist diese Studie darauf hin, dass sich IMPACS zur Messung negativer Auswirkungen und zur weiteren Entwicklung hinreichend eignet.

Die in Kapitel 5 vorgestellte Studie wurde zur Untersuchung der Test-Retest-Stabilität der Aggressionseinstellungsskala (,Perception of Aggression Scale" - POAS) und zur Anfertigung einer Kurzversion durchgeführt. Zur Prüfung der Test-Retest-Stabilität füllten drei Gruppen von Pflegenden den POAS zweimal aus (30 PflegestudentInnen nach 4 Tagen, 32 qualifizierte Pflegende nach 14 Tagen und 36 qualifizierte Pflegende nach 70 Tagen). Die Kurzversion wurde mittels einer anderen Stichprobe von 729 Psychiatriepflegenden entwickelt. Das statistische Verfahren zur Etablierung einer Skala mit möglichst wenigen Items beinhaltete eine Hauptkomponentenanalyse und die Prüfung von Cronbach's Alpha. Aus den verschiedenen Modellen wurde jenes mit der höchsten Zuverlässigkeit bei 70 oder 14 Tagen ausgewählt. Es entstand eine Skala bestehend aus 12 der ursprünglichen 32 
Items mit Alpha-Werten von $r=0.69$ und $r=0.67$ für die zwei POASFaktoren. Die Test-Retest-Zuverlässigkeit der Faktoren beträgt $r=0.76$ und $r$ $=0.77$. Die Kurzversion ist somit eine gute Alternative zur Vollversion.

Kapitel 6 untersucht die Auswirkungen des Trainingskurses in Aggressionshandhabung auf das Selbstvertrauen und die Einstellung hinsichtlich Aggression bei PflegestudentInnen im Rahmen einer quasiexperimentellen Studie. Diese Personen machen die wahrscheinlichste Zielgruppe im Hinblick auf Aggression durch PatientInnen aus. Studien belegen, dass Trainingskurse bereits zu einer Steigerung des Selbstvertrauens und zur Einstellungsveränderung beitragen können. Die Interventionsgruppe zeigte ein gesteigertes Selbstvertrauen aber keine Einstellungsveränderung hinsichtlich Aggression nach dem Trainingskurs. Die Personen in der Kontrollgruppe blieben stabil in allen gemessenen Variablen. Mögliche Gründe für diese Ergebnisse sind der kurze Zeitrahmen, der Trainingskurs selbst und die Instrumente zur Messung der Einstellung. Diese Studie lässt den vorsichten Schluss zu, dass bei dieser Stichprobe möglich war, das Selbstvertrauen von PflegestudentInnen zu steigern ohne deren grundlegenden Einstellungen beeinflussen zu müssen.

Kapitel 7 berichtet über eine multizentrische randomisiertkontrollierte Studie zur Prüfung der Hypothese, ob ein fünftägiger Trainingskurs in Aggressionsmanagement zu einer positiven Beeinflussung der Einstellung von Aggression, der Aggressionstoleranz und der nachteiligen Gefühle nach dem Umgang mit aggressiven PatientInnen führt. Die Grundlage dieser Studie beruht auf Berichten, dass die Einstellung Pflegender hinsichtlich Aggression ihr Verhalten gegenüber PatientInnen beeinflussen kann. Es wurde ferner angenommen, dass Interventionen zur Verbesserung der Fertigkeiten im Umgang mit Aggression zu einer positiveren Einstellung und zur Abschwächung der infolge PatientInnenaggression entstehenden nachteiligen Gefühle führen. Nach Randomisierung der Stationen nahmen 30 Pflegende in der Interventions- und 28 in der Kontrollgruppe an der Studie teil. Die demographischen Merkmale waren zwischen den Gruppen vergleichbar. Zur Überwachung der Veränderungen wurde ein Studiendesign mit Wiederholungsmessungen (repeated measures design) gewählt. Es ergaben sich keine statistisch signifikanten Gruppenunterschiede. Die Ergebnisse weisen darauf hin, dass der Trainingkurs keine Auswirkung auf die gemessenen Variablen hatte. Mögliche Gründe dafür sind neben einer Unwirksamkeit des Trainingsprogrammes der kurze Zeitrahmen von drei Monaten zwischen dem Trainingskurs und die Nachmessung oder die Unempfindlichkeit der Messinstrumente.

In Kapitel 8 wird über eine prospektive, nicht-randomisierte Machbarkeitsstudie auf zwei akutpsychiatrische Aufnahmestationen mit jeweils 12 Betten in der Schweiz berichtet. Die Hypothese lautete, dass zwei Interventionen zu einer Senkung der Aggressionsraten, des Schweregrads von Aggressionsereignissen und der Zwangsmassnahmenraten führen. Die Interventionen bestanden in einer systematischen Risikoeinschätzung für aggressives Verhalten alleine und in einer Kombination mit einem standardisierten Trainingskurs in Aggressionsmanagement. Die primären Zielvariablen waren die Rate und der Schweregrad von 
Aggressionsereignissen und die Zwangsmassnahmenrate. Inzidenzraten pro 100 Hospitalisationstage von 3.51 für Aggressionsereignisse, 1.68 für Übergriffe auf Personen und 3.05 für Zwangsmassnahmen wurdeN ermittelt. Nach Einführung der Interventionen wurde keine signifikante Senkung der Aggressionsereignissen und der Übergriffe gefunden. Die Rate von Zwangsmassnahmen je 100 Hospitalisationstage ging nach dem Trainingskurs jedoch signifikant zurück. Der mit Hilfe des SOAS-R gemessene Schweregrad der Aggressionsereignisse blieb unverändert, während der subjektive Schweregrad nach dem Trainingskurs zurückging. Als Schlussfolgerung kann angenommen werden, dass eine systematische Risikoeinschätzung und ein Trainingskurs in Aggressionsmanagement zu einer Senkung der Aggressionsraten und der Zwangsmassnahmen auf akutpsychiatrischen Aufnahmestationen beitragen können. Weitere Untersuchungen in randomisiert-kontrollierten Studien wären erforderlich, um einerseits die vorläufigen Ergebnisse zu bestätigen und die Auswirkungen des Trainingskurses allein zu messen.

Kapitel 9 beschreibt eine multizentrische randomisiert-kontrollierte Studie zur Überprüfung der Auswirkungen eines Trainingskurses in Aggressionsmanagement auf die Raten und den Schweregrad von Aggressionsereignissen, auf Übergriffe gegen Personen und auf Zwangsmassnahmen. Die sechs teilnehmenden Stationen wurden blockweise randomisiert auf die Interventions- und Kontrollgruppe verteilt. Die Intervention bestand in einem fünftägigen Trainingskurs in Aggressionsmanagement, an dem ganze Pflegeteams geschlossen teilnahmen. Aggressionsereignisse und Zwangsmassnahmen wurden drei Monate vor und nach der Intervention aufgezeichnet. Die Merkmale der PatientInnen waren in den zwei Gruppen vergleichbar. Nach Ausschluss einer kleinen Zahl von PatientInnen, die an einer überproportionalen Anzahl von Aggressionsereignissen und Zwangsmassnahmen beteiligt waren und nach Anpassung der Aggressionsraten der Kontrollgruppe für die zweite Studienphase ergab sich eine signifikante Senkung von schwer wiegenden Aggressionsereignissen und Zwangsmassnahmen. Eine beträchtliche Senkung des subjektiv empfundenen Schweregrads konnte nach dem Trainingskurs in der Interventionsgruppe im Vergleich zur Kontrollgruppe. Keine signifikanten Änderungen der Aggressionsereignisse insgesamt, der Übergriffe gegen Personen und des objektiven Schweregrads wurden gefunden. Die Studienergebnisse weisen darauf hin, dass der Trainingskurs einen Einfluss auf schwer wiegende Aggressionsereignisse, Zwangsmassnahmen und die subjektive Wahrnehmung des Schweregrads der Aggressionsereignisse hat. Verschiedene Einschränkungen, wie etwa die unvorhersagbare Verteilung von Aggressionsereignissen und Zwangsmassnahmen oder die wahrscheinlich Variabilität der Wirkung des Trainingskurses auf den verschiedenen Stationen, müssen jedoch bedacht werden.

Kapitel 10 enthält die allgemeine Diskussion zur Dissertation. Nach einer Zusammenfassung der Haupt-Ergebnisse (siehe Abbildung 2) bei den Pflegenden (Aggressionswahrnehmung und Selbstvertrauen) und bei den PatientInnen (klinische Veränderungen der Raten von Aggression und 
Zwangsmassnahmen und des Schweregrads von Aggressionsereignissen) werden verschiedene methodologische Grundfragen reflektiert. Das Fehlen von Ergebnissen zur Aggressionswahrnehmung auf der Ebene der individuellen Pflegenden nach dem Trainingskurs lässt sich möglicherweise zurückführen auf Probleme der Messinstrumente oder auf den kurzen Zeitraum, in dem sich eine Veränderung einstellen könnte. Mögliche methodische Unzulänglichkeiten der klinischen Studien sind Verzerrungen bei der Aufzeichnung der Variablen, Änderungen im Management auf den Stationen während der Studie, die kurze Dauer von sechs Monaten pro klinische Studie und die unvorhersagbare zeitliche Verteilung von Aggressionsereignissen auf den Studienstationen. Die Stabilität der Aggressionswahrnehmung basiert möglicherweise auf der nicht distinkten Messung von gefestigten Charaktermerkmalen (traits) einerseits und flüchtigen Zuständen (states) andererseits, in der nicht gegeben Sensitivität/Sensibilität der Instrumente zur Veränderungsmessung oder den niedrigen Aggressionsraten, die dem Individuum eine Veränderungswahrnehmung erschweren. Für die randomisiert-kontrollierten Studien wurden weiterhin Annahmen getroffen, die auf dem Gesetz der grossen Zahlen basieren. Die kleine Anzahl von sechs teilnehmenden Stationen war jedoch zu klein zur sicheren Gewährleistung ähnlicher Verteilungen von Aggressionsereignissen und Zwangsmassnahmen. Die klinischen Studien zeigten ferner, dass nicht alle PatientInnen - etwa solche mit schweren Störungen der Impulskontrolle - auf die im Trainingskurs erworbenen Fertigkeiten der Pflegenden reagieren. Trotz einiger Einschränkungen scheint der Trainingskurs geeignet zu sein, um Raten bestimmter Aggressionsformen und Zwangsmassnahmen zu senken. Der Kurs wird darüber hinaus für PflegestudentInnen als Hilfe zur Steigerung ihres Selbstvertrauens empfohlen. Schliesslich werden sich anschliessende Forschungsbereiche vorgeschlagen: die Untersuchung von Langzeitauswirkungen des Trainingskurses, Studien zur Ermittlung der Perspektive der PatientInnen über den Trainingskurs oder qualitative Studien zur Ermittlung möglicher positiver Vorteile für die Pflegenden.

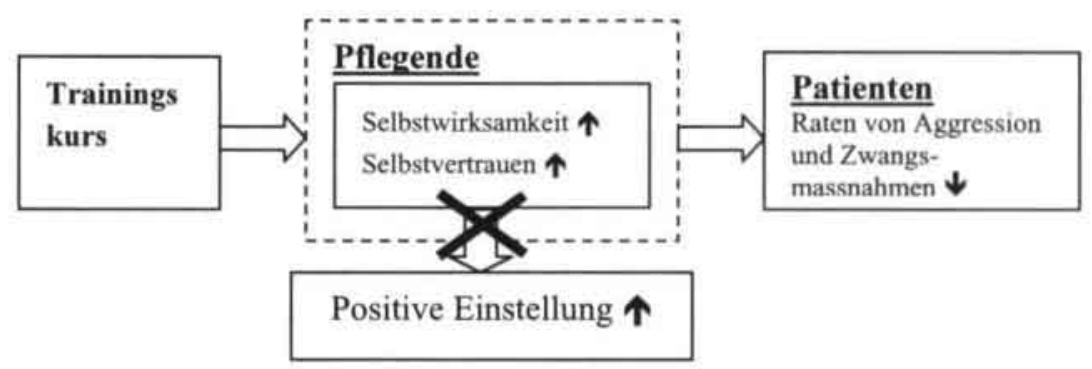

Abbildung 2: Die Auswirkungen des Trainingskurses in Aggressionsmanagement 


\section{RÉSUMÉ}

\section{Une intervention soignante pour gérer l'agressivité des patientes: L'effet d'un cours d'entraînement à la gestion de l'agression}

Le comportement agressif est un problème de société majeur. Il représente un défi pour les professionnels de la santé qui travaillent dans les soins psychiatriques aigus. L'agression est un phénomène à multiples facettes qui comprend différents types de comportement. Il n'existe pas de définition universellement admise de l'agression. Dans la présente thèse la définition de Morrison est utilisée: L'agression est "tout comportement verbal, non verbal ou physique qui constitue une menace pour soi-même, pour autrui ou pour la propriété d'autrui ou qui cause des dommages à soi-même, à autrui ou à la propriété d'autrui." Cette recherche se concentre sur l'agression du patient envers le personnel soignant.

Les comportements agressifs de patients psychiatriques hospitalisés ont des causes multiples et vont de la réaction, relativement "normale" due à la frustration, à la psychopathologie. Souvent les interactions (p. ex. entre patients et personnel soignant) contribuent à l'apparition du comportement agressif.

Cette thèse examine l'effet d'un cours d'entraînement de gestion de l'agression sur l'attitude des soignants et sur l'agression des patients. Le choix de cette intervention de soins a été motivé par de multiples raisons. Le manque de mise en évidence de l'efficacité de tels entraînements, l'absence d'un curriculum de soins standardisé concernant la gestion de l'agression en Suisse, la nécessité de promouvoir des interventions soignantes développées par des soignants, la nécessité d'introduire des méthodes de gestion d'agression de patients qui visent à réduire le comportement coercitif des équipes de soins et diminuent les expériences humiliantes pour les patients.

Le cours d'entraînement à la gestion de l'agression de cinq jours, qui est l'objet de cette recherche, a été développé par N. Oud aux Pays-bas. Ce cours est orienté sur l'apprentissage participatif d'aptitudes, centré sur l'action et le problème. Il comprend des aspects tels que nature et prévalence de l'agression, violence et harcèlement sexuel, l'utilisation d'échelles d'évaluation de l'agression, mesures et stratégies préventives, techniques de retour à la norme, aspects éthiques de la gestion de l'agression et de la gestion de la sécurité. L'objectif principal de ce cours est la prévention de l'agression et le retour à la norme. Il propose également des techniques d'aide destinées aux patients ouvertement agressifs. Ceci inclus des techniques de dégagement corporel, de contrôle, de contention et de prise en charge de patients après des incidents agressifs. Les participants au cours sont familiarisés avec le concept d'"acteur" dans une interaction sociale qui évite la perspective dichotomique "agresseur-victime". Ce cours met également l'accent sur un autre point important, la coordination et la concertation des soignants dans la prise en 
charge de l'agression du patient. Ce cours a reçu des louanges anecdotiques de la part des participants mais ceci est la première investigation scientifique des effets de ce cours.

Il a été supposé que le cours d'entrainement aurait des effets sur les soignants en ce qui concerne leurs attitudes et leur confiance en soi par rapport à la gestion des agressions des patients et les sentiments négatifs qui résultent des interactions avec des patients agressifs. Un effet de cet entraînement était également espéré pour les patients. Il a été supposé que les changements d'attitudes et les modifications de comportements amélioreraient les capacités des soignants d'aider les patients agressifs et de ce fait amèneraient une baisse de l'agression et une diminution des mesures de contrainte. Ces suppositions découlent en partie du concept d' efficience personnelle de Bandura, qui stipule que l'évaluation de ses propres capacités a une influence considérable sur le comportement de l'individu.

Au regard de cet aspect de la théorie de Bandura les objectifs suivants ont été développés en ce qui concerne le cours d'entraînement: La recherche a investigué...

- la capacité du cours d'entraînement d'influencer les attitudes des soignants.

- l'effet du cours d'entraînement sur la gestion de l'agression des patients en ce qui concerne la fréquence de l'agression, les attaques, les mesures de contrainte (isolement, médication contre la volonté et contention) et la gravité des incidents agressifs.

Ces objectifs de la recherche ont mené aux hypothèses suivantes:

1. Le cours d'entraînement a comme effet a) de modifier positivement l'attitude envers l'agression, b) que les soignants vivent les agressions de patients comme moins traumatisantes, c) d'améliorer la confiance en soi des soignants en ce qui concerne la gestion de l'agression.

2. Le cours d'entraînement diminue a) le nombre d'incidents agressifs, b) le nombre d'attaques contre des personnes, c) le nombre de mesures de contrainte.

La figure 1 est une représentation graphique des effets escomptés. La perception d'efficience personnelle améliore la capacité de gestion des agressions de patients et ceci augmente la confiance en soi dans les situations de gestion d'agression. Une amélioration de l'efficience personnelle et de la confiance en soi devraient amener une attitude plus positive envers l'agression. Des capacités améliorées en ce qui concerne la perception des signes précurseurs du comportement agressif peuvent éviter l'escalade et réduire la gravité de certains incidents voire même les empêcher. De ce fait des améliorations de performances dans la prise en charge de patients agressifs devraient diminuer la fréquence des agressions et des mesures de contrainte. 


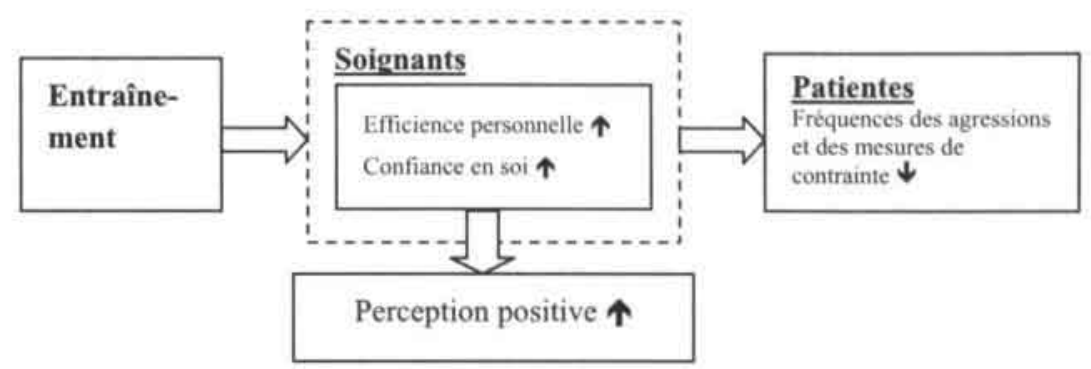

\section{Figure 1: Effets escomptés par l'entraînement}

La première partie de cette thèse (chapitres 2 à 5) est composée de recherches préliminaires. La deuxième partie (chapitres 6 à 9) traite de deux thèmes, les effets du cours d'entrainement sur les soignants et sur les patients. Toutes les recherches de cette thèse ont été approuvées, si nécessaire, par les commissions d'éthiques locales ou cantonales. Les données ont été traitées de manière confidentielle afin de garantir l'anonymat des personnes concernées. Le sommaire qui suit décrit les différentes études et leur contribution à l'atteinte des objectifs de cette recherche.

Le chapitre 2 décrit une enquête conduite dans le domaine de cette recherche. Un questionnaire concernant l'équipement et l'application de mesures de contraintes a été distribué aux chefs de 86 unités de soins de psychiatrie aigue en Suisse allemande. Ceci couvre le territoire de $75 \%$ de la population Suisse. Le taux de réponse de $95 \%$ signifie que l'enquête peut être considérée comme représentative. La majorité des unités de soins dispose de chambres d'isolement et $55 \%$ des chefs d'unités de soins considère les possibilités d'isolement comme suffisantes. Pour maîtriser un patient dangereux il faut entre 2 et 20 membres du personnel. Ces interventions se déroulent parfois de manière chaotique et sont source de mécontentement. Environ $70 \%$ des unités de soins utilisent des formulaires de rapport d'incidents agressifs, $42 \%$ des unités établissent des statistiques concernant des incidents violents et $17 \%$ des unités ont accès à ces données. $84 \%$ des unités tiennent un registre des injections effectuées contre la volonté des patients et $78 \%$ concernant les contentions. Une minorité d'unités tient un registre des médications forcées orales, des prises d'alimentation forcées et les menaces de mesures contraignantes en cas de non-compliance médicamenteuse. Parmi les insuffisances signalées par les unités figurent les infrastructures permettant les mesures de contraintes et la gestion de l'agression, et notamment la formation à l'utilisation de moyens de contention et à la maitrise de patients dangereux.

Le chapitre 3 est une énumération systématique des principales séquelles non somatiques des soignants suite à une attaque de patients. La recherche littéraire a été effectuée à l'aide de MEDLINE, CINAHL, PsychINFO et PSYINDEX et couvre la période de 1983 à Mai 2003. Y ont été inclus des articles parus dans les revues internationales en anglais ou allemand qui rap- 
portaient au moins trois séquelles non somatiques suite à des agressions de patients. Grâce à la recherche électronique 6616 articles furent trouvés. Après application des critères d'inclusion 25 articles de 8 pays et de 4 domaines de soins furent retenus. Les 28 séquelles identifiées ont été catégorisées selon les dimensions biophysiologiques, émotionnelles, cognitives et sociales. Les séquelles prédominantes décrites sont la colère, la peur ou l'angoisse, le syndrome de stress post-traumatique, les sentiments de culpabilité, d'autoreproches et de honte. Ces séquelles principales apparaissent dans la plupart des pays et domaines de soins. En dépit des différences de pays, de cultures, de plans de recherche et de domaines de soins les réactions des soignants sont similaires. Lors de recherches futures, l'utilisation de questionnaires standardisés affinerait les estimations des taux de prévalence des séquelles non somatiques. Au vu de l'importance de la souffrance causée par ces séquelles non somatiques la recherche devrait viser à prévenir les agressions par les patients et à préparer des moyens plus efficaces pour aider les soignants à y faire face. Cette revue systématique forme la base pour le chapitre 4 .

Le chapitre 4 présente l'étude de développement d'un instrument de mesure des effets négatifs vécus par les soignants. L "Impact of Patient Aggression on Carers Scale (IMPACS)" est un instrument qui permet en peu de temps de mesurer les séquelles après une agression par un patient. Les items de I'IMPACS ont été élaborés principalement à partir des séquelles après agression identifiées grâce à la recherche de littérature. L'IMPACS a été testé sur un échantillon de soignants provenant de 14 unités de psychiatrie aigue en Suisse allemande (échantillon de commodité). Après analyse factorielle trois items furent retirés. Ceci permet une solution interprétable des trois facteurs qui ont chacun un valeur Eigen supérieur à 1.Ces facteurs montrent une consistance interne de modérée à bonne. La corrélation canonique en utilisant les dimensions du "Maslach-Burnout-Inventory" (MBI) donne un coefficient de corrélation de 0,457 ce qui démontre une fiabilité externe. Malgré quelques réserves tel une possible distorsion des réponses ou la nécessité d'examiner la fidélité test-retest de l'échelle, la présente recherche démontre que l'IMPACS est un instrument adéquat pour mesurer des séquelles et mérite un développement ultérieur.

L'étude présentée dans le chapitre 5 a été réalisée pour évaluer la fidélité test-retest de l'échelle de perception de l'agression (Perception of Aggression Scale - POAS) et a permis d'en élaborer une version courte. Pour l'évaluation de la fidélité test-retest trois groupes de soignants ont rempli le POAS deux fois ( 30 étudiants en soins infirmiers à 4 jours d'intervalle, 32 soignants qualifiés à 14 jours d'intervalle, et 36 soignants qualifiés à 70 jours d'intervalle). La version courte a été élaborée a partir d'un autre échantillon de 729 soignants en psychiatrie. Le procédé statistique qui a permis d'établir une échelle avec le moins d'items possibles comprenait une analyse des composantes principales et le calcul de l'alpha de Cronbach. Des différents modèles de versions courtes celui qui montrait la plus grande fiabilité à 70 ou 14 jours a été retenu. La version courte comprend 12 des 32 items initiaux avec des valeurs alpha de $r=0.69$ et $r=0.67$ pour les deux facteurs POAS. La fidélité 
de test-retest des facteurs est de $r=0.76$ et $r=0.77$. La version courte est de ce fait une alternative pratique et viable à la version longue.

Le chapitre 6 est une recherche quasi-expérimentale faite sur des étudiants en soins infirmiers qui investigue les effets du cours d'entraînement de gestion de l'agression sur la confiance en soi et les attitudes envers l'agression. Parmi la profession soignante ils sont probablement le groupe le plus exposé à l'agression de patients. Il a été démontré que les cours d'entraînement peuvent améliorer la confiance en soi et changer l'attitude envers l'agression. Le groupe expérimental a montre un niveau de confiance en soi plus élevé mais pas de changement d'attitude après avoir suivi le cours d'entraînement, tandis que les résultats des variables du groupe de contrôle sont restés stables. Des raisons possibles pouvant expliquer ces résultats sont le court laps de temps, l'entraînement en soi et les instruments utilisés pour mesurer l'attitude. Une prudente tentative de conclusion à cette recherche permet de penser que dans cet échantillon il a été possible d'augmenter la confiance en soi des étudiants sans changer fondamentalement leur attitude.

Le Chapitre 7 traite d'une recherche multicentrique randomisée et contrôlée qui doit permettre de vérifier l'hypothèse suivante: qu'un cours de cinq jours de gestion de l'agression influence positivement l'attitude envers l'agression, la tolérance à l'agression et les sentiments négatifs après une interaction avec un patient agressif. Les réflexions de base de cette recherche reposent sur des données littéraires qui stipulent que l'attitude des soignants envers les patients agressifs influence leur comportement. Il a également été admis que des interventions capables d'améliorer les capacités des soignants de s'occuper de patients agressifs mèneraient à une attitude plus positive et atténueraient les sentiments négatifs après l'agression par un patient. Après une randomisation au niveau des unités 30 infirmiers ont été inclus dans le groupe expérimental et 28 dans le groupe de contrôle de la recherche. Les deux groupes étaient comparables par rapport aux caractéristiques démographiques. Afin de contrôler les changements dans les groupes un design de mesures répétées (repeated measures design) fut appliqué. Statistiquement il n'y eut pas de différences significatives entre les deux groupes. Les résultats montrent que le cours d'entraînement n'a pas eu d'effet sur les variables mesurées. Des raisons possibles sont le court laps de temps (trois mois entre le cours d'entraînement et la deuxième mesure) ou la relative insensibilité des instruments de mesure.

Le chapitre 8 présente une étude de faisabilité prospective et non randomisée dans deux unités d'admission, comptant 12 lits, en psychiatrie aigue en Suisse. L'hypothèse stipulait que deux interventions entraîneraient une baisse du taux d'agression, de la gravité des incidents agressifs et des mesures de contention. Ces interventions consistaient en une évaluation systématique des risques de comportement agressif seule et en combinaison avec un entraînement standardisé en gestion de l'agression. Les variables principales étaient la fréquence et le degré de gravité des incidents d'agression et la fréquence des mesures de contention. Des incidences de 3,51 incidents d'agressions, de 1,68 attaques sur des personnes et de 3,05 mesures de contention par 100 jours d'hospitalisation ont été trouvées. Après la mise en route 
des interventions aucune diminution significative des incidents d'agression et des attaques n'a pu être constatée. Le taux de mesures de contention a diminué de manière significative après le cours d'entraînement. Le degré de gravité des incidents mesuré avec le SOAS-R est resté inchangé, tandis que le degré de gravité subjectif a diminué après le cours d'entraînement. La conclusion est qu'une évaluation systématique du comportement agressif et qu'un cours d'entraînement en gestion d'agression peuvent contribuer à une diminution du taux d'agressions et de mesures de contention. Une nouvelle recherche randomisée et contrôlée s'avère nécessaire afin d'une part confirmer les résultats provisoires et d'évaluer l'effet du cours d'entraînement seul.

Le chapitre 9 décrit une étude multicentrique randomisée et contrôlée qui a pour but d'évaluer les effets d'un cours d'entraînement en gestion d'agression sur les taux et le degré de gravité d'incidents d'agression, d'attaques contre des personnes et de mesures de contention. Les six unités qui ont participé à cette étude ont été randomisées par blocs pour le groupe expérimental ou de contrôle. L'intervention consistait en un cours d'entraînement de gestion d'agression de cinq jours auquel des équipes entières d'unités de soins ont participé. Les incidents d'agression et les mesures de contention ont été relevés pendant les trois mois précédents l'intervention et pendant les trois mois suivants. Les caractéristiques des patients étaient comparables dans les deux groupes. Après exclusion d'un petit nombre de patients qui ont été impliqué proportionnellement dans un trop grand nombre d'incidents d'agression ou de mesures de contention et après adaptation des taux d'agression du groupe de contrôle pour la deuxième phase de recherche il en est résulté une baisse significative des incidents d'agression graves et des mesure de contention. Une diminution de la perception subjective de la gravité des incidents a été constatée dans le groupe expérimental par rapport au groupe de contrôle. Aucune modification statistiquement significative n'a été mise en évidence par rapport au nombre total d'incidents d'agression, au nombre d'attaques contre les personnes et à la gravité objective des incidents. Les résultats de la recherche suggèrent que le cours d'entraînement a un effet sur les incidents d'agression graves, les mesures de contention et la perception subjective de la gravité des incidents d'agression. Diverses limitations telle la répartition imprévisible d'incidents d'agression et de mesures de contention et les probables variations de réponses dans les différentes unités suite au cours d'entraînement doivent être pris en compte.

Le chapitre 10 est une discussion générale de la thèse. Après un résumé des principaux résultats (voir figure 2) auprès des soignants (perception de l'agression confiance en soi) et des patients (modification clinique des taux d'agression et de mesures de contraintes et de la gravité des incidents d'agression) suivent diverses réflexions sur des considérations méthodologiques. $\mathrm{L}^{\prime}$ absence de résultats concernant le changement d'attitude des soignants pris individuellement après le cours d'entraînement peut être éventuellement attribuée à des problèmes liés aux instruments ou le trop bref laps de temps pour permettre à l'entraînement de produire des changements. Des possibles défauts méthodologiques des études cliniques sont des distorsions lors de la récolte de données, des changements de direction dans les unités pendant la 
recherche, le bref laps de temps de six mois pour chaque étude clinique et la répartition imprévisible d'incidents d'agression dans les unités. L'impression statique d'absence de changement dans la perception de l'agression peut être une conséquence de mesures erronées qui mesureraient plutôt des traits que des états, d'instruments trop peu sensibles pour mesurer des changements ou d'un taux d'incidents d'agression trop faible pour que le changement puisse être perçu par l'individu. Pour les études randomisées et contrôlées des suppositions ont été faites qui se basent sur les théories des grands nombres. Le petit nombre de six unités ne suffit néanmoins pas pour garantir une répartition similaire d'incidents d'agression et de mesures de contention entre les différentes unités. Ensuite les études cliniques ont démontré que les patients ne réagissent pas tous de la même manière aux nouvelles techniques apprises par les soignants- p.ex les patients qui ont des troubles impulsifs sévères. Malgré quelques réserves le cours d'entraînement peut être recommandé afin de diminuer le taux de certains types d'agressions et des mesures de contentions. Ce cours peut être recommandé aux étudiants en soins infirmiers pour augmenter la confiance en soi.

Finalement des propositions de domaines de recherches futurs sont faites, tel les effets à long terme de ce cours d'entraînement, des études sur la position des patients par rapport à ce cours ou encore des études qualitatives sur des avantages pour les soignants.

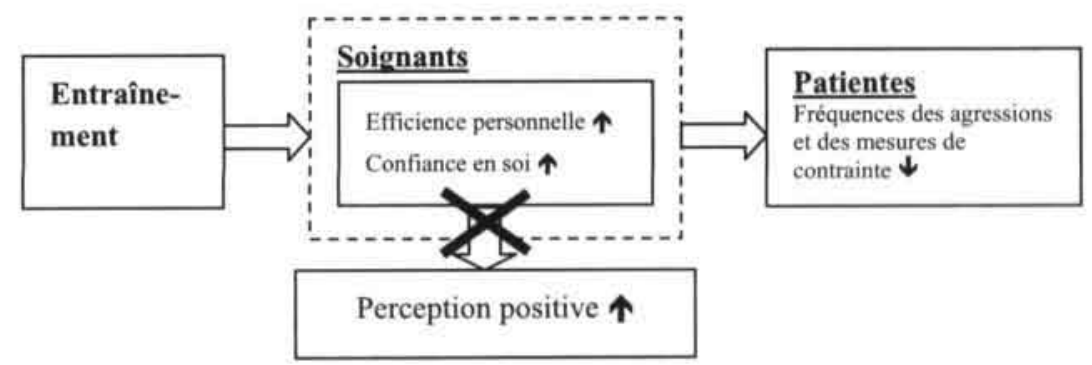

Figure 2: Effets effectués par l'entraînement 


\section{ACKNOWLEDGEMENTS}

I am indebted to numerous persons and institutions for their help and support during this project. I would like to thank the following professors and teachers for their guidance, constructive criticism, and expertise: Professor Dr. H. Philipsen (Universiteit Maastricht, NL), Professor Dr. T. Dassen (Humboldt-University, Berlin, D), Professor Dr. H-J. Haug (University of Zurich, $\mathrm{CH}$ ), associate Professor JE. Fischer (Swiss Federal Institute of Technology, Zurich, $\mathrm{CH}$ ) and associate Professor RJG. Halfens (Universiteit Maastricht, NL).

The European Violence in Research Group - EViPRG - provided many useful resources for the research work. The group members helped in terms of mental stimulus, expertise, assistance for funding and practical matters such as scales and instruments. My special thanks go to Professor Dr. L. Bowers (City University, London, UK), Professor Dr. H. Nijman (de Kijvelanden, Portugaal, NL), Dr. T. Palmstierna (Karolinska Hospital, Stockholm, S), G. Jansen (University of Groningen, NL), N. Oud (Connecting, Amsterdam, NL), Dr. R. Whittington (University of Liverpool, UK), and Dr. B. van der Werf (De Geestgronden, NL).

I am also grateful to the following institutions for their generous financial or logistic support: The Swiss Academy of Medical Science, the Swiss Association of Nursing Experts, the Swiss National Science Foundation, the Education Centre of the Swiss Association of Nurses, the Swiss Network for Psychiatric Nursing Research, the School of Nursing Südhalde, the Horten Institute of Research and the Swiss Federal Institute of Technology.

Many thanks go also to the numerous hospitals and nurses who participated in the study and who manage aggression and patient violence on a daily basis.

My special expressions of gratitude are extended to my colleague Chris Abderhalden. Thanks to his collaboration we were able to embark on a large project yielding such a fecund data set for our investigations. Working with Chris was a great help and source of inspiration.

Finally I am greatly - and mostly - indebted to my family, especially to my wife Lucia, for the encouragement and warm support during all stages of this endeavour. 


\section{CURRICULUM VITAE}

Ian Needham was born on the 19th of June 1953 in Oldham, England. In 1977 he completed training in psychiatric nursing at the Nursing School in Wil, Switzerland and in 1979 he was appointed as head of a geronto-psychiatric unit in the Psychiatric Hospital of Wil in Switzerland. In 1981 he became an assistant in the Nursing School in Wil. He achieved his diploma as a nurse tutor in psychiatric nursing at the Post-Basic School for Nursing in Zurich in 1893 and consequently held the post of deputy head of post-basic study unit at the Cantonal Psychiatric Clinic in Wil. From 1987 till 1995 he was a tutor in psychiatric nursing at the nursing school of the Cantonal Psychiatric Clinic in Wil. After training as a clinical nursing expert he held the post of clinical nurse expert from 1995 till 2003 at the Cantonal Psychiatric Clinic in Wil. During this period he completed his master's studies at the Universiteit Maastricht (the Netherlands) and the Post-basic School for Nursing in Aarau (Switzerland) in Nursing Science. In 2000 he commenced his $\mathrm{PhD}$ studies at the Humboldt University of Berlin (Prof. Dr. T. Dassen) and the Universiteit Maastricht (Dr. R. Halfens and Prof. Dr. H. Philipsen). From 2003 onwards he holds the posts of research fellow at the Swiss Federal Institute of Technology Zurich, Institute of Behavioural Sciences (Prof. Dr. $\mathrm{K}$. Frey) and as head of the research department at the University of Applied Sciences Fribourg, Switzerland. 



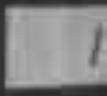

